\title{
UTILIZING SATELLITE FUSION METHODS TO ASSESS VEGETATION PHENOLOGY IN A SEMI-ARID ECOSYSTEM
}

by

Megan Gallagher

\author{
A thesis \\ submitted in partial fulfillment \\ of the requirements for the degree of \\ Master of Science in Geophysics
}

Boise State University

August 2018 


\section{Megan Gallagher SOME RIGHTS RESERVED}

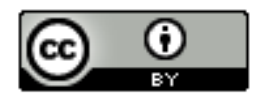

This work is licensed under a Creative Commons Attribution-Noncommercial 4.0 International License. 


\title{
BOISE STATE UNIVERSITY GRADUATE COLLEGE
}

\section{DEFENSE COMMITTEE AND FINAL READING APPROVALS}

\author{
of the thesis submitted by
}

\author{
Megan Gallagher
}

Thesis Title: Utilizing Satellite Fusion Methods to Assess Vegetation Phenology in a Semi-Arid Ecosystem

Date of Final Oral Examination: 13 June 2018

The following individuals read and discussed the thesis submitted by student Megan Gallagher and they evaluated her presentation and response to questions during the final oral examination. They found that the student passed the final oral examination.

Nancy F. Glenn, Ph.D.

Jennifer Pierce, Ph.D.

Hans-Peter Marshall, Ph.D.
Chair, Supervisory Committee

Member, Supervisory Committee

Member, Supervisory Committee

The final reading approval of the thesis was granted by Nancy F. Glenn, Ph.D., Chair of the Supervisory Committee. The thesis was approved by the Graduate College. 


\section{DEDICATION}

I dedicate this work to my family and friends, who have successfully distracted me for the past two years. 


\section{ACKNOWLEDGEMENTS}

I would like to thank the Bureau of Land Management under Cooperative Agreement L14AC00371 for the funding for this project. Thank you to Nancy Glenn, Lucas Spaete, and the rest of the Boise Center Aerospace Lab for guiding, aiding, advising and many other synonyms for just how brilliant they all were for their contributions for the past two years of my life. I would like to thank my committee members, Hans-Peter Marshall and Jennifer Pierce for their support and guidance. I

would lastly like to thank the Google Earth Engine Support team, without whom I would have been lost. 


\begin{abstract}
Dryland ecosystems cover over $40 \%$ of the Earth's surface, and are highly heterogeneous systems dependent upon rainfall and temperature. Climate change and anthropogenic activities have caused considerable shifts in vegetation and fire regimes, leading to desertification, habitat loss, and the spread of invasive species. Modern public satellite imagery is unable to detect fine temporal and spatial changes that occur in drylands. These ecosystems can have rapid phenological changes, and the heterogeneity of the ground cover is unable to be identified at course pixel sizes (e.g. $250 \mathrm{~m}$ ). We develop a system that uses data from multiple satellites to model finer data to detect phenology in a semi-arid ecosystem, a dryland ecosystem type.

The first study in this thesis uses recent developments in readily available satellite imagery, coupled with new systems for large-scale data analysis. Google Earth Engine is used with the Spatial and Temporal Adaptive Reflectance Fusion Model (STARFM) to create high resolution imagery from Landsat and Moderate Resolution Imaging Spectroradiometer (MODIS). The $250 \mathrm{~m}$ daily MODIS data are downscaled using the 16day, $30 \mathrm{~m}$ Landsat imagery resulting in daily, $30 \mathrm{~m}$ data. The downscaled images are used to observe vegetation phenology over the semi-arid region of the Morley Nelson Snake River Birds of Prey National Conservation Area in Southwestern Idaho, USA. We found the fused satellite imagery has a high accuracy, with $\mathrm{R}^{2}$ ranging from 0.73 to 0.99 , when comparing fusion products to the true Landsat imagery. From these data, we
\end{abstract}


observed the phenology of native and invasive vegetation, which can help scientists develop models and classifications of this ecosystem.

The second study in this thesis builds upon the fused satellite imagery to understand pre-and post-fire vegetation response in the same ecosystem. We investigate the phenology of five areas that burned in 2012 by using the fusion imagery (daily) to derive the normalized difference vegetation index (NDVI, a measure of vegetation greenness) in areas dominated by grass $(n=4)$ and shrub $(n=1)$. The five areas also had a range of historical burns before 2012, and overall we investigated the phenology of these areas over a decade. This proof of concept resulted in observations of the relationship between the timing of fire and the vegetation greenness recovery. For example, we found that early and late season fires take the longest amount of time for vegetation greenness to recover, and that the number of historical fires has little impact in the vegetation greenness response if it has already burned once, and is a grass-dominated region. The greenness dynamics of the shrub-dominated study site provides insight into the potential to monitor post-fire invasion by nonnative grasses. Ultimately the systems developed in this thesis can be used to monitor semi-arid ecosystems over long-time periods at high spatial and temporal resolution. 
TABLE OF CONTENTS

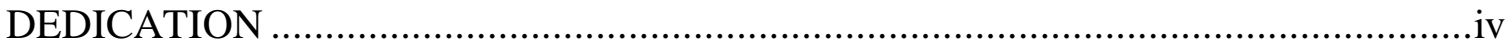

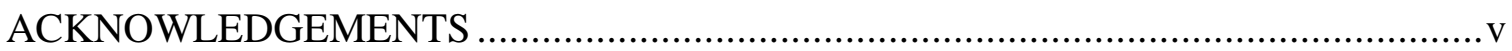

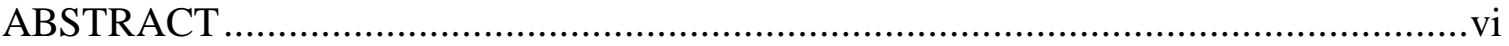

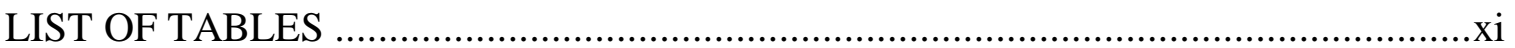

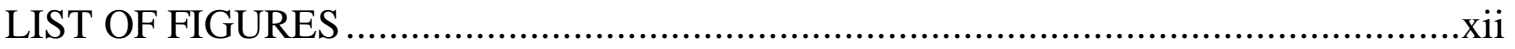

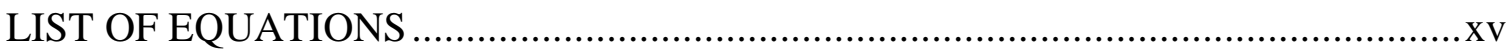

LIST OF ABBREVIATIONS ....................................................................

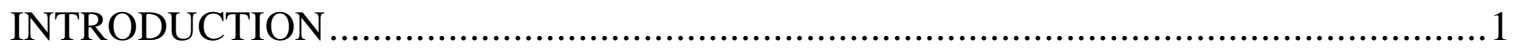

Semi-Arid Ecosystems .................................................................

Satellite Remote Sensing ....................................................................

Morley Nelson Snake River Birds of Prey National Conservation Area...............6

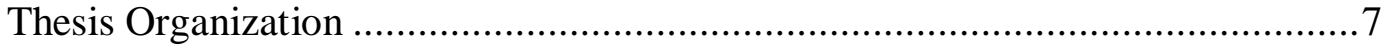

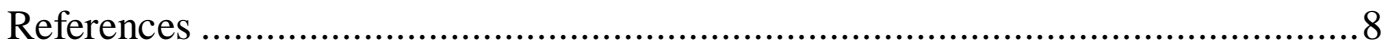

LEVERAGING SATELLITE FUSION TECHNIQUES WITH GOOGLE EARTH ENGINE TO CREATE HIGH SPATIAL AND TEMPORAL RESOLUTION DATA: A PHENOLOGICAL STUDY IN SEMI-ARID ECOSYSTEMS................................... 14

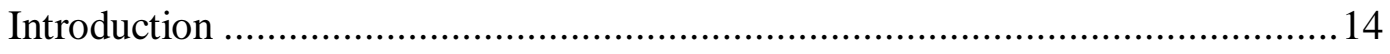

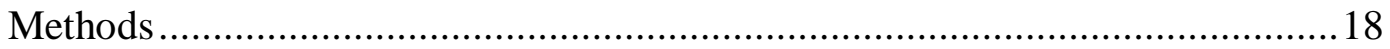

Study Area ....................................................................... 18

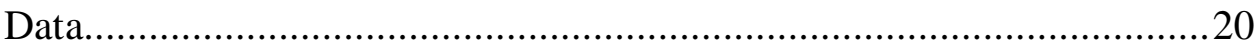


Google Earth Engine (GEE) ................................................20

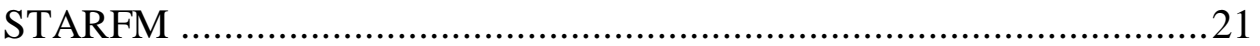

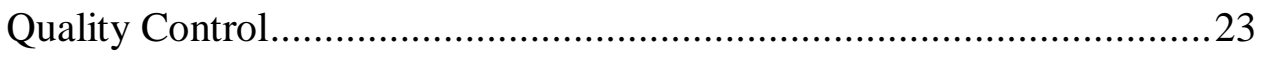

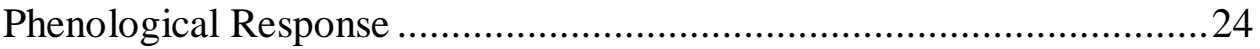

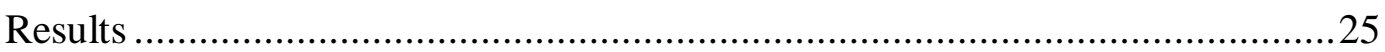

Quality Control 1: Asphalt Pixel Time Series Analysis ........................26

Quality Control 2: True Landsat Images vs. Fusion Product..................28

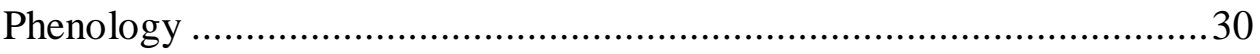

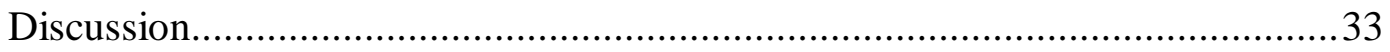

Quality Control................................................................. 33

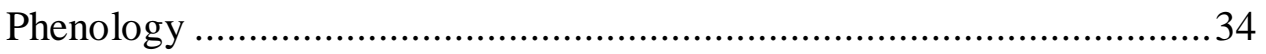

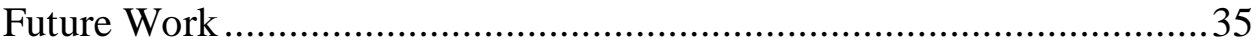

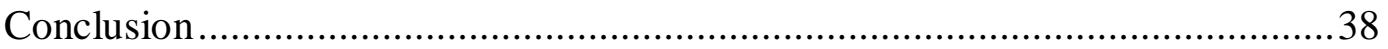

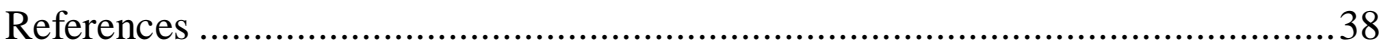

SATELLITE FUSION METHODS FOR DECADAL-SCALE PRE- AND POST- FIRE VEGETATION MONITORING IN A SEMI-ARID ECOSYSTEM ..........................48

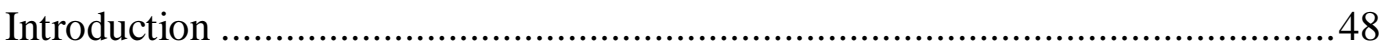

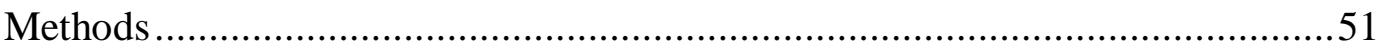

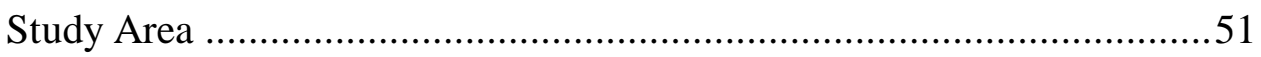

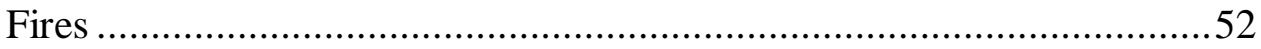

Experimental Design .........................................................56

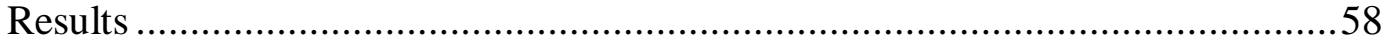

Vegetation Response …..........................................................58

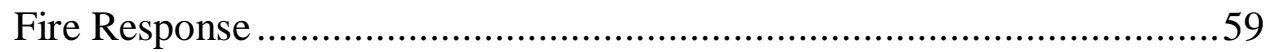


Timing of Burns .......................................................................64

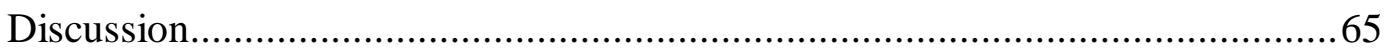

Control Area ..............................................................................6 65

Number of Historic Fires and Their Responses ...............................66

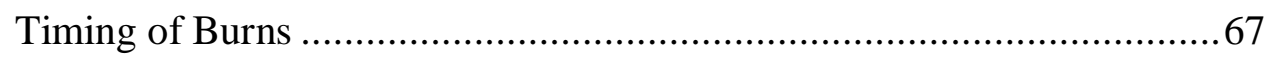

Management Implications......................................................... 70

Conclusion ...................................................................................... 70

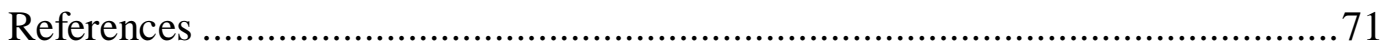

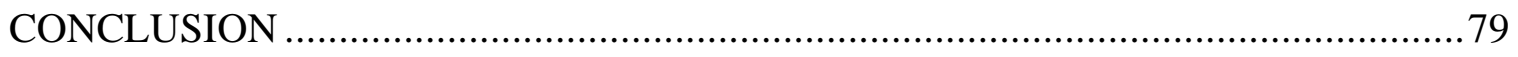

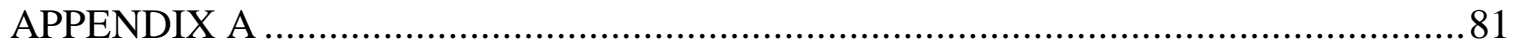

Google Earth Engine STARFM Code link........................................... 82

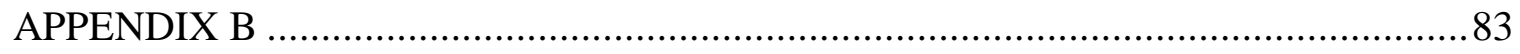

Correlation between the Fusion Product and MODIS Asphalt Pixel Response ....84

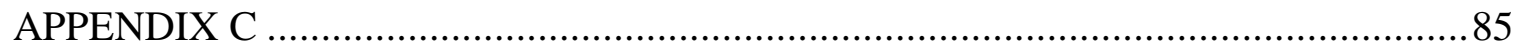

Delta Normalized Burn Ratio, Equation and Fire Information .........................86

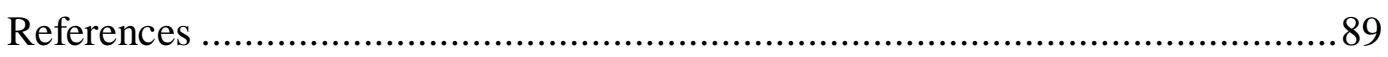

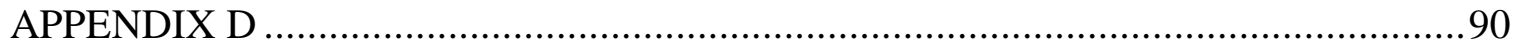

MODIS, Landsat, Fusion Product Comparison ........................................... 91

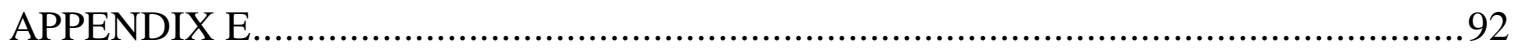

Precipitation and Temperature over the BoP.............................................93 


\section{LIST OF TABLES}

Table 2.1: $\quad$ MODIS and Landsat bands showing wavelength overlap, which allows STARFM to create models between the satellite systems.

Table 2.1: $\quad$ Dates for removed Landsat to test fusion image quality ........................24

Table 2.3: $\quad$ Download time (DT) for MODIS and Landsat from GEE and Processing time $(\mathrm{PT})$ in STARFM...........................................................25

Table 2.4: $\quad$ Statistical measures calculated from original and fusion products over the

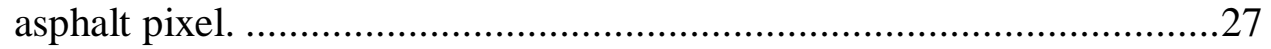

Table 3.1: $\quad$ Fires in the BoP used in this study and their fire start and end dates, area, and dominant vegetation type.

Table 3.2: $\quad$ Change in NDVI for the burned areas. Though the late season MM 12 HWY 67 has the highest NDVI loss, it also has the largest total increase in NDVI, and the MM 109 I 84 fire has risen above its pre-fire mean by $11 \%$. 


\section{LIST OF FIGURES}

Figure 1.1: Dryland Ecosystems separated by precipitation amount into hyper-arid (>100 $\mathrm{mm}$ precipitation annually), arid (100-300 $\mathrm{mm}$ precipitation annually), semi-arid (300-800 mm precipitation annually), and dry subhumid (< $800 \mathrm{~mm}$ precipitation annually with high humidity). Image from: FAO, 2018, (http://www.fao.org/dryland-forestry/background/what-aredrylands/en/).....

Figure 1.2: $\quad$ Spectral and temporal response trends using Landsat pixels from an August 26, 2016 image. Top figure is reflectance over time and bottom figure is the Normalized Difference Vegetation Index (NDVI) over time. .5

Figure 2.1: $\quad$ Morley Nelson Snake River Birds of Prey National Conservation Area, Idaho. A) BoP NDVI with high responses over agriculture and the below zero responses from water bodies. B) BoP in Idaho C) NDVI over MHAFB.

Figure 2.2: NDVI of Landsat and MODIS of the MHAFB. Coarse resolution MODIS imagery is on top, with matching dates of fine resolution Landsat imagery below.

Figure 2.3: A pixel of asphalt is shown using the spectral bands in Landsat 8. Red and NIR, which are used for NDVI, have similar spectral responses

Figure 2.4: NDVI of MODIS scenes (top row) in comparison with two fusion products and the true Landsat scene (bottom row)

Figure 2.5: $\quad$ MODIS (green, $250 \mathrm{~m}$ x $250 \mathrm{~m}$ ) and Landsat (red, $30 \mathrm{~m}$ x $30 \mathrm{~m}$ ) pixels over asphalt

Figure 2.6: MODIS, Landsat, and Fusion NDVI responses over a pixel of black asphalt over the 225-day period. MODIS pixels in spring contain noise caused by cloud cover and vegetation growth during this season, and is relatively stable for the summer period.

Figure 2.7: Agriculture and anthropogenic structures cause bounding effects on the fusion imagery. A) The fusion and original imagery compared one-to-one with bounding along the $\mathrm{X} \& \mathrm{Y}$ axis. B) Fusion and original imagery with 
the southern agricultural fields and MHAFB removed. C) Map of the difference between the fusion and original images, with negative values showing under-estimation and positive values showing over-estimation. 28

Figure 2.8: One-to-one plots of original 2016 Landsat images (X-axis) versus fusion images (Y-axis) over all matching dates. Bounding effects occur in the late September dates, caused by an active late season agricultural field.

Figure 2.9: Gaussian smoothing applied to known vegetation and anthropogenic influences. A-G) The mean of every response is shown in red. Agriculture has a separate scaling level to match the high green vegetation response in late season. $\mathrm{H}$ ) shows the mean response of vegetation cover, excluding agriculture.

Figure 2.10: Sentinel-2 band versus Landsats $7 \&$ 8, image from USGS EROS center, 2015 (https://landsat.gsfc.nasa.gov/wpcontent/uploads/2015/06/Landsat.v.Senti nel2.png) ........................................................................... 36

Figure 3.1: $\quad$ Morley Nelson Snake River Birds of Prey National Conservation Area with fires of interest in red, and the control area in blue.

Figure 3.2: Number of fires per year in the BoP between 1957-2015. 2012 is the highest known fire year during this period.

Figure 3.3: Daily NDVI pixel values from the Chattin Flatt burn area. Green are original values and red values are the Gaussian smoothing values. Subtle shifts in timing are seen in the smoothed data as compared to the original data.

Figure 3.4: Chattin Flatt burned area NDVI in relation to number of historic fires. A) The Chattin Flatt region post-fire NDVI response on August 8, 2015. B) Historic burned areas by color (see legend in (C) for number of times burned (between 2007-2016). C) Time series NDVI from 2007 to 2016. Standard deviation is shown with transparent ribbon around every line. The time of fire is shown with the red line, and the cheatgrass control in black

Figure 3.5: $\quad$ MM 109 I 84 burned area NDVI. A) The MM 109 I 84 post-fire NDVI response on August 8, 2015. B) Historic burned areas by color, see legend in (C) for number of times burned (between 2007-2016). C) Time series from 2007 to 2016, high variation is seen in the area with no previous burns. The time of fire is shown in red line, standard deviation is shown with transparent ribbons around lines. 
Figure 3.6: Impact fire burned area NDVI. A) The Impact post-fire NDVI response on August 8, 2015. B) Historic burned areas by color, see legend in (C) for number of times burned (between 2007-2016). C) Time series from 2007 to 2016, areas that have burned three to four times previously have the largest increase post-fire, areas that burned $<1$ before have the highest variation, with the standard deviation shown as the transparent ribbons for each area. Time of fire is shown with the red line.

Figure 3.7: MM 12 HWY 67 burned area NDVI. A) The MM 12 HWY 67 post-fire NDVI response on August 8, 2015. B) Historic burned areas by color, see legend in (C) for number of times burned (between 2007-2016). C) Time series from 2007 to 2016, like the Chattin Flatt Fire low NDVI persists until 2015, when an abrupt increase in NDVI occurs. The area with two burns has a larger response once post-fire NDVI increase begins. Time of fire shown with red line. Standard deviation is shown as the transparent ribbon on each line.

Figure 3.8: $\quad$ Xmas Fire (August 27, 2013) response. A) Region of Xmas fire. B) This shrub dominated region had never burned before the Xmas fire. C) Decadal response of the vegetation over the Xmas fire. NDVI is visible directly after the fire year, increases seen every year post-fire. Time of fire shown with red line, cheatgrass control in black. .64 


\section{LIST OF EQUATIONS}

Equation 2.1: Normalized difference vegetation index (NDVI) which uses the nearinfrared and red bands to highlight vegetation greenness..

Equation 2.2: STARFM algorithm. Landsat (L) and MODIS (M) imagery is used at time $t_{0}$ to find the Landsat imagery at time $t_{k}$. $W$ is moving window used, and $\mathrm{w} / 2$ is the central pixel of the moving window 


\section{LIST OF ABBREVIATIONS}

MODIS

AVHRR

NPP

BoP

NDVI

SAVI

STARFM

GEE

MHAFB

EVI

VIIRS

TOA

BLM

$\triangle \mathrm{NBR}$
Moderate Resolution Imaging Spectroradiometer

Advanced Very-High-Resolution Radiometer

Net Primary Production

Morley Nelson Snake River Birds of Prey National Conservation

Area

Normalized Difference Vegetation Index

Soil Adjusted Vegetation Index

Spatial and Temporal Adaptive Reflectance Fusion Model

Google Earth Engine

Mountain Home Air Force Base

Enhanced Vegetation Index

Visible Infrared Imaging Radiometer Suite

Top Of Atmosphere

Bureau of Land Management

delta Normalized Burn Ratio 


\section{INTRODUCTION}

\section{Semi-Arid Ecosystems}

Dryland ecosystems, which include semi-arid and hyper-arid ecosystems, are defined by the amount of rainfall and their range of temperatures. For example, hyperarid ecosystems receive less than $100 \mathrm{~mm}$ of rain a year; while semi-arid ecosystems can experience up to $800 \mathrm{~mm}$ of precipitation a year (Bailey, 1979; Bullard, 1997). As dryland ecosystems constitute over $41 \%$ of the Earth's surface they consist of a diverse mixture of flora, fauna, and climate regimes (Figure 1.1) (Chesson et al., 2004; Cowling et al., 1994; Morton et al., 1995; Salem, 1989). Three billion people subsist off these dryland ecosystems, with over $40 \%$ of the world's cultivation and $50 \%$ of the world's livestock within these regions (Secretariat, 1997; Secretariat, 1999).

Semi-arid ecosystems make up $15 \%$ percent of the total cover of dryland ecosystems, and at low, dry elevations consist of grasses, shrubs, small trees and other low-lying water dependent vegetation (Billings, 1994; Salem, 1989). Riparian areas of richer, more diverse vegetation are often found along water pathways, and evergreen cover increases with elevation (Billings, 1994; Kepner et al., 2000 Patten, 1998). The heterogeneity of these ecosystems due to the elevation gradient, temperature, and percent rainfall causes them to be floristically diverse across small geographic areas (Walker et al., 2014). Greening of vegetation in these regions is dependent on rainfall, with plants responding after the first rain of the spring season, and senescing (drying out) soon after the rain period has ended (Fischer \& Turner, 1978; Schmidt \& Karnieli, 2000). 


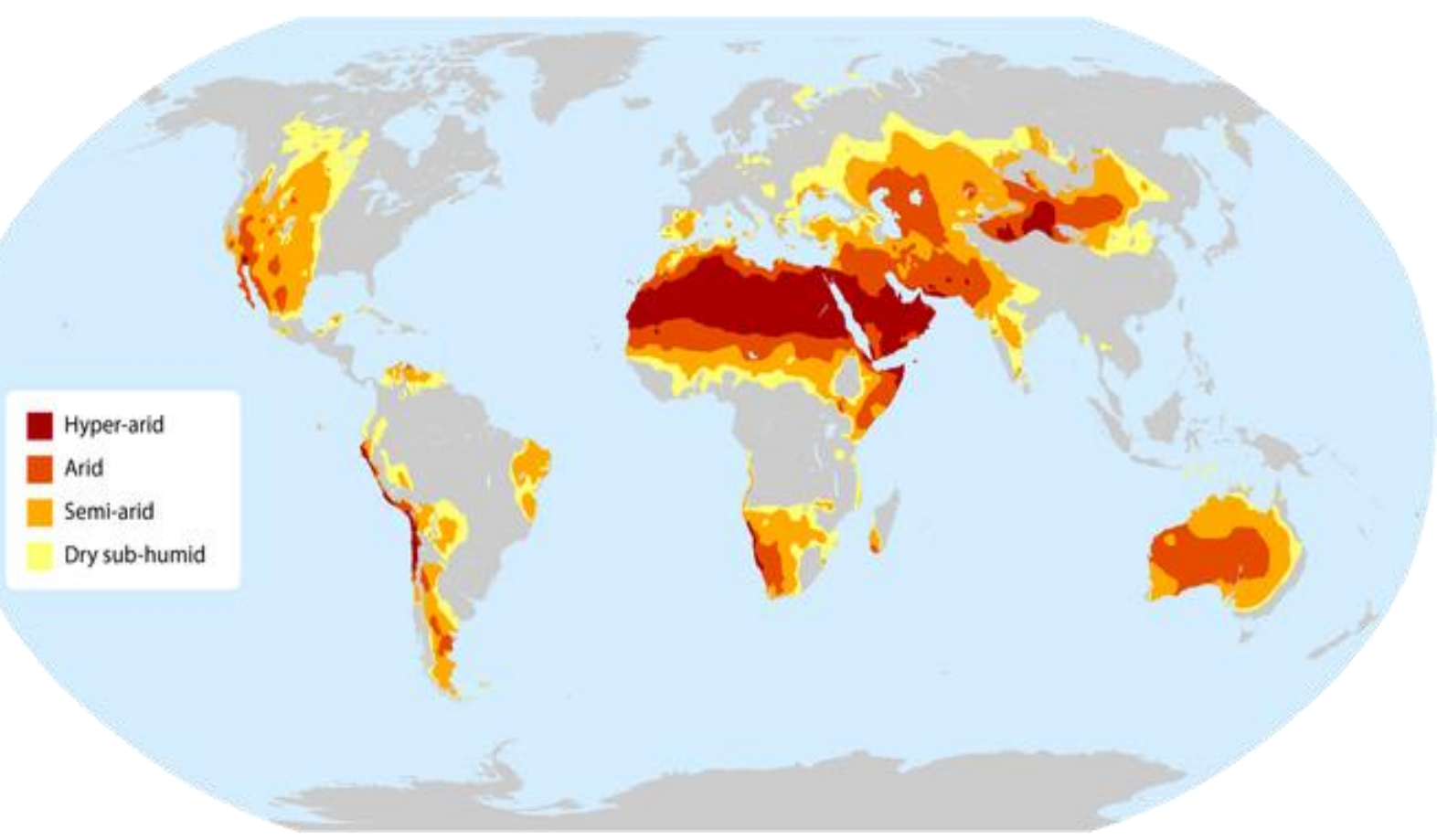

Figure 1.1: $\quad$ Dryland Ecosystems separated by precipitation amount into hyper-arid ( $>100$ $\mathrm{mm}$ precipitation annually), arid (100-300 $\mathrm{mm}$ precipitation annually), semi-arid (300-800 mm precipitation annually), and dry sub-humid ( $<800 \mathrm{~mm}$ precipitation annually with high humidity). Image from: FAO, 2018, (http://www.fao.org/drylandforestry/background/what-are-drylands/en/)

Dryland ecosystems are heterogeneous over space and time, making studies of vegetation and climate responses difficult to quantify at larger scales (Anyambe \& Tucker, 2005; Snyder \& Tartowski, 2006; Homer et al., 2012). In addition, rapid green up and quick senescence of vegetation makes tracking vegetation changes from daily to monthly periods challenging (Ramsey et al., 2004; Sonnenschein, 2011). Desertification, invasive species, fires, and erosion have increased in the past century, and diversity in these regions and sustainable living has begun to decrease (Warren \& Agnew, 1988; Lavee et al., 1998; Smith et al., 2000; Huxman et al., 2004, Clarke et al., 2005; D’Antonio \& Vitousek, 1992 Wei et al., 2007; Bartley et al., 2006). Invasive grass and forbs species such as cheatgrass (Bromus tectorum), medusahead (Taeniatherum caput- 
medusae), and sahara mustard (Brassica tournefortii) have increased the propensity for burning, and in combination with the rising temperature have increased fire timing and intensity (Brooke et al., 2001; Clarke 2005; Duke \& Money, 1999). Grazing in these regions has also contributed to the lack of regrowth of many native species, and the expansion of the growth of exotic grasses (D'Antonio \& Vitousek, 1992; Fleischner, 1994). The loss of native flora provokes habitat loss for endangered native species, such as sage grouse (Centrocercus urophasianus), and an increase in the positive feedback loop for fire response (Brooke et al., 2001).

Recent studies have indicated that semi-arid ecosystems have significant influence on global carbon cycles. For example, Poulter et al., (2014) found that semiarid biomes are important drivers of inter-annual variability of the global carbon cycle. Their study used Moderate Resolution Imaging Spectroradiometer (MODIS, .25-1 km pixels) along with Advanced Very-High-Resolution Radiometer (AVHRR, 2.5 km pixels) data to obtain annual Net Primary Production (NPP). However, the NPP flux they observed had large error bounds, which may have been caused by the coarse scale of their study. Huang et al., (2016) estimated NPP in semi-arid ecosystems using the same two satellite systems. They found semi-arid ecosystems are responsible for $29 \%$ of the interannual variation in global NPP, despite its $16 \%$ contribution to total global NPP. These coarse-scale studies have important implications for the role in which semi-arid ecosystems serve in carbon cycling. However, due to their scale, they were unable to pinpoint the mechanisms that are driving this variability. Fine resolution imagery (spatial and temporal) may help elucidate the mechanisms and dynamics of vegetation green up, and thus the influence of semi-arid ecosystems on global carbon cycles. For example, 
fine spatial and temporal resolution satellite data, may help us better attribute green up to post-fire responses or invasive grasses (Huang \& Asner, 2009). In addition, a better understanding of the presence and absence of vegetation communities will increase the efficiency of management, mitigation, and restoration of these areas.

\section{Satellite Remote Sensing}

Plot-scale studies are limited by the inability to efficiently cover larger areas and to capture the heterogeneity of semi-arid ecosystems for extrapolation over entire regions (Huang et al., 2010; Homer et al., 2012). Using satellite remote sensing is the next logical step, but the spatial and temporal variability of semi-arid ecosystems results in large margins of error for tracking vegetation responses over fine scales (Poulter et al., 2014; Olexa \& Lawrence 2014).

Modern, publicly-available satellite data can have a spatial resolution (pixel size) of $10 \mathrm{~m}$ (Sentinel-2), to upwards of $1000 \mathrm{~m}$ (e.g. AVHRR, MODIS). These scales typically result in mixed pixels, or radiometric responses from multiple targets. The mixed pixel effect is exacerbated in semi-arid ecosystems because bare soil often dominates the vegetation response (Richardson \& Everitt, 1992; Lyon et al., 1998; Senseman et al., 1996).

In addition to the spatial scale of satellite data, the temporal resolution is also of importance, especially in semi-arid ecosystems. Observing the green up in the spring is optimal to obtain reflectance differences among plants, but as this green up is induced by rain, satellite imagery may be blocked by clouds (Diouf \& Lambin, 2001). During the late summer and fall the rapid senescence in the absence of rain leads to vegetation having a similar spectral response. These attributes make detection and classification in 
semi-arid ecosystems difficult with publicly-available satellite imagery. However, exploiting the temporal response of vegetation reflectance helps separate similar pixel responses (Figure 1.2)

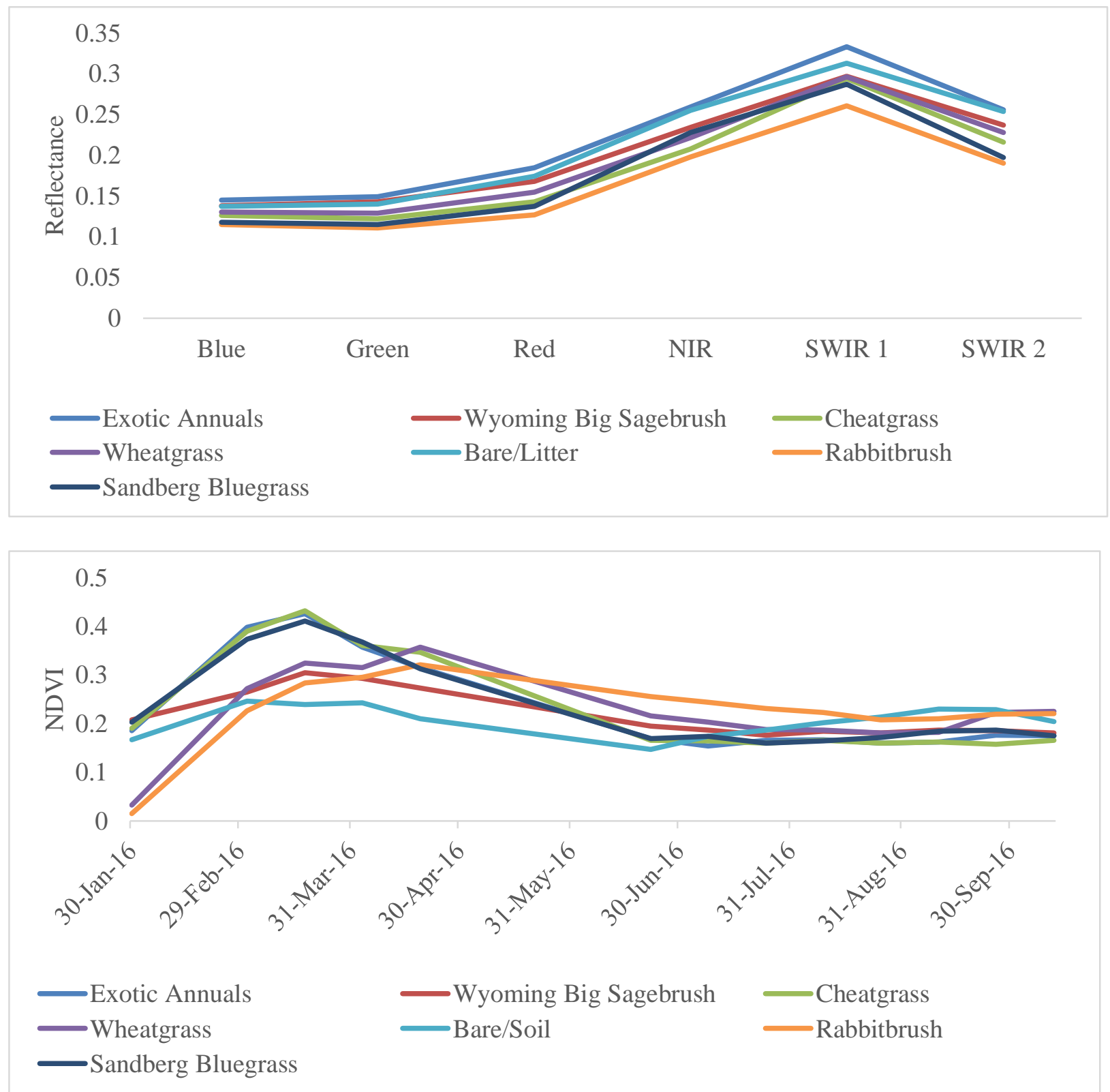

Figure 1.2: Spectral and temporal response trends using Landsat pixels from an August 26, 2016 image. Top figure is reflectance over time and bottom figure is the Normalized Difference Vegetation Index (NDVI) over time. 
A quantitative approach to leverage modern public satellite systems is needed to improve the spatial and temporal observations in semi-arid ecosystems in order to understand vegetation dynamics. The increase in free publicly-available satellite imagery and processing capabilities has revolutionized the bounds of computer modeled satellite imagery. These advances aid in the major increase in large data interpolation and analysis.

\section{Morley Nelson Snake River Birds of Prey National Conservation Area}

Our study area is located within the Morley Nelson Snake River Birds of Prey National Conservation Area (BoP). The BoP is managed by the Bureau of Land Management (BLM) and is located southeast of Boise, Idaho, USA. The BoP is 196,300 ha, with an elevation range of $684 \mathrm{~m}$ to $1107 \mathrm{~m}$ (Danielson \& Gesch, 2011). This semiarid ecosystem receives precipitation ranging from 20 to $30 \mathrm{~cm}$ annually (Kochert \& Pellant, 1986). The parent material for the soils in the BoP area include loess, volcanic ash and alluvium (Soil Survey Staff, 2018). This area has been protected since 1993 which has allowed a wide spectrum of research for detailed knowledge on vegetation and fuels (Shinneman et al., 2015; Raymondi, 2017). The BoP consists of a range of land cover and land use types including shrub-steppe, agricultural fields and recreational areas. It has been heavily grazed, and has a history of repeated fire with over half of the native vegetation lost since the 1980's (Mutz et al., 2004). The native vegetation was dominated by Wyoming big sagebrush (Artemisia tridentata wyomingensis), and winterfat (Krascheninnikovia lanata), whereas invasive plants such as cheatgrass (Bromus Tectorum) and medusahead (Taeniatherum caput-medusae) have rapidly expanded. (BLM, 2008; West \& York, 2002; Pellant, 1990; Allen et al., 1995; Billings, 
1994). Over 400 fires have been documented in the BoP since 1957, with the largest in 2005 reaching over 88,000 ha (Welty et al., 2017). Multiple historical burns in many areas have led to the increase of cheatgrass and other exotic grasses, and over 121,406 ha of shrub land lost (BLM, 2008). Management efforts are currently underway to restore native species and protect endangered species (i.e slickspot peppergrass, Lepidium papilliferum) in accordance with the Final Environmental Impact Decision Statement PL 103-64. Finer scale temporal and spatial resolution imagery systems will allow for easier monitoring of these and similar areas, and will increase our knowledge towards mitigation and management of post-fire vegetation responses.

\section{Thesis Organization}

This thesis contains two separate studies, followed by conclusions to investigate the ability of image fusion to provide high spatial and temporal resolution imagery to track vegetation phenology in a semi-arid ecosystem. The first study is the formation of a method that allows for the fusion of images from two satellite systems to create finer spatial and temporal measurements. MODIS and Landsat are used to create daily $30 \mathrm{~m}$ imagery, which is assessed for quality and demonstrated by tracking vegetation phenology. This system can be applied to studies in which vegetation change is of interest over weekly to decadal time scales. As a proof of concept, the second study uses the previous system to track changes in vegetation of five areas that burned by wildfire. The number of previous fires, and the season in which the fires occurred are evaluated for their effect on vegetation growth. A decade of daily imagery, five years pre-fire and five years post-fire, is used to track the vegetation greenness response. The study results and 
findings can be expanded upon for use in restoration and understanding long-term effects of fire and management.

\section{References}

Allen, E. B., Roundy, B. A., McArthur, E. D., \& Haley, J. S. (1995). Restoration ecology: limits and possibilities in arid and semiarid lands. In Proceedings of the Wildland Shrub and Arid Land Restoration Symposium, Roundy, BA; McArthur, ED (pp. $715)$.

Anyamba, A., \& Tucker, C. J. (2005). Analysis of Sahelian vegetation dynamics using NOAA-AVHRR NDVI data from 1981-2003. Journal of Arid Environments, 63(3), 596-614.

Bailey, H. P. (1979). Semi-arid climates: their definition and distribution. In Agriculture in semi-arid environments (pp. 73-97). Springer, Berlin, Heidelberg.

Bartley, R., Roth, C. H., Ludwig, J., McJannet, D., Liedloff, A., Corfield, J., ... \& Abbott, B. (2006). Runoff and erosion from Australia's tropical semi-arid rangelands: Influence of ground cover for differing space and time scales. Hydrological Processes, 20(15), 3317-3333.

Billings, W. D. (1994). Ecological impacts of cheat grass and resultant fire on ecosystems in the western Great Basin. SB Monsen and SG Kitchen, 22-30.

BLM. (2008). Final Environmental Impact Statement Volume I, Final Environmental Impact Statement

Brooks, M. L., Pyke, D. A., Galley, K. E. M., \& Wilson, T. P. (2001). Invasive plants and fire in the deserts of North America. In The First National Congress on Fire Ecology, Prevention, and Management, San Diego, CA, Tall Timbers Research Station, Tallahassee, FL.

Bullard, J. E. (1997). Vegetation and dryland geomorphology. Arid Zone Geomorphology, 109-131. 
Chesson, P., Gebauer, R. L., Schwinning, S., Huntly, N., Wiegand, K., Ernest, M. S., ... \& Weltzin, J. F. (2004). Resource pulses, species interactions, and diversity maintenance in arid and semi-arid environments. Oecologia, 141(2), 236-253.

Clarke, P. J., Latz, P. K., \& Albrecht, D. E. (2005). Long-term changes in semi-arid vegetation: invasion of an exotic perennial grass has larger effects than rainfall variability. Journal of Vegetation Science, 16(2), 237-248.

Cowling, R. M., Esler, K. J., Midgley, G. F., \& Honig, M. A. (1994). Plant functional diversity, species diversity and climate in arid and semi-arid southern Africa. Journal of Arid Environments, 27(2), 141-158.

D'Antonio, C. M., \& Vitousek, P. M. (1992). Biological invasions by exotic grasses, the grass/fire cycle, and global change. Annual review of ecology and systematics, 23(1), 63-87.

Danielson, J. J., \& Gesch, D. B. (2011). Global multi-resolution terrain elevation data 2010 (GMTED2010) (No. 2011-1073). US Geological Survey.

Diouf, A., \& Lambin, E. F. (2001). Monitoring land-cover changes in semi-arid regions: remote sensing data and field observations in the Ferlo, Senegal. Journal of Arid Environments, 48(2), 129-148.

Dukes, J. S., \& Mooney, H. A. (1999). Does global change increase the success of biological invaders? Trends in Ecology \& Evolution, 14(4), 135-139.

Fleischner, T. L. (1994). Ecological costs of livestock grazing in western North America. Conservation biology, 8(3), 629-644.

Fischer, R., \& Turner, N. C. (1978). Plant Productivity in the. Ann. Rev. Plant Physiology, 29(99), 277-317.

Homer, C. G., Aldridge, C. L., Meyer, D. K., \& Schell, S. J. (2012). Multi-scale remote sensing sagebrush characterization with regression trees over Wyoming, USA: laying a foundation for monitoring. International Journal of Applied Earth Observation and Geoinformation, 14(1), 233-244. 
Huang, C. Y., \& Asner, G. P. (2009). Applications of remote sensing to alien invasive plant studies. Sensors, 9(6), 4869-4889.

Huang, L., He, B., Chen, A., Wang, H., Liu, J., Lü, A., \& Chen, Z. (2016). Droughtdominates the interannual variability in global terrestrial net primary production by controlling semi-arid ecosystems. Scientific reports, 6, 24639.

Huang, S., Potter, C., Crabtree, R. L., Hager, S., \& Gross, P. (2010). Fusing optical and radar data to estimate sagebrush, herbaceous, and bare ground cover in Yellowstone. Remote Sensing of Environment, 114(2), 251-264.

Huxman, T. E., Cable, J. M., Ignace, D. D., Eilts, J. A., English, N. B., Weltzin, J., \& Williams, D. G. (2004). Response of net ecosystem gas exchange to a simulated precipitation pulse in a semi-arid grassland: the role of native versus non-native grasses and soil texture. Oecologia, 141(2), 295-305.

Kepner, W. G., Watts, C. J., Edmonds, C. M., Maingi, J. K., Marsh, S. E., \& Luna, G. (2000). A landscape approach for detecting and evaluating change in a semi-arid environment. In Monitoring Ecological Condition in the Western United States (pp. 179-195). Springer, Dordrecht.

Kochert, M. N., \& Pellant, M. (1986). Multiple use in the Snake River Birds of Prey Area. Rangelands Archives, 8(5), 217-220.

Lavee, H., Imeson, A. C., \& Sarah, P. (1998). The impact of climate change on geomorphology and desertification along a Mediterranean-arid transect. Land degradation \& development, 9(5), 407-422.

Lyon, J.G., Yuan, D., Lunetta, R.S., and C.D. Elvidge. (1998). A change detection experiment using vegetation indices. Photogrammetric Engineering and Remote Sensing 64(2):143-150.

Morton, S. R., Short, J., \& Barker, R. D. (1995). Refugia for biological diversity in arid and semi-arid Australia.

Mutz, K. M., Cannon, D., \& Simmons, C. (2004). Snake River Birds of Prey National Conservation Area Case Study. 
Olexa, E. M., \& Lawrence, R. L. (2014). Performance and effects of land cover type on synthetic surface reflectance data and NDVI estimates for assessment and monitoring of semi-arid rangeland. International Journal of Applied Earth Observation and Geoinformation, 30, 30-41.

Patten, D. T. (1998). Riparian ecosytems of semi-arid North America: Diversity and human impacts. Wetlands, 18(4), 498-512.

Pellant, M. (1990). The cheatgrass-wildfire cycle — are there any solutions. In McArthur et al.(eds.) Proceedings of a Symposium on cheatgrass invasion, shrub die-off, and other aspects of shrub biology and management. US For. Serv., Int. Res. Sta., Gen. Tech. Rep. INT-276. Ogden, UT (pp. 11-18).

Poulter, B., Frank, D., Ciais, P., Myneni, R. B., Andela, N., Bi, J., ... \& Running, S. W. (2014). Contribution of semi-arid ecosystems to interannual variability of the global carbon cycle. Nature, 509(7502), 600.

Ramsey, R. D., Wright Jr, D. L., \& McGinty, C. (2004). Evaluating the use of Landsat 30m Enhanced Thematic Mapper to monitor vegetation cover in shrub-steppe environments. Geocarto International, 19(2), 39-47.

Raymondi, A. M. (2017). The Relative Importance of Fire History, Management Treatments, Biotic, and Abiotic Factors on the Abundance of Key Vegetative Components in an Endangered Sagebrush-Steppe Ecosystem.

Salem, B. B. (1989). Arid zone forestry: a guide for field technicians (No. 20). Food and Agriculture Organization (FAO).

Schmidt H., Karnieli A. (2000). Remote sensing of the seasonal variability of vegetation in a semi-arid environment, Journal of Arid Environments, Volume 45, Issue 1, 2000, Pages 43-59, ISSN 0140-1963, http://dx.doi.org/10.1006/jare.1999.0607.

Secretariat, C. C. D. (1997). United Nations Convention to Combat Desertification in those countries experiencing serious drought and/or desertification, particularly in Africa. Text with Annexes Geneva, 7-71. 
Secretariat. (1999). United Nations Convention to Combat Desertification in Those Countries Experiencing Serious Drought And/or Desertification, Particulary in Africa. Secretariat of the United Nations Convention to Combat Desertification.

Senseman, G.M., Bagley, C.F., and S.A. Tweddale. (1996). Correlation of rangeland cover measures to satellite-imagery-derived vegetation indices. Geocarto International 11(3):29-38

Shinneman, D., Pilliod, D., Arkle, R., \& Glenn, N. F. (2015). Quantifying and predicting fuels and the effects of reduction treatments along successional and invasion gradients in sagebrush habitats. Joint Science Program.

Soil Survey Staff. (2018). Natural Resources Conservation Service, United States Department of Agriculture. Web Soil Survey. Available online at https://websoilsurvey.nrcs.usda.gov/. Accessed [May/19/2018].

Sonnenschein, R., Kuemmerle, T., Udelhoven, T., Stellmes, M., \& Hostert, P. (2011). Differences in Landsat-based trend analyses in drylands due to the choice of vegetation estimate. Remote sensing of environment, 115(6), 1408-1420.

Smith, S. D., Huxman, T. E., Zitzer, S. F., Charlet, T. N., Housman, D. C., Coleman, J. S., ... \& Nowak, R. S. (2000). Elevated CO 2 increases productivity and invasive species success in an arid ecosystem. Nature, 408(6808), 79.

Snyder, K. A., \& Tartowski, S. L. (2006). Multi-scale temporal variation in water availability: implications for vegetation dynamics in arid and semi-arid ecosystems. Journal of Arid Environments, 65(2), 219-234.

Walker, J. J., De Beurs, K. M., \& Wynne, R. H. (2014). Dryland vegetation phenology across an elevation gradient in Arizona, USA, investigated with fused MODIS and Landsat data. Remote Sensing of Environment, 144, 85-97.

Warren, A., \& Agnew, C. (1988). An assessment of desertification and land degradation in arid and semi-arid areas. London: IIED 72p. En IIED Drylands Programme, Drylands Paper, (2). 
Welty, J.L., Pilliod, D.S., and Arkle, R.S. (2017). Combined wildfire dataset for the United States and certain territories, 1870-2015: U.S. Geological Survey data release, https://doi.org/10.5066/F75H7F5M.

West, N. E., \& Yorks, T. P. (2002). Vegetation responses following wildfire on grazed and ungrazed sagebrush semi-desert. Journal of Range Management, 171-181. 


\section{LEVERAGING SATELLITE FUSION TECHNIQUES WITH GOOGLE EARTH ENGINE TO CREATE HIGH SPATIAL AND TEMPORAL RESOLUTION DATA: A PHENOLOGICAL STUDY IN SEMI-ARID ECOSYSTEMS Introduction}

Moderate Resolution Imaging Spectroradiometer (MODIS) is a satellite constellation of two satellites, Terra and Aqua, managed by NASA from 1999 to present. The sensors on these satellites are designed to collect atmospheric, terrestrial, cryospheric, and oceanic information. These satellites revisit the same geographic area every one to two days; however, the pixel sizes range from 250 to $1000 \mathrm{~m}$ (Justice et al., 2002). In comparison, NASA's Landsat system (1972 - present), which most recently includes Landsat 5, 7, and 8, has $30 \mathrm{~m}$ pixel sizes and a revisit period of 16-days. These satellite systems are positioned on either end of the time versus space data collection spectrum, and the data from both are used to assess various ecological factors (Leprieur et al., 2000; Olexa \& Lawrence 2014; Poulter et al., 2014), including vegetation phenology (Peterson, 2005; Sakamoto, 2005; Zhang et al., 2003).

Remote sensing of vegetation phenology using MODIS and Landsat has been applied to differentiate plant species and plant function based on when they germinate and how verdant they become (Gould, 2000; Wardlow et al., 2007). Our ability to observe green up is widely affected by the spatial and temporal characteristics of satellites (Sivanpillai et al., 2009). The community type, cover, continuity, rate and magnitude of phenology all affect the capacity to remotely sense greenness (Mirik et al., 
2007; Olexa \& Lawrence, 2014; Walker et al., 2014). Vegetation indices created from satellite data are commonly used to differentiate between plant types for detection and classification (Sivanpillai et al., 2009; Zhou et al., 2001). The Normalized Difference Vegetation Index (NDVI) is the most common vegetation index [Equation 2.1], with others such as the Soil-adjusted Vegetation Index (SAVI), and the Enhanced Vegetation Index (EVI) adjusted for different desired responses (Huete, 1988; Pettorelli et al., 2005, Geerkan \& Ilaiwi, 2004; Richardson \& Everitt, 1992; Lyon et al., 1998; Senseman et al., 1996, Sims et al., 2008). These indices enhance vegetation characteristics and are essential for detecting vegetation in diverse ecosystems.

$$
N D V I=\frac{(N I R-R E D)}{(N I R+R E D)}
$$

Equation 2.1: Normalized difference vegetation index (NDVI) which uses the near-infrared and red bands to highlight vegetation greenness.

Arid and semi-arid regions make up more than a third of the Earth's surface, and these areas are prone to abrupt environmental changes caused by subtle shifts in rainfall, temperature, and/or land use (Paylore \& Greenwell, 1979). Shrubs and grasses can have rapid greening after rainfall, but just as quickly the plants may senesce (dry out) depending on the temperature and other weather conditions (Fischer \& Turner, 1978; Schmidt \& Karnieli, 2000). Fine temporal data are necessary to capture rapid greening and senescing at a spatial resolution that supports grass-shrub differentiation in arid regions (Lambin \& Strahlers, 1994; Stefanov et al., 2001). The $250 \mathrm{~m}$ pixel size of MODIS limits our ability to differentiate many vegetation species, especially in heterogeneous ecosystems; however, previous studies have shown its applicability to capture the differences between shrubs, trees, or grass (Saha et al., 2015; Fensholt et al., 
2012; Yichun et al., 2008). Landsat's pixel size is potentially more appropriate to capture differences between vegetation species, but lacks the revisit time to characterize rapid changes in greenness that occur in semi-arid regions (Ramsey et al., 2004; Tucker, Townshend et al., 1985; Elmore et al., 2000; Schmidt \& Karnieli, 2000). Both systems provide important functions to monitor semi-arid environments, but neither is individually capable of obtaining results that are necessary for highly accurate characterization (Yichun et al., 2008).

An additional confounding factor in semi-arid regions is that even with Landsat's relatively finer spatial scale, the spectral response of shrubs and grasses are similar. In fact, Landsat's broad bands and $30 \mathrm{~m}$ spatial resolution, coupled with spectrally indeterminate vegetation such as shrubs and grasses in drylands make differentiation a challenging task (Okin et al., 2001). However, previous studies have leveraged timeseries remote sensing to improve cheatgrass (bromus tectorum) detection (Singh \& Glenn, 2009) and have found favorable results, especially when coupled with rainfall data (Bradley \& Mustard, 2005). The Spatial and Temporal Adaptive Reflectance Fusion Model (STARFM) uses reflectance similarities between MODIS and Landsat bands to create finer-scale temporal and spatial products that can be used for vegetation studies (Gao et al., 2006) (Table ). STARFM is unique in that it's well-calibrated for the shared reflectance bands of MODIS and Landsat. Same date pairs from these sensors are used to tune the interpretation, using the similarities between pixel reflectance, surrounding Landsat pixel reflectance, and time between images for weighting. Whereas resolution enhancement techniques such as panchromatic sharpening and hue saturation value transforms result in the loss of reflectance information, STARFM is intended to preserve 
reflectance data (Gao et al., 2006; Shettigara, 1992). Well-defined growing periods from before green up to senescence increase accuracy for STARFM allowing the best possible fit of full phenological cycles (Hilker et al., 2009). In 2012, Walker et al. tested the capabilities of STARFM to interpret synthetic imagery over heterogeneous dryland sites in Northern Arizona. STARFM was also tested over the Dry Creek Experimental Watershed, in southwestern Idaho, where it was found to have high accuracy on nonsnow covered pixels (Olsoy et al., 2017). Both studies found the algorithm was significantly robust to work in dryland ecosystems.

Table 2.1: $\quad$ MODIS and Landsat bands showing wavelength overlap, which allows STARFM to create models between the satellite systems.

\begin{tabular}{lcccc} 
& Landsat 8 & Wavelength (nm) & MODIS & Wavelength(nm) \\
\hline Blue & 2 & $450-510$ & 3 & $459-479$ \\
Green & 3 & $530-590$ & 4 & $545-565$ \\
Red & 4 & $640-670$ & 1 & $620-670$ \\
NIR & 5 & $850-880$ & 2 & $841-876$ \\
SWIR 1 & 6 & $1570-1650$ & 6 & $1628-1652$ \\
SWIR 2 & 7 & $2110-2290$ & 7 & $2105-2155$ \\
\hline
\end{tabular}

Daily remote sensing observations result in a large amount of preprocessing. Furthermore, a fusion algorithm such as STARFM requires several preprocessing steps including cloud masking, atmospheric correction, geo-referencing, and sampling to equivalent pixel sizes (Gao et al., 2006). Google Earth Engine (GEE), an online repository and code editor for public remote sensing information, is an invaluable asset in easing the amount of time to perform this preprocessing (Gorelick et al., 2017). The 
system is run on Google Cloud which automatically spins up and hosts appropriate processing power and memory. GEE allows for startlingly fast image processing in the cloud, and the ability to download the processed images. Multiple studies have used GEE for time series analysis and vegetation studies because of the ease of information processing (Dong et al., 2016; Johansen et al., 2015; Huang et al., 2017).

First created by Faye Peters, a combination of GEE and STARFM allows for processing 16-day Landsat coupled with 16-day MODIS NDVI composites to study the invasive plant Kudzu (Pueraria montana) (Peters, 2016). We build off this work to create a system that leverages MODIS daily NDVI with Landsat imagery for processing in STARFM. The intention of this study is to utilize this fine spatial and temporal resolution product to observe phenology that allows for improved vegetation detection and classification.

\section{Methods}

$\underline{\text { Study Area }}$

We chose the Morley Nelson Snake River Birds of Prey National Conservation Area (BoP) for testing our methods. The BoP is southeast of Boise, ID, and covers 196,300 ha (BLM, 2008). The vegetation communities range from riparian to multiple upland habitats: greasewood (Sarcobatus), winterfat (Krascheninnikovia lanata), Wyoming big sagebrush (Artemisia tridentata wyomingensis), grassland, and rock (US, 2008). Wildfire, grazing, and invasive species have led to only $37 \%$ of the BoP to be categorized as Wyoming big sagebrush, winterfat, or salt desert shrub in 2008. Multiple recovery efforts have been, and are being enacted, over this area for restoration of species habitat and wildfire mitigation (Mutz et al., 2004, Raymondi, 2017). Over 98,864 ha of 
the BoP are a mixture of cheatgrass with shrubs, or exotic annuals. This area is highly monitored and mapped, which allows for validation of the fusion system's results (Kochert \& Pellant, 1986; Spaete et al., 2016). We chose a 18,800 ha study area within the $\mathrm{BoP}$ because of available field data and an accompanying remote sensing project (Enterkine, in prep). The region also covers part of the Mountain Home Air Force Base (MHAFB) which provides large areas of asphalt that we use as stable reflectance responses to compare our data.
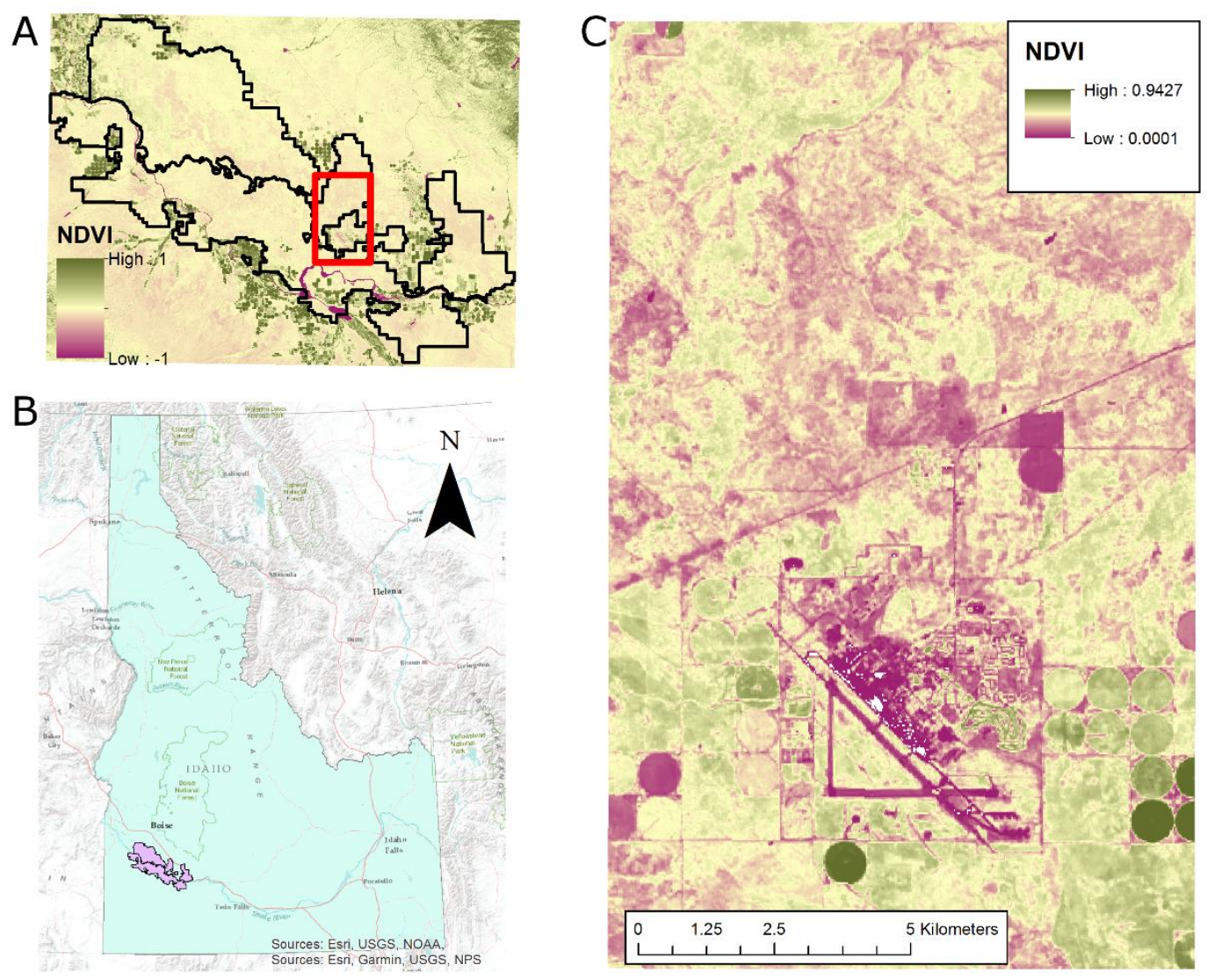

Figure 2.1: Morley Nelson Snake River Birds of Prey National Conservation Area, Idaho. A) BoP NDVI with high responses over agriculture and the below zero responses from water bodies. B) BoP in Idaho C) NDVI over MHAFB. 
Data

Two remote sensing data sets are used in this project. MODIS product MOD09GQ.006 (Terra Surface Reflectance Daily L2G Global $250 \mathrm{~m}$ ) is used for the daily reflectance values. This MODIS dataset has the highest spatial and temporal resolution and has been corrected for aerosols and mapped in a level space-time grid (Vermote \& Wolfe, 2015). The second dataset is the USGS Landsat Surface Reflectance Tier 1 (Landsat/LC08/C01/T1_SR Path 41 Row 30, 30 m). The Tier 1 data are atmospherically corrected using LaSCR, and CFMask, and the bands have been orthorectified to surface reflectance (USGS, 2018, Foga et al., 2017). The image dates chosen correspond to the year of field sampling and are from March 2, 2016 to October 13, 2016 (Enterkine, in prep). March 2nd is the first non-cloud covered image with Landsat and MODIS, and is out of the range of the MODIS Terra 2016 safe mode entrance (February 18, 2016; NASA, 2016) when all non-essential systems were shut down for a limited period. October 13th is the last non-cloud non-snow response with Landsat and MODIS. A total of 12 Landsat images with less than $30 \%$ cloud cover and 225 MODIS images were used in the final compilation.

Google Earth Engine (GEE)

We use Google Earth Engine (GEE) to provide the capacity to store the large amount of daily data necessary to record phenological responses. The MODIS data are filtered to match the dates of interest, and the Quality Assurance band (Bit mask QC_250m) is used to select bad pixels in each image and mask them. This band uses binary number values to denote if a pixel is of ideal quality, or if errors have occurred (Vermote \& Wolfe, 2015). The Normalized Difference Vegetation Index (NDVI) is then 
calculated for each image. The images are bounded by the area of interest, projected to 30 $\mathrm{m}$, and stacked into one large multi-band image with one band representing one day for ease of exporting. The first band is a duplicate of the first day of information due to processing, and is removed from the data set. Analogous to the MODIS process, the Landsat images are filtered by date, cloud masked using the 'pixel_qa' band, and filtered by the bounds of interest. MODIS NDVI imagery are scaled by 10,000 to the Landsat imagery, and so the Landsat imagery are pre-scaled to match the MODIS values. The Landsat imagery are also stacked into an image with 225 bands, with the dates of true Landsat images being filled and the bands of no Landsat images remaining empty for future interpolation. Date matching is performed between the MODIS and Landsat data sets to identify when these images have aligning dates. The image files are exported from GEE using the export.Image.toDrive function as .tif files, with the dates as a separate .csv file.

\section{$\underline{\text { STARFM }}$}

We process the images with STARFM (Gao et al., 2006). MODIS and Landsat images that occur on the same day are paired to create the model. MODIS pixels map to their corresponding Landsat pixels, and a weighting window is created based upon the central Landsat pixel and the surrounding Landsat pixels that affect the MODIS reflectance. The MODIS pixels are weighted based on the values of the pixels they cover, both spatially and in relation to the amount of time from one image to the next [Equation 2.2]. 


$$
L\left(x_{\frac{w}{2}}, y_{\frac{w}{2}}, t\right)=\sum_{i=1}^{w} \sum_{j=1}^{w} W_{i j}\left(M\left(x_{i}, y_{j}, t_{k}\right)+L\left(x_{i}, y_{j}, t_{0}\right)-M\left(x_{i}, y_{j}, t_{0}\right)\right)
$$

Equation 2.2: STARFM algorithm. Landsat (L) and MODIS (M) imagery is used at time $\mathrm{t}_{0}$ to find the Landsat imagery at time $\mathrm{t}_{\mathrm{k}}$. $\mathrm{W}$ is moving window used, and $\mathrm{w} / 2$ is the central pixel of the moving window.

Every MODIS image that does not have a matching Landsat image is modelled in between the closest former and latter Landsat-MODIS pairs. When running this model, we set the max search width to $750 \mathrm{~m}$, as this covered our areas of interest and large areas outside for help with weighting. Gaussian smoothing is applied to the output pixels over time, with a standard deviation of 5, and a month of smoothing applied to decrease noise.

Simulated images are created from the Landsat images where less than $30 \%$ of the image has cloud cover.
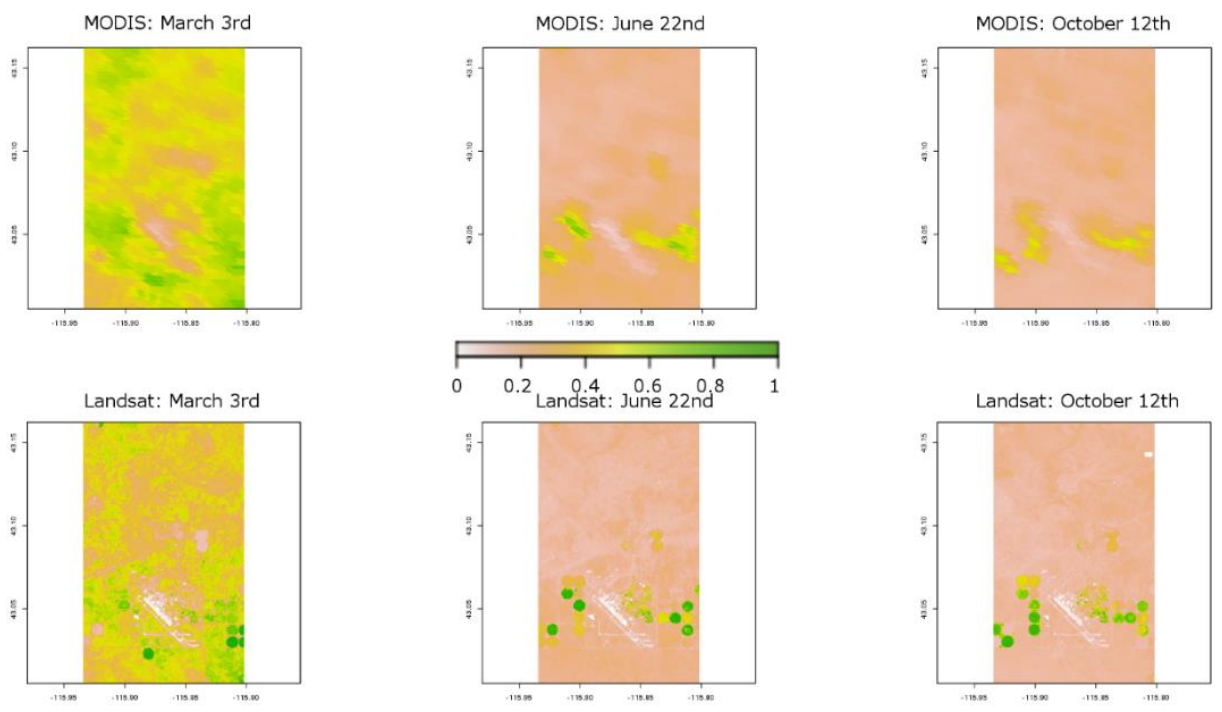

Figure 2.2: NDVI of Landsat and MODIS of the MHAFB. Coarse resolution MODIS imagery is on top, with matching dates of fine resolution Landsat imagery below. 
The output file has daily interpolated NDVI data which is rescaled from -10,00010,000 to $-1-1$, with most vegetation and ground cover falling between 0 and 1 . ENVI and Geotiff files are produced at the end of this process for analysis. STARFM is implemented using an R-shell based on the work by Faye Peters (Peters, 2016). The system allows for large data sets to be run through STARFM in a loop to induce less labor-intensive processing.

\section{Quality Control}

Multiple quality control methods test the output fusion imagery for temporal response and matching of true Landsat imagery. We use a pixel of pure black asphalt for quality control for the temporal response. Ideally, the reflectance of asphalt will be stable over the entire interpolation period (Figure 2.3).

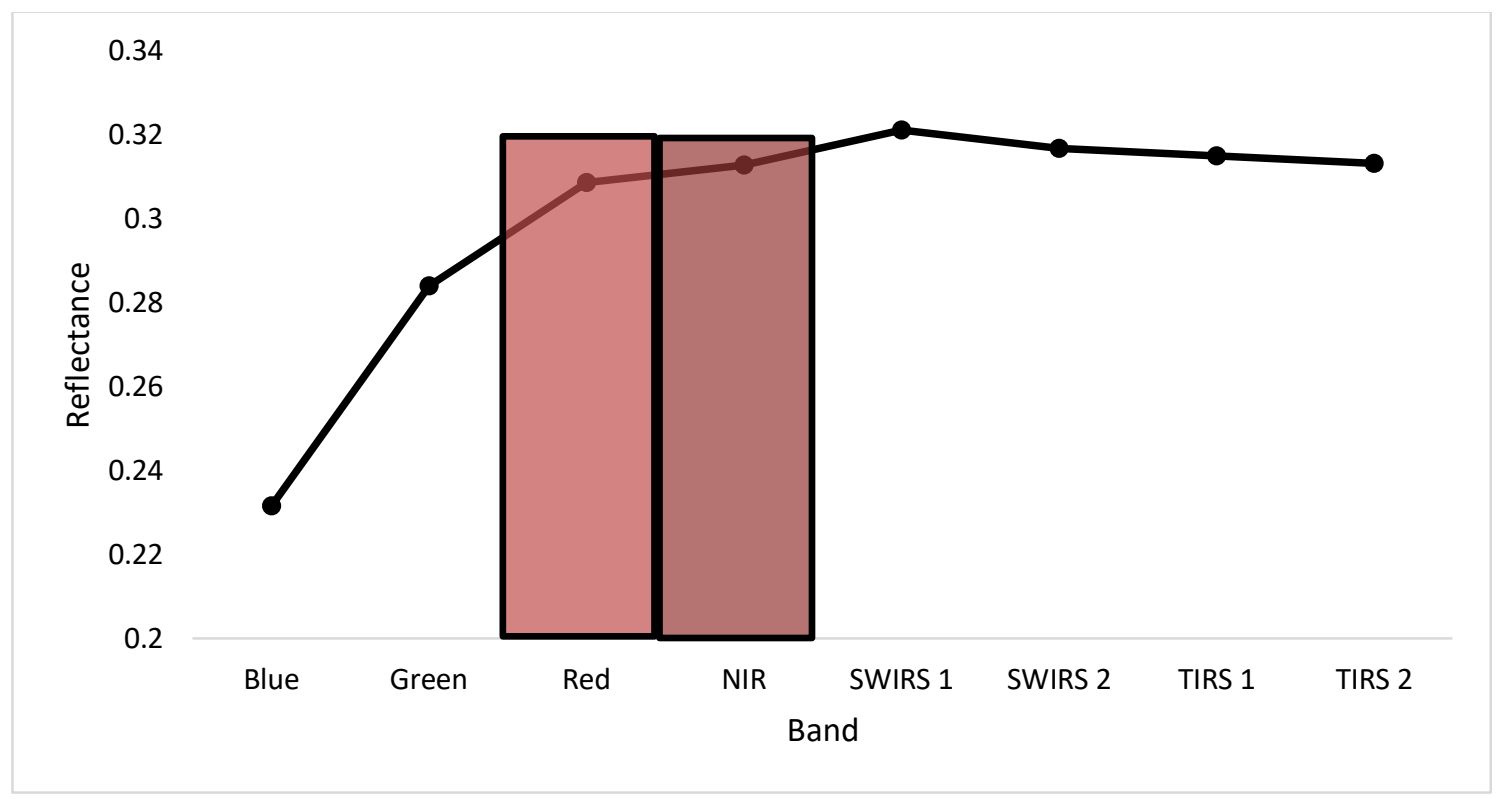

Figure 2.3: A pixel of asphalt is shown using the spectral bands in Landsat 8. Red and NIR, which are used for NDVI, have similar spectral responses.

Statistical measures including mean, median, minimum, maximum, standard deviation, and $25^{\text {th }}$ and $75^{\text {th }}$ percentiles are used to test the change in the signal response 
with MODIS, Landsat, and the fusion system. The fusion method is run a second time removing multiple true Landsat images that occur during the time period (Table 2.2). This allows for the true Landsat images to be compared against the fusion images to test spatial interpolation. The increase in the temporal gap between matching MODIS and Landsat may also induce temporal errors to the scenes.

Table 2.1: Dates for removed Landsat to test fusion image quality

\begin{tabular}{lllll}
\hline Date before: & March 3 & April 3 & July 24 & August 25
\end{tabular}

$\begin{array}{llllll}\text { Removed } & \text { March } 18 & \text { April } 19 & \text { August } 9 & \text { September } 10 & \text { September } 26\end{array}$

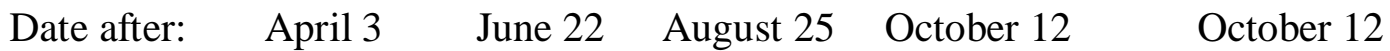

\section{$\underline{\text { Phenological Response }}$}

Phenological vegetation responses are tracked using $20 \mathrm{~m}^{2}$ field vegetation plots and land cover types identified by Google imagery. The field plots are chosen over homogeneous areas, and five images per plot are taken at nadir for ground cover analysis using the SamplePoint program (Enterkine, in prep.). SamplePoint places a ten by ten grid over the images, and the line overlap is classified as vegetation type or soil. The totals for all five images per plot are tallied to estimate total ground cover. There are multiple plot sites for every vegetation cover chosen. Major cover is found using any points that have greater than $80 \%$ of the plot in the specific vegetation type. In addition to these plots, we choose points of land cover classes for agriculture, road, and shrub using Google imagery (DigitalGlobe, $0.65 \mathrm{~m}$ ) as these were not collected in the field. Shrub points contain a mix of bare ground and grasses, causing a high probability of mixed pixel responses. Gaussian smoothing is applied to the pixels in the time series to remove the noise caused by the MODIS daily data (Kandasamy et al., 2013). In total we used six 
shrub points, five road points, four agriculture points, four sandberg bluegrass (Poa secunda) plots, six exotic annual plots, eight cheatgrass (Bromus Tectorum) plots, and five bare/litter covered ground plots for mapping phenology.

\section{Results}

The total runtime of using GEE and STARFM took approximately three hours for 225 images sampled to $30 \mathrm{~m}$ pixel sizes over the 18,800 ha area. During this process, a total of $1,598,000$ pixels were interpolated. A link to the full code is included in Appendix A.

Table 2.3: Download time (DT) for MODIS and Landsat from GEE and Processing time (PT) in STARFM

\begin{tabular}{llll}
\hline \# of Images & Landsat DT & MODIS DT & STARFM PT \\
\hline 225 & $44 \mathrm{~s}$ & $2 \mathrm{~min}$ & $2.9 \mathrm{hrs}$. \\
\hline
\end{tabular}
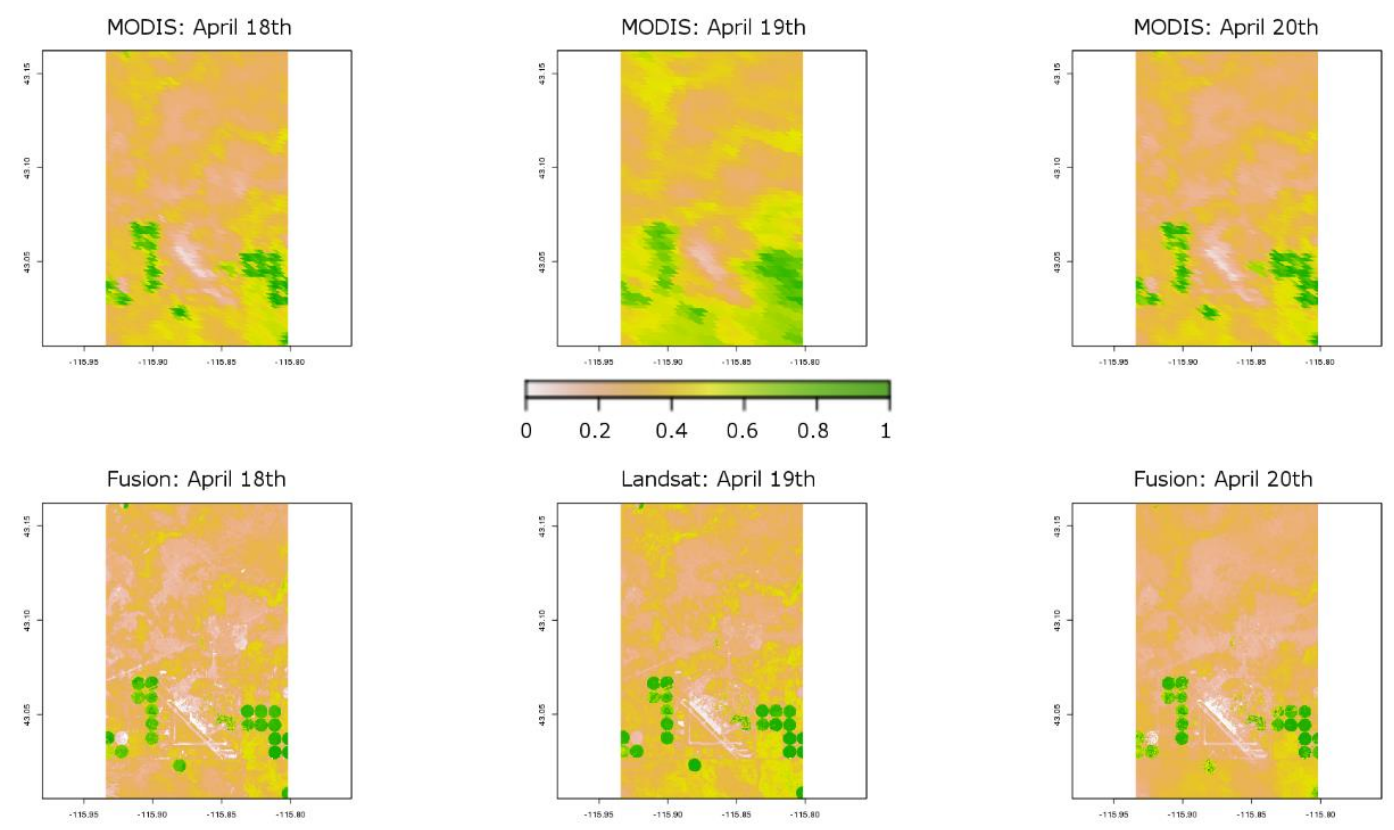

Figure 2.4: NDVI of MODIS scenes (top row) in comparison with two fusion products and the true Landsat scene (bottom row) 
Quality Control 1: Asphalt Pixel Time Series Analysis

We extracted a time series for the single pixel of asphalt on MHAFB before smoothing to detect possible noise that exists in the raw data for comparison to the Landsat and MODIS pixels. Table 2.6 shows the Landsat response of that pixel is centered around an NDVI of 0.0683 which is appropriate for the similar reflectance response of the red and NIR bands. The MODIS NDVI response comes from a larger pixel size, and thus is a mixture of asphalt, vegetation, litter and bare ground (Figure 2.5). Noise is apparent in the MODIS response (Figure 2.6) with rapid shifts from high to low NDVI within days, likely from the vegetation surrounding the asphalt runway.

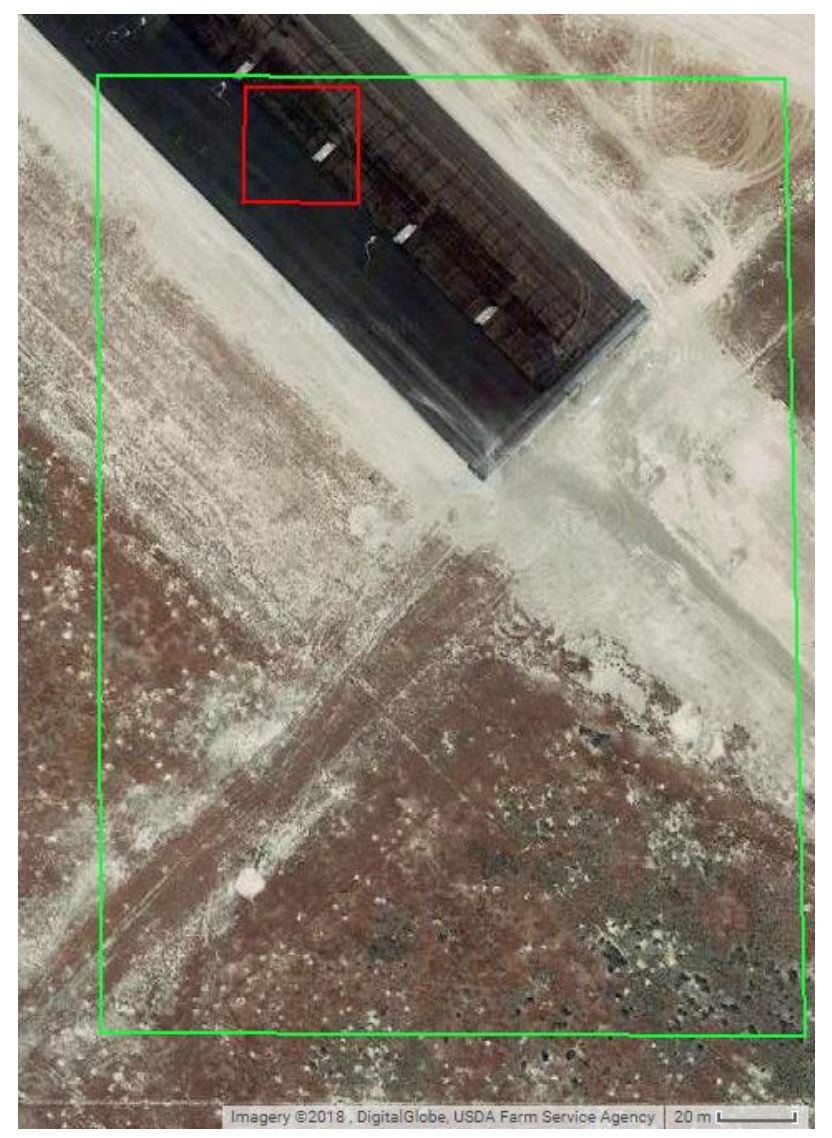

Figure 2.5: MODIS (green, $250 \mathrm{~m} \times 250 \mathrm{~m}$ ) and Landsat (red, $30 \mathrm{~m} \times 30 \mathrm{~m}$ ) pixels over asphalt 
The asphalt pixel has a 0.0586 mean NDVI over the period of analysis, which is similar to Landsat (Figure 2.6). The fusion response has a high correlation with the MODIS pixel response with a correlation coefficient of 0.6383 , meaning it follows the MODIS signal strongly (see APPENDIX B) Thus while the mean is similar to Landsat, we capture the MODIS signal pattern.

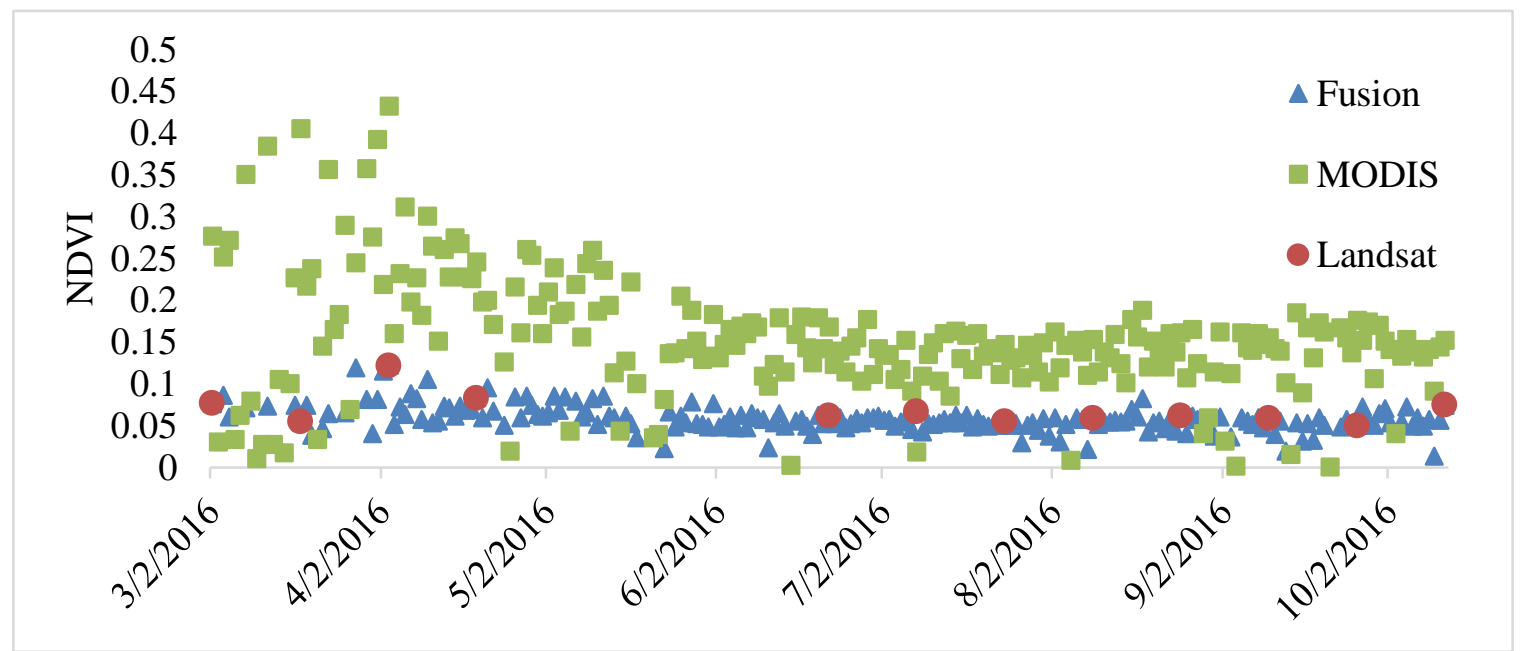

Figure 2.6: MODIS, Landsat, and Fusion NDVI responses over a pixel of black asphalt over the 225-day period. MODIS pixels in spring contain noise caused by cloud cover and vegetation growth during this season, and is relatively stable for the summer period.

Table 2.4: Statistical measures calculated from original and fusion products over the asphalt pixel.

\begin{tabular}{llllllll}
\hline & Mean & STD & Min & Max & $\mathbf{2 5}^{\text {th }}$ & Median & $\mathbf{7 5}^{\text {th }}$ \\
\hline Landsat & 0.0684 & 0.0195 & 0.0494 & 0.1215 & 0.0565 & 0.0619 & 0.0756 \\
MODIS & 0.1503 & 0.0765 & 0.0078 & 0.4326 & 0.1144 & 0.1459 & 0.1788 \\
Fusion & $\mathbf{0 . 0 5 8 7}$ & $\mathbf{0 . 0 1 5 8}$ & $\mathbf{0 . 0 1 3 6}$ & $\mathbf{0 . 1 2 2 4}$ & $\mathbf{0 . 0 5 1 0}$ & $\mathbf{0 . 0 5 7 1}$ & $\mathbf{0 . 0 6 4 0}$ \\
\hline
\end{tabular}


Quality Control 2: True Landsat Images vs. Fusion Product

The fusion images that occurred on the same days as the Landsat images from the secondary run are plotted against each other to test for quality. Bounding effects are seen along the $\mathrm{X}$ and $\mathrm{Y}$ axis (Figure 2.7). A differencing of the images shows that the majority difference is caused by agriculture and anthropogenic features. We remove the agricultural fields and the MHAFB from the interpretation, as we are interested in the capabilities of this program for semi-arid vegetation (Figure 2.8). Two agricultural fields remained in the data, which will be addressed in the discussion.
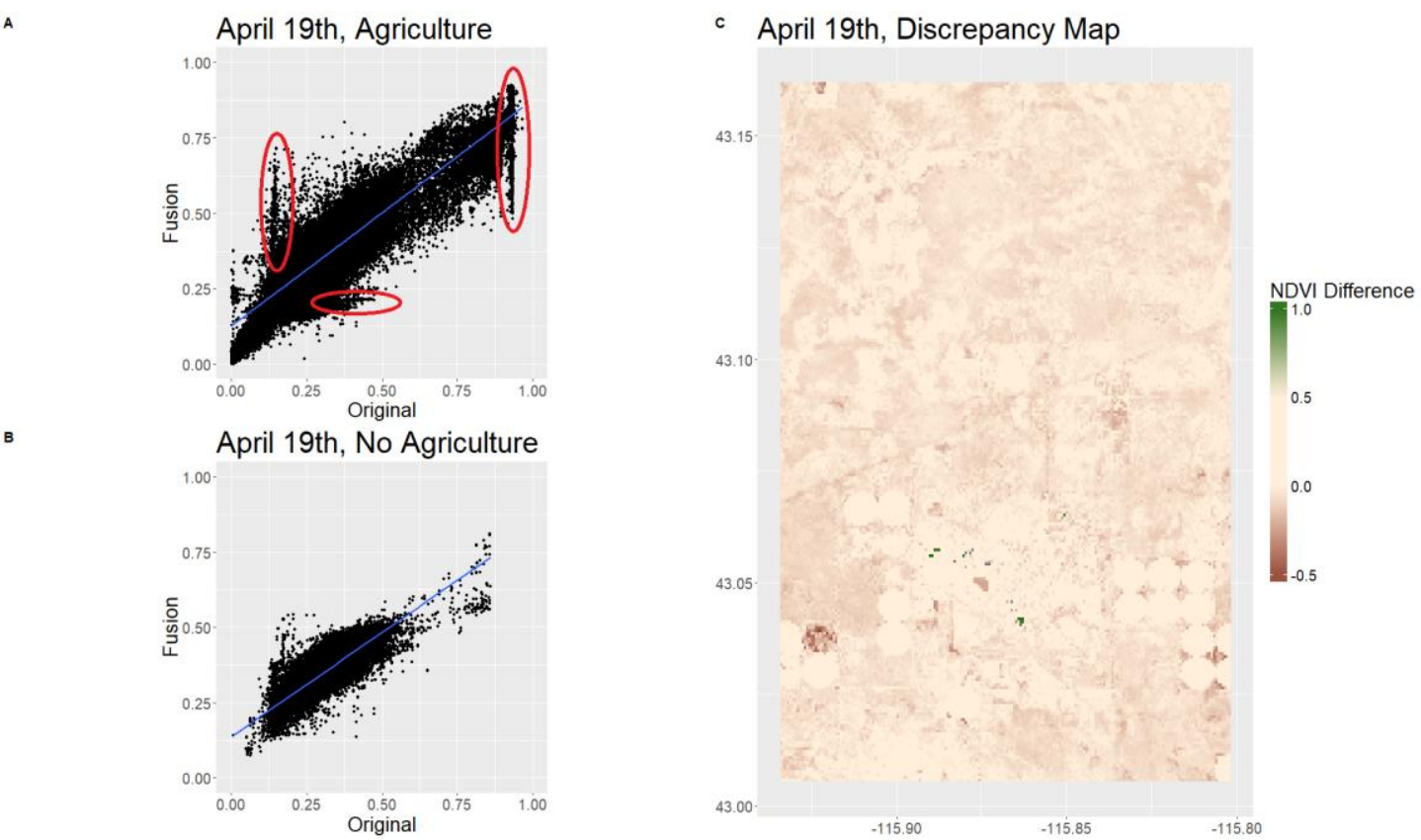

Figure 2.7: Agriculture and anthropogenic structures cause bounding effects on the fusion imagery. A) The fusion and original imagery compared one-to-one with bounding along the $X \& Y$ axis. B) Fusion and original imagery with the southern agricultural fields and MHAFB removed. C) Map of the difference between the fusion and original images, with negative values showing under-estimation and positive values showing over-estimation. 

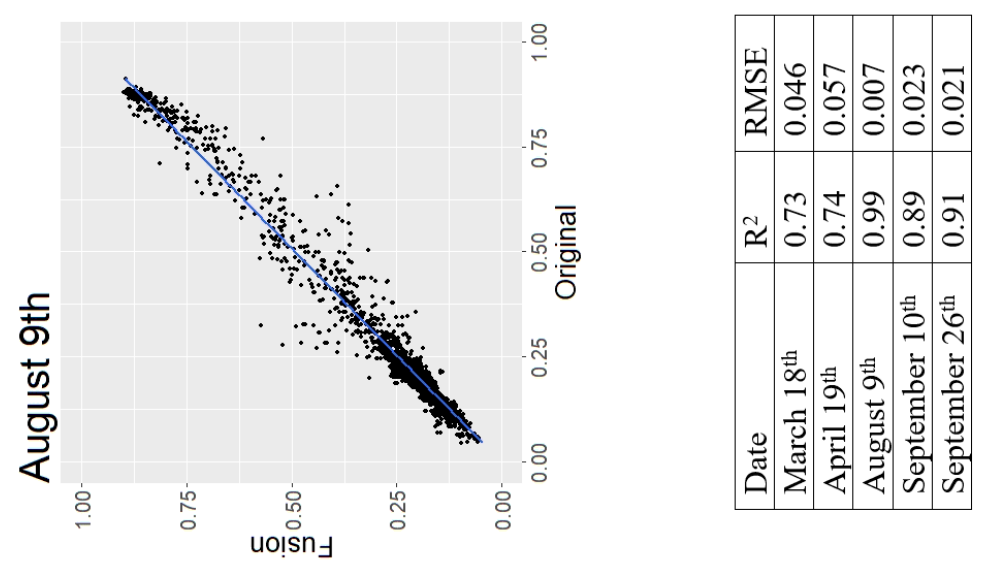

0
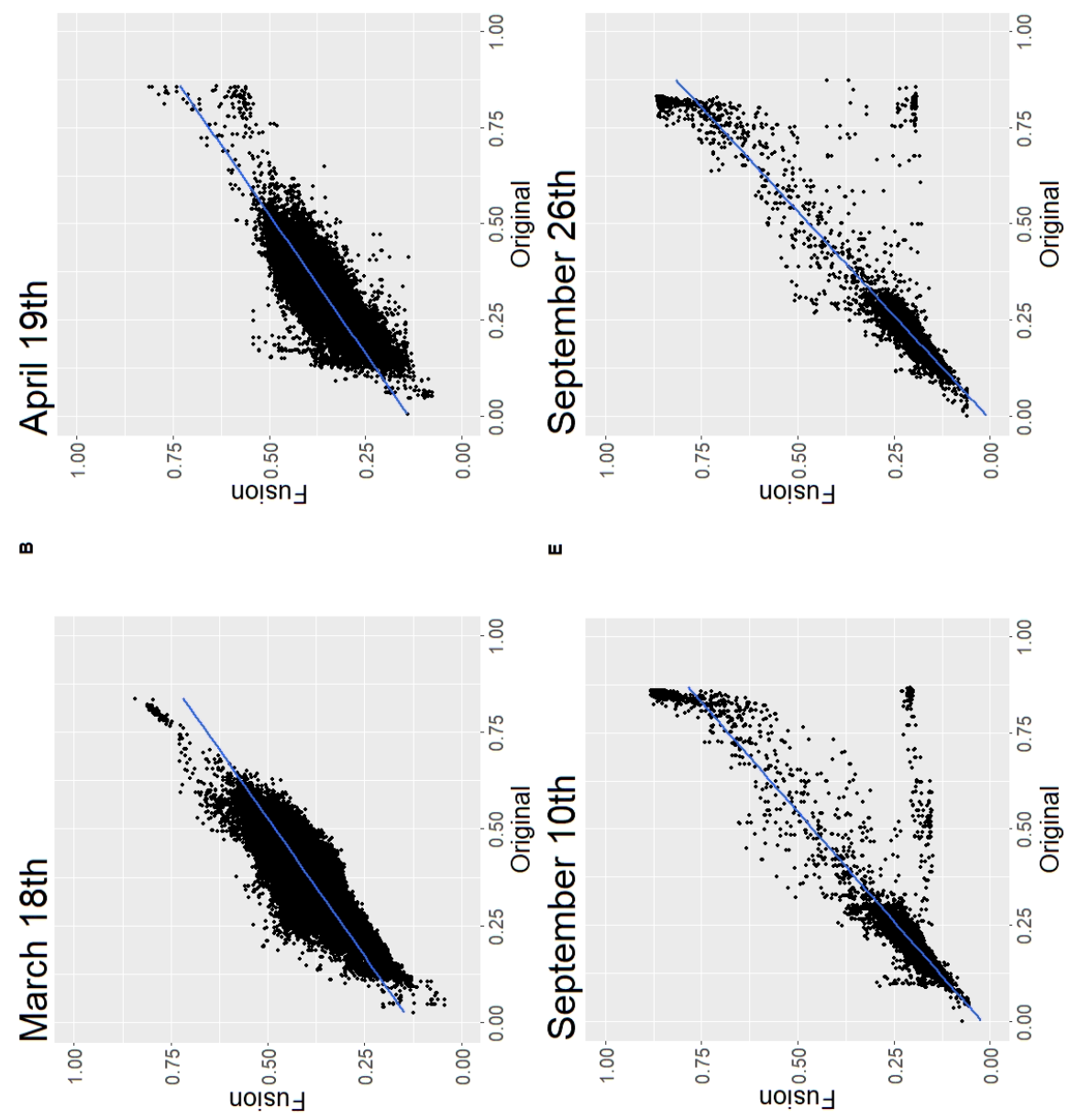

口

Figure 2.8: One-to-one plots of original 2016 Landsat images (X-axis) versus fusion images (Y-axis) over all matching dates. Bounding effects occur in the late September dates, caused by an active late season agricultural field. 
Phenology

Phenological responses for the test points and plots for the year 2016 indicate several trends. Grasses such as cheatgrass and sandberg bluegrass are easily differentiated by the amplitude and pattern that emerge from their time series (Figure 2.9), even within mixed pixels. A plant-defining-characteristic of the sandberg bluegrass is a second seasonal greening (Howard, 1997). The exotic annuals category has varying responses as a mixed class of plants containing: Bur Buttercup (Ceratocephala testiculata), Clasping Pepperweed (Lepidium Perfoliatum), Russian Thistle (Salsola Tragus), Weed Kochia (Kochia Scoparia), and Mustard (Brassica).

Shrub:

The shrub response is the lowest vegetation response, with the peak reaching 0.25 NDVI. The late April green up occurs later than the other vegetation types, and some responses seem to plateau and remain at a stable greenness before slowly senescing around late May to June (Howard, 1999). The trends stabilize towards the mid-summer, as the summer-drought season causes only the perennial leaves to remain on the shrub.

\section{Sandberg Bluegrass:}

Sandberg bluegrass is known to germinate earlier in spring than most grasses, and we catch peak greenness with the start of our study period (Howard, 1997). The sandberg plots reach a max NDVI of 0.25 to 0.3 , and rapidly decline from March to April. A small secondary peak of growth is observed at the end of the summer, which is a phenological difference to some other semi-arid region grass cycles. 

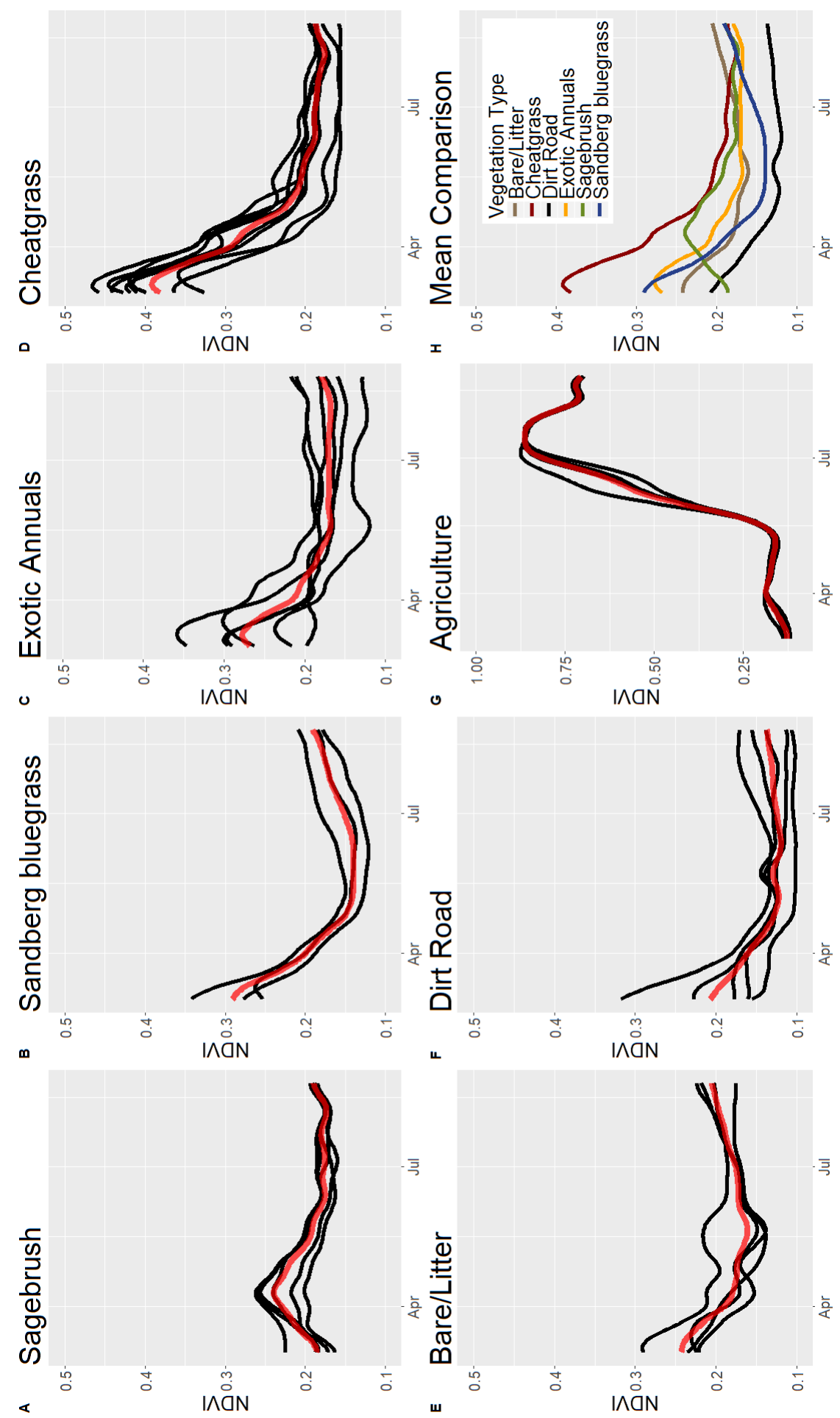

Figure 2.9: Gaussian smoothing applied to known vegetation and anthropogenic influences. A-G) The mean of every response is shown in red. Agriculture has a separate scaling level to match the high green vegetation response in late season. $\mathrm{H}$ ) shows the mean response of vegetation cover, excluding agriculture. 


\section{Exotic Annuals:}

The exotic annuals cover a large range of vegetation responses, and therefore are not easily classifiable. However, they appear to be differentiable from cheatgrass as their NDVI is relatively lower.

\section{Cheatgrass:}

Cheatgrass has the most well-defined response, with the plots peaking at around 0.4 NDVI, and a rapid decline occurring immediately after. They reach full growth towards the end of April, and then senesce through May (Zouhar, 2003).

Bare/Litter:

The bare ground response has an increase in NDVI in the early spring, and rapid variations in the summer and fall. There is variation between samples, and little correlation between responses beside timing of peaks.

\section{$\underline{\text { Road: }}$}

The road response shows a NDVI increase in the spring caused by plants surrounding the dirt road overwhelming the pixel, but as the plants senesce we observe a stable response with small fluctuations. There is a significant drop in the NDVI response over the road, resting at 0.1 .

\section{Agriculture:}

The agriculture response has a low base NDVI as the fields are barren, and then increases dramatically at the time of plant growth. Peak NDVI is reached in August, and begins to decrease in September. 


\section{Discussion}

\section{Quality Control}

The overall quality control metrics show this fusion method between MODIS and Landsat to be viable for daily, $30 \mathrm{~m}$ spatial responses. We tested a stable asphalt pixel with the fused product and compared it to the true Landsat and MODIS response. The stable asphalt fusion response is similar to the stable Landsat response. Noise is observed in the fusion asphalt response, which is caused by the large $250 \mathrm{~m}$ MODIS pixels. The MODIS covered a range of ground surfaces, and the mixed pixel response causes fluctuations in the NDVI of the fusion response. The standard deviation and mean of the fusion product stay well within the bounds of the Landsat imagery over a stable pixel, as seen in Gao et al., 2006.

The secondary quality control test we use in this study was the removal of specific Landsat images. The removal of these data tested the ability of the STARFM program to accurately match the true imagery. With $\mathrm{R}^{2}$ ranging from 0.73 to 0.99 (with agriculture and anthropogenic regions removed) the STARFM program has a high accuracy in semiarid ecosystems.

We found two major areas of error in the fused images and they include agricultural and anthropogenic areas. Rapid change is known to be difficult to characterize using STARFM (Hilker et al., 2009). The pixel's response from roughly zero to oversaturation of the NDVI also resulted in error in these regions. Oversaturation of NDVI is a drawback for this method in largely green regions, as the ability to distinguish between pixels decreases. To solve this problem, one could use other vegetation indices such as the Enhanced Vegetation Index (EVI) (Huete et al., 2002; Nagler et al., 2001; 
Nagler et al., 2005). Well defined bounding dates of MODIS and Landsat before, during, and after major changes must be well timed, but Landsat's 16-day period does not necessarily allow for this. This method has done well with the overall trends of the agricultural system, but as seen in the quality control methods, lacks the ability to capture precise timing and NDVI values. Man-made objects, such as concrete (not asphalt) and buildings, with high reflective surfaces were un-interpretable in this method, and caused large errors to occur. Bodies of water were also masked from the satellite imagery.

Winter months are excluded from the data set as it was found that the amount of cloud cover and snow on the ground caused a low signal to noise ratio. For example, the MODIS pixel's response to the snow increased the noise, making the underlying signal impossible to interpret.

$\underline{\text { Phenology }}$

The vegetation phenological response from the fusion system is found to compare well with the overall growth cycles. Variations within each plant species is also expected as no plant (or plot) will have the same greening cycle, especially in heterogeneous semiarid rangelands (e.g. water patterns, grazing, seeding) (Saco et al., 2007;

HilleRisLambers et al., 2001).

The shrub, cheatgrass, and sandberg bluegrass plots are all clearly delineated from each other by their growth cycles. The timing of their peaks and amplitude of the NDVI vary among these species. Coupled with weather and other environmental observations, one may be able to explain changes in annual phenological trends. Delineating species and observing their phenology may aid our understanding of changes in carbon cycling in 
semi-arid ecosystems, as well as provide increased accuracy in vegetation parameters in earth system models.

The bare ground response is observed to have a spring green up. This may be the result of biocrust presence in areas classified as bare ground. Biocrust rapidly greens immediately after small amounts of rainfall, or even morning dew, and this greenness may have been captured by the imagery. Additionally, litter covers much of the ground in these areas, and the litter response may have contributed to the reflectance peak. The STARFM model could be used to calculate indices other than NDVI, such as the soil adjusted vegetation index (SAVI), to account for interactions between vegetation and soil (Huete, A. R., 1988).

A major limitation of the fusion system is that ecosystem-level changes that occur at scales finer than $250 \mathrm{~m}$ and within time periods of less than two weeks are hard to characterize. The large MODIS pixels may be unable to pick up the small changes in the overall reflectance of the pixel response, and the bounding Landsat updates the fine resolution information every 16-days. These limitations incur higher inconsistencies on quick, small temporal and spatial scale developments. This test of the fusion system has shown high accuracy over long periods of interpretation, but as seen with the rapid agricultural growth, small rapid changes are not well defined.

Future Work

$\underline{\text { Uses: }}$

The fusion system can be useful to many different ecosystems for both long and short-term studies. A limitation is the time and storage space that GEE allows in its 
exporting process; however, this may be circumvented by exporting multiple images and bricking them together in the $\mathrm{R}$ environment.

\section{Sentinel-2:}

Sentinel-2 is a USGS satellite system with 13 spectral bands ranging from 10 to $60 \mathrm{~m}$, and compliments current Landsat satellite imagery (Drusch et al., 2012). The first satellite was launched June 23, 2015, with a 10-day repeat cycle, and the second launched March 7, 2017, increasing the repeat cycle to 5 days (Drusch et al., 2012). We also developed code for the fusion system to work with the Sentinel-2 MSI instrument, but there are some difficulties as the STARFM code is developed for the specific spectral overlap of MODIS and Landsat. Further, STARFM uses the timing and nadir points of these satellites to create plausible similarities for interpolation (Gao et al., 2006). Resultantly, Sentinel-2 has different reflectance responses that may cause error by using the current STARFM system (Figure 2.10). Future studies could use band pass resampling to aid in the differences of reflectance, and techniques to match BRDF between the systems for higher accuracy (Claverie et al., 2017).

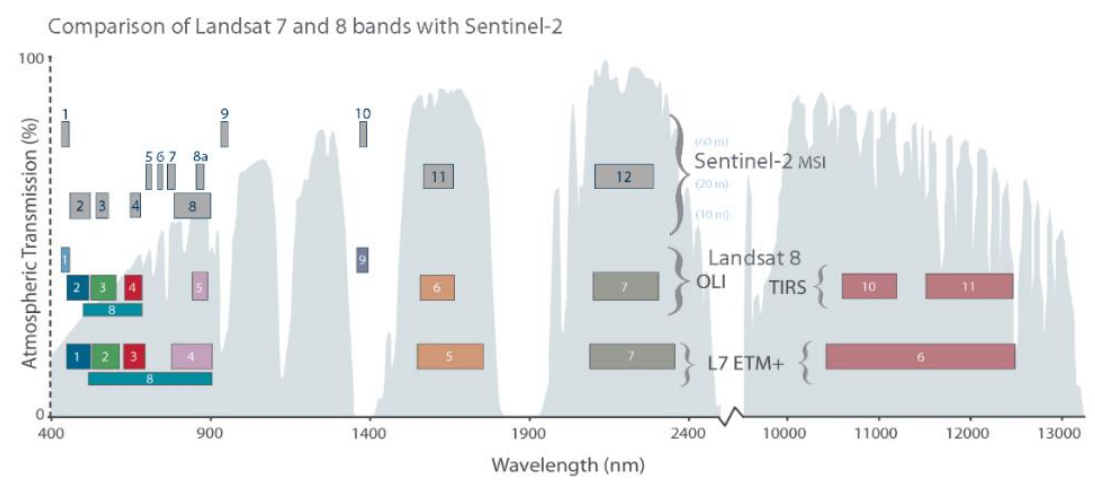

Figure 2.10: Sentinel-2 band versus Landsats $7 \& 8$, image from USGS EROS center, (https://landsat.gsfc.nasa.gov/wpcontent/uploads/2015/06/Landsat.v.Sentinel2.png) 
GEE has Sentinel-2 data at level 1C which is orthorectified, and provides top-ofthe-atmosphere (TOA) reflectance. This method uses surface reflectance to remove the atmospheric influence during the interpolation, which is a necessary step for the STARFM process. Cloud-masking is also necessary for the STARFM process to work, and the Sentinel systems use the B10 (cirrus band, $60 \mathrm{~m}$ ) and the QA60 (cloud mask, 60 m). Cloud mask algorithms using the cirrus band do not function correctly yet on GEE, but this will likely be updated soon (GEE Developers, 2016). NDVI used with Sentinel-2 can be created many ways, including the use of the red-edge bands. Using the red-edge bands for NDVI may induce error within STARFM due to wavelength changes caused by less overlap. If a $10 \mathrm{~m}$ NDVI response is desired over an area, bands B4 and B8 may be used. Band B8 has a similar response to Landsat 7 and MODIS, but a broader wavelength compared to Landsat 8 . The red-edge band of B8a is also closely linked to the MODIS and Landsat responses, but all red-edge bands are collected at $20 \mathrm{~m}$ pixel sizes, which means the red response must be interpolated to match the higher response, possibly inducing error.

Regardless of these potential differences, it is highly likely that a mixture of Sentinel-2 aided by MODIS or Landsat can lead to higher quality phenology measures, as seen with the Harmonized Landsat-8 Sentinel-2 product (Claverie et al., 2017). This system can be used to fill in historic information for the ability to pair it with the modern, finer resolution Sentinel-2 data. As Sentinel-2 was launched in 2015, and MODIS has been in orbit since 1999, we have the capability of adding over 16 years of finer spatial and temporal historic information. Sentinel-2 and Landsat could provide a 20-year record, altogether providing over 40 years of data. The future of MODIS is uncertain, and 
the Visible Infrared Imaging Radiometer Suite (VIIIRS) is set to replace it (Lee et al., 2006). It was launched in 2011 to be a continuity to MODIS, and the VIIRS VNP09 products are equivalent to the MODIS MOD09G, with daily revisit periods and 0.5 to 1 km pixel size (Skakun et al., 2018; Murphy et al., 2001). VIIIRS comparisons to MODIS show it to be a viable option in arid areas, allowing us to continue future long-term fine resolution monitoring ( $\mathrm{Li}$ et al., 2014; Jarchow et al., 2018) This data is already available on GEE from 1/19/2012 to present, for possible analysis between MODIS/Landsat fusion, and future VIIRS/Landsat fusion.

\section{Conclusion}

We found that creating a fusion product between MODIS and Landsat resulting in high temporal and spatial resolution imagery is viable, and the resulting imagery provides insights to phenological processes in our semi-arid ecosystem. Though there are sources of error and noise, this method still allows for phenological cycles to be observed and provides a viable data source in regions with vegetation changes that occur more rapidly than Landsat is able to capture and/or in regions with high cloud cover. Google Earth Engine and STARFM are easily linked to create large, detailed data sets over regions of interest. This method can be applied to observe moderate to long term (weekly to decadal) vegetation phenology. Other band combinations and indices may be implemented in this system to optimize the observations for the ecosystem of interest.

\section{References}

Bradley, A., Mustard, J.,(2005) Identifying land cover variability distinct from land cover change: Cheatgrass in the Great Basin, Remote Sensing of Environment, Volume 94, Issue 2, 30 January 2005, Pages 204-213, ISSN 0034 4257, https://doi.org/10.1016/j.rse.2004.08.016. 
BLM. (2008). Final Environmental Impact Statement Volume I, Final Environmental Impact Statement

Claverie, M., Masek, J. G., Ju, J., \& Dungan, J. L. (2017). Harmonized Landsat-8 Sentinel-2 (HLS) Product User's Guide. National Aeronautics and Space Administration (NASA): Washington, DC, USA.

Dong J., Xiao X., Menarguez M., Zhang G., Qin Y., Thau D., Biradar C., Moore B. (2016). Mapping paddy rice planting area in northeastern Asia with Landsat 8 images, phenology-based algorithm and Google Earth Engine, Remote Sensing of Environment, Volume 185, 2016, Pages 142-154, ISSN 0034-4257, https://doi.org/10.1016/j.rse.2016.02.016. (http://www.sciencedirect.com/science/article/pii/S003442571630044X)

Drusch, M., Del Bello, U., Carlier, S., Colin, O., Fernandez, V., Gascon, F., ... \& Meygret, A. (2012). Sentinel-2: ESA's optical high-resolution mission for GMES operational services. Remote sensing of Environment, 120, 25-36.

Elmore A., Mustard J., Manning S., Lobell D. (2000). Quantifying Vegetation Change in Semiarid Environments: Precision and Accuracy of Spectral Mixture Analysis and the Normalized Difference Vegetation Index, Remote Sensing of Environment, Volume 73, Issue 1, July 2000, Pages 87-102,ISSN 0034-4257, https://doi.org/10.1016/S0034-4257(00)00100-0.

Enterkine J, in prep. Assessing impacts temporally based classification methods in asemiarid environment using Sentinel-2.

Fensholt R., Langanke T. , Rasmussen K., Reenberg A., Prince S., Tucker C., Scholes R., Le Q., Bondeau A., Eastman R., Epstein H., Gaughan A., Ulf H., Cheikh M., Lennart O., Jose P., Schweitzer C., Seaquist J., Wessels K. (2012). Greenness in semi-arid areas across the globe 1981-2007 — an Earth Observing Satellite based analysis of trends and drivers, Remote Sensing of Environment, Volume 121, June 2012,Pages 144-158, ISSN 0034-4257, https://doi.org/10.1016/j.rse.2012.01.017.

Fischer, R., \& Turner, N. C. (1978). Plant Productivity in the. Ann. Rev. Plant Physiology, 29(99), 277-317. 
Foga, S., Scaramuzza, P. L., Guo, S., Zhu, Z., Dilley, R. D., Beckmann, T., ... \& Laue, B. (2017). Cloud detection algorithm comparison and validation for operational Landsat data products. Remote sensing of environment, 194, 379-390.

Gao, F., Masek, J., Schwaller, M., \& Hall, F. (2006). On the blending of the landsat and MODIS surface reflectance: Predicting daily landsat surface reflectance. IEEE Transactions on Geoscience and Remote Sensing, 44(8), 2207-2218. http://doi.org/10.1109/TGRS.2006.872081

GEE Developers. (2016). Cloud Masking Sentinel 2, Google Earth Engine Developers Forum, https://groups.google.com/forum/\#!topic/google-earth-engine developers/i63DS-Dg8Sg

Geerken, R., \& Ilaiwi, M. (2004). Assessment of rangeland degradation and development of a strategy for rehabilitation. Remote Sensing of Environment, 90(4), 490-504.

Gorelick, N., Hancher, M., Dixon, M., Ilyushchenko, S., Thau, D., \& Moore, R. (2017). Google Earth Engine: Planetary-scale geospatial analysis for everyone. Remote Sensing of Environment.

Gould, W. (2000). Remote sensing of vegetation, plant species richness, and regional biodiversity hotspots. Ecological applications, 10(6), 1861-1870.

Hilker, T., Wulder M., Coops N., Seitz N., White J., Gao F., Masek J., Stenhouse G. (2009). Generation of dense time series synthetic Landsat data through data blending with MODIS using a spatial and temporal adaptive reflectance fusion model, Remote Sensing of Environment, Volume 113, Issue 9, 2009, Pages 19881999, ISSN 0034-4257, https://doi.org/10.1016/j.rse.2009.05.011. (http://www.sciencedirect.com/science/article/pii/S0034425709001709)

HilleRisLambers, R., Rietkerk, M., van den Bosch, F., Prins, H. H., \& de Kroon, H. (2001). Vegetation pattern formation in semi-arid grazing systems. Ecology, 82(1), 50-61.

Howard, J. (1997). Poa secunda. In: Fire Effects Information System, [Online]. U.S. Department of Agriculture, Forest Service, Rocky Mountain ResearchStation, Fire Sciences Laboratory (Producer). Available: 
https://www.fs.fed.us/database/feis/plants/graminoid/poasec/all.html [2018, May13].

Howard, J. (1999). Artemisia tridentata subsp. wyomingensis. In: Fire Effects Information System, [Online]. U.S. Department of Agriculture, Forest Service, Rocky Mountain Research Station, Fire Sciences Laboratory (Producer). Available: https://www.fs.fed.us/database/feis/plants/shrub/arttriw/all.html [2018, May 13].

Huang H., Chen Y., Clinton N., Wang J., Wang X., Liu C., Gong P., Yang J., Bai Y., Zheng Y., Zhu Z., (2017). Mapping major land cover dynamics in Beijing using all Landsat images in Google Earth Engine, Remote Sensing of Environment, Volume 202, 2017, Pages 166-176, ISSN 0034 4257,https://doi.org/10.1016/j.rse.2017.02.021. http://www.sciencedirect.com/science/article/pii/S0034425717300810)

Huete, A. R. (1988) A Soil-Adjusted Vegetation Index (SAVI). Remote Sensing of Environment, vol. 25:295 309.

Huete,A., K. Didan, T. Miura, E.P. Rodriguez, X. Gao and L.G. Ferreira. (2002). Overview of the radiometric and biophysical performance of the MODIS vegetation indices. Remote Sensing of Environment 83:195-213.

Jarchow, C. J., Didan, K., Barreto-Muñoz, A., Nagler, P. L., \& Glenn, E. P. (2018). Application and Comparison of the MODIS-Derived Enhanced Vegetation Index to VIIRS, Landsat 5 TM and Landsat 8 OLI Platforms: A Case Study in the Arid Colorado River Delta, Mexico. Sensors, 18(5), 1546.

Johansen K., Phinn S., Taylor M. (2015). Mapping woody vegetation clearing in Queensland, Australia from Landsat imagery using the Google Earth Engine, Remote Sensing Applications: Society and Environment, Volume 1, 2015, Pages 36-49, ISSN 2352-9385, https://doi.org/10.1016/j.rsase.2015.06.002. (http://www.sciencedirect.com/science/article/pii/S2352938515000051) 
Kandasamy, S., Baret, F., Verger, A., Neveux, P., \& Weiss, M. (2013). A comparison of methods for smoothing and gap filling time series of remote sensing observations-application to MODIS LAI products. Biogeosciences, 10(6), 40554071 .

Kochert, M. N., \& Pellant, M. (1986). Multiple use in the Snake River Birds of Prey Area. Rangelands Archives, 8(5), 217-220.

Lambin, E. F., \& Strahlers, A. H. (1994). Change-vector analysis in multitemporal space:a tool to detect and categorize land-cover change processes using high temporal resolution satellite data. Remote sensing of environment, 48(2), 231-244.

Lee, T. F., Miller, S. D., Schueler, C., \& Miller, S. (2006). NASA MODIS Previews NPOESS VIIRS Capabilities. Weather and Forecasting, 21(4), 649-655.

Leprieur, C., Kerr, Y. H., Mastorchio, S., \& Meunier, J. C. (2000). Monitoring vegetationcover across semi-arid regions: comparison of remote observations from various scales. International Journal of Remote Sensing, 21(2), 281-300.

Li, H., Sun, D., Yu, Y., Wang, H., Liu, Y., Liu, Q., ... \& Cao, B. (2014). Evaluation of the VIIRS and MODIS LST products in an arid area of Northwest China. Remote Sensing of Environment, 142, 111-121.

Lyon, J.G., Yuan, D., Lunetta, R.S., and C.D. Elvidge. (1998). A change detection experiment using vegetation indices. Photogrammetric Engineering and Remote Sensing 64(2):143-150.

Mirik, M., Norland, J. E., Biondini, M. E., Crabtree, R. L., \& MICHELS, G. J. (2007). Relationships between remotely sensed data and biomass components in a big sagebrush (Artemisia tridentata) dominated area in Yellowstone National Park. Turkish Journal of Agriculture and Forestry, 31(2), 135-145.

Murphy, R. E., Barnes, W. L., Lyapustin, A. I., Privette, J., Welsch, C., DeLuccia, F., ... \& Kealy, P. S. (2001). Using VIIRS to provide data continuity with MODIS. In Geoscience and Remote Sensing Symposium, 2001. IGARSS'01. IEEE 2001 International (Vol. 3, pp. 1212-1214). IEEE. 
Mutz, K. M., Cannon, D., \& Simmons, C. (2004). Snake River Birds of Prey National Conservation Area Case Study.

Nagler, P.L., R.L. Scott, C. Westenburg, J.R. Cleverly, E.P. Glenn, and A.R. Huete. (2005). Evapotranspiration on western U.S. rivers estimated using the enhanced vegetation index from MIDOS and data from eddy covariance and Bowen ratio flux towers. Remote Sensing of the Environment 97(3):337-351.

Nagler, P.L., E.P. Glenn, and A.R. Huete. (2001). Assessment of spectral vegetation indices for riparian vegetation in the Colorado River delta, Mexico. Journal of Arid Environments 49(1):91-110.

NASA, (2016). LP DAAC: Terra Satellite Enters Safe Mode,https://lpdaac.usgs.gov/about/news_archive/terra_satellite_enters_safe_mo de

Okin G., Roberts D., Murray, Okin B., William J. (2001). Practical limits on hyperspectral vegetation discrimination in arid and semiarid environments, Remote Sensing of Environment, Volume 77, Issue 2, August 2001, Pages 212 225, ISSN 0034-4257,https://doi.org/10.1016/S0034-4257(01)00207-3.

Olexa, E. M., \& Lawrence, R. L. (2014). Performance and effects of land cover type on synthetic surface reflectance data and NDVI estimates for assessment and monitoring of semi-arid rangeland. International Journal of Applied Earth Observation and Geoinformation, 30, 30-41.

Olsoy, P. J., Mitchell, J., Glenn, N. F., \& Flores, A. N. (2017). Assessing a multi platform data fusion technique in capturing spatiotemporal dynamics of heterogeneous dryland ecosystems in topographically complex terrain. Remote Sensing, 9(10), 981.

Paylore, P., \& Greenwell, J. R. (1979). Fools rush in: pinpointing the Arid Zones. Arid Lands Newsletter, 10, 17-18.

Peters, F. (2016). "Analyzing the phenologic dynamics of kudzu (Pueraria montana) infestations using remote sensing and the normalized difference vegetationindex." 
(2016). Electronic Theses and Dissertations. Paper 2437.

https://doi.org/10.18297/etd/2437

Peterson, E. B. (2005). Estimating cover of an invasive grass (Bromus tectorum) using tobit regression and phenology derived from two dates of Landsat ETM+ data. International Journal of Remote Sensing, 26(12), 2491-2507.

Poulter, B., Frank, D., Ciais, P., Myneni, R. B., Andela, N., Bi, J., ... \& Running, S. W. (2014). Contribution of semi-arid ecosystems to interannual variability of the global carbon cycle. Nature, 509(7502), 600.

Ramsey, R. D., Wright, D. L., \& McGinty, C. (2004). Evaluating the Use of Landsat 30 Enhanced Thematic Mapper to Monitor Vegetation Cover in Shrub-Steppe Environments.

Raymondi, A. M. (2017). The Relative Importance of Fire History, Management Treatments, Biotic, and Abiotic Factors on the Abundance of Key Vegetative Components in an Endangered Sagebrush-Steppe Ecosystem.

Saha, M. V., T. M. Scanlon, and P. D'Odorico. (2015). Examining the linkage between shrub encroachment and recent greening in water-limited southern Africa. Ecosphere 6(9):156. http://dx.doi.org/10.1890/ES15-00098.1

Saco, P. M., Willgoose, G. R., \& Hancock, G. R. (2007). Eco-geomorphology of banded vegetation patterns in arid and semi-arid regions. Hydrology and Earth System Sciences Discussions, 11(6), 1717-1730.

Sakamoto, T., Yokozawa, M., Toritani, H., Shibayama, M., Ishitsuka, N., \& Ohno, H. (2005). A crop phenology detection method using time-series MODIS data. Remote sensing of environment, 96(3-4), 366-374.

Schmidt H., Karnieli A., (2000). Remote sensing of the seasonal variability of vegetation in a semi-arid environment, Journal of Arid Environments, Volume 45, Issue 1, 2000, Pages 43-59, ISSN 0140-1963, http://dx.doi.org/10.1006/jare.1999.0607.

Senseman, G.M., Bagley, C.F., and S.A. Tweddale. (1996). Correlation of rangeland cover measures to satellite-imagery-derived vegetation indices. Geocarto International 11(3):29-38 
Shettigara, V. K. (1992). A generalized component substitution technique for spatial enhancement of multispectral images using a higher resolution data set. Photogram. Enggineer. Remote Sen., 58, 561-567.

Sims, D. A., Rahman, A. F., Cordova, V. D., El-Masri, B. Z., Baldocchi, D. D., Bolstad, P. V., ... \& Monson, R. K. (2008). A new model of gross primary productivity for North American ecosystems based solely on the enhanced vegetation index and land surface temperature from MODIS. Remote Sensing of Environment, 112(4), 1633-1646.

Singh, N., \& Glenn, N. F. (2009). Multitemporal spectral analysis for cheatgrass (Bromustectorum) classification. International Journal of Remote Sensing, 30(13), 3441 3462. https://doi.org/10.1080/01431160802562222

Sivanpillai R., Prager S., Storey T., (2009) Estimating sagebrush cover in semi-arid environments using Landsat Thematic Mapper data, International Journal of Applied Earth Observation and Geoinformation, Volume 11, Issue 2, April 2009, Pages 103-107, ISSN 0303-2434, https://doi.org/10.1016/j.jag.2008.10.001.

Skakun, S., Justice, C. O., Vermote, E., \& Roger, J. C. (2018). Transitioning from MODIS to VIIRS: an analysis of inter-consistency of NDVI data sets for agricultural monitoring. International Journal of Remote Sensing, 39(4), 971-992.

Spaete, L. P., Glenn, N. F., \& Baun, C. W. (2016). 2013 Morley Nelson Snake River Birds of Prey National Conservation Area RapidEye 7m Landcover Classification.

Stefanov, W. L., Ramsey, M. S., \& Christensen, P. R. (2001). Monitoring urban land cover change: An expert system approach to land cover classification of semiarid to arid urban centers. Remote sensing of Environment, 77(2), 173-185.

Tucker, C. J., Townshend, J. R. G., \& Goff, T. E. (1985). African Land-Cover Classification Using Satellite Data. Science, 227(4685), 369-375. https://doi.org/10.1126/science.227.4685.369

United States, Congress. (2008). "Snake River Birds of Prey National Conservation Area: proposed resource management plan and final environmental impact statement." 
Snake River Birds of Prey National Conservation Area: proposed resource management plan and final environmental impact statement, Bureau of Land Management, Boise District Office, 2008.

USGS (2018), Landsat 8 Surface Reflectance Code (LaSRC) Product Version 4.3, Product Guide

Walker J.J., de Beurs K.M., Wynne R.H., Gao F. (2012). Evaluation of Landsat and MODIS data fusion products for analysis of dryland forest phenology, RemoteSensing of Environment, Volume 117, 2012, Pages 381-393, ISSN 0034 4257, https://doi.org/10.1016/j.rse.2011.10.014. (http://www.sciencedirect.com/science/article/pii/S0034425711003622)

Walker, J. J., De Beurs, K. M., \& Wynne, R. H. (2014). Dryland vegetation phenology across an elevation gradient in Arizona, USA, investigated with fused MODIS and Landsat data. Remote Sensing of Environment, 144, 85-97.

Vermote, E., Wolfe, R. (2015). MOD09GQ MODIS/Terra Surface Reflectance DailyL2G Global 250m SIN Grid V006 [Data set]. NASA EOSDIS LP DAAC. doi:10.5067/MODIS/MOD09GQ.006

Wardlow, B. D., Egbert, S. L., \& Kastens, J. H. (2007). Analysis of time-series MODIS $250 \mathrm{~m}$ vegetation index data for crop classification in the US Central Great Plains. Remote Sensing of Environment, 108(3), 290-310.

Yichun X., Sha Z.,Yu M., (2008). Remote sensing imagery in vegetation mapping: a review. J Plant Ecol 2008; 1 (1): 9-23. doi: 10.1093/jpe/rtm005 Zhang, X., Friedl, M. A., Schaaf, C. B., Strahler, A. H., Hodges, J. C., Gao, F., ... \& Huete, A. (2003). Monitoring vegetation phenology using MODIS. Remote sensing of environment, 84(3), 471-475.

Zhang, X., Friedl, M. A., Schaaf, C. B., Strahler, A. H., Hodges, J. C., Gao, F., ... \& Huete, A. (2003). Monitoring vegetation phenology using MODIS. Remote sensing of environment, 84(3), 471-475.

Zhou, L., Tucker, C. J., Kaufmann, R. K., Slayback, D., Shabanov, N. V., \& Myneni, R. B. (2001). Variations in northern vegetation activity inferred from satellite data of 
vegetation index during 1981 to 1999. Journal of Geophysical Research:

Atmospheres, 106(D17), 20069-20083.

Zouhar, K. (2003). Bromus tectorum. In: Fire Effects Information System, [Online]. U.S. Department of Agriculture, Forest Service, Rocky Mountain Research Station, Fire Sciences Laboratory (Producer). Available: https://www.fs.fed.us /database/feis/plants/graminoid/brotec/all.html [2018, May 13]. 


\section{SATELLITE FUSION METHODS FOR DECADAL-SCALE PRE- AND POST- FIRE VEGETATION MONITORING IN A SEMI-ARID ECOSYSTEM \\ Introduction}

In recent years, semi-arid ecosystems have experienced a rise in the frequency, size, and intensity of wildfires (Brooks et al., 2004; O'Donnell et al., 2011;

Puisdefábregas \& Medizabal, 1998). Human encroachment and climate changes have altered the historic fire regime (Schussman et al., 2006; Obrist et al., 2003; Maestre et al., 2012). In areas such as the Great Basin sagebrush-steppe, an altered fire regime has resulted in changes in the vegetation dynamics, including an increase in litter caused by bare ground being converted to grasses (Mack \& D'Antonio, 1998). In addition, invasive species (e.g. cheatgrass (Bromus tectorum)) have expanded across the Great Basin, increasing the flammability of these regions by decreasing bare ground and conversely escalating the amount of highly flammable vegetation cover (D'Antonio \& Vitousek, 1992). Cheatgrass dominates burned areas due to its root growth outcompeting native grasses after fire, and the ability of its seed banks to withstand low to medium intensity flames (Klemmedson \& Smith, 1964; Melgoza et al., 1990; Arredondo et al., 1998). These dynamics allow for cheatgrass to gain dominance, and exacerbate the fire cycle (Balch et al., 2013). Three to four century-based fire cycles in shrub-steppe have decreased to less than a century in cheatgrass invaded areas, greatly altering the ecosystem (Baker, 2006; Balch et al., 2013). 
Recent studies have highlighted the lack of knowledge of long term ecosystem responses to wildfire, and especially in semi-arid ecosystems (Prichard et al., 2017; Miller et al., 2013). Long term studies on wildfire responses are difficult due to their complexity, and because companion sites and control groups are challenging to designate (Ellsworth \& Kauffman, 2017). While some long-term (>5 year) studies are possible at the plot scale, studies at the landscape scale are difficult due to their size, and heterogeneity (Reed-Dustin et al., 2016). Studies of post-fire vegetation regrowth, including fuel succession and the effects of precipitation and temperature on the regrowth at regional to landscape scales are lacking (Prichard et al., 2017). Understanding long term and large scale dynamics helps us to interpret fire responses, and where and when mitigation is most efficient and effective. For example, post-fire treatments such as burning, pesticides, and seeding may be used to rehabilitate an area to establish native flora and reduce fire frequency (Eiswerth et al., 2009). The timing of seeding in relation to precipitation, temperature, and pre-fire vegetation is essential for germination of postfire areas (Jessop \& Anderson, 2007; Shinneman \& Baker, 2009).

Satellite remote sensing is a common tool used to study landscapes. The ability to have periodic, large area information creates an increase in our ability to understand dynamic vegetation changes and their drivers. However, modern, free satellite imagery does not have the combined temporal or spatial resolution necessary for monitoring semiarid ecosystems. For example, data from publically available satellite systems such as Moderate Resolution Imaging Spectroradiometer (MODIS) and Landsat, have pixel sizes of $0.25-1 \mathrm{~km}$ and $30 \mathrm{~m}$, respectively; and repeat orbits of 1-day and 16-days, respectively. Thus these systems are on either end of the space versus time spectrum 
(Justice et al., 2002; Chander et al., 2009). The high frequency orbit of MODIS is designed to observed swift changes, but unable to observe small spatial scale effects (Pettorelli et al., 2005). Landsat has a finer spatial resolution, which captures smaller scale responses such as vegetation regrowth at ha-scales, but the temporal resolution can be problematic (Van Wagtendonk et al., 2004; Verbyla et al., 2008). While both satellites have been used to assess vegetation and phenological effects to improve global and local understanding of ecosystems (Peterson 2005; Sakamoto, 2005; Zhang et al., 2003), a combination of the temporal and spatial resolutions of these satellites will improve our ability to monitor semi-arid ecosystems.

Vegetation indices from satellite imagery are used to monitor photosynthetic activity of plants. The Normalized Difference Vegetation Index (NDVI), Soil-Adjusted Vegetation Index (SAVI), and Enhanced Vegetation Index (EVI) are a few examples of the many indices created from satellite bands to track vegetation "greenness" (Huete, 1988; Geerken \& Ilaiwi, 2004; Richardson \& Everitt, 1992; Lyon et al., 1998; Senseman et al., 1996). Greenness is a vegetation response of green, leafy ground cover (Tucker \& Seller, 1986) and provides a measure of phenological activity if tracked over time. The vegetation in semi-arid ecosystems have similar greenness responses, as they rapidly green up after the first rains in the spring, and begin to senesce (dry out) soon after. Furthermore, the significant litter and woody biomass of shrubs can overpower the greenness response of semi-arid vegetation, making subtle changes in greenness difficult to observe. This challenge, and especially the rapid fluctuations and heterogeneity of these ecosystems provide an opportunity to develop a new remote sensing system to improve our ability to monitor vegetation responses. 
The objective of this study is to use NDVI as a measure of greenness from fusion remote sensing to examine post-fire vegetation responses in semi-arid ecosystems. The increased spatial and temporal resolution is also used to examine the pre-fire greenness. In this proof of concept, we seek to understand if timing of a fire, or the number of historical burns causes differences in vegetation greenness. Ultimately, the system we develop may be used by land managers to assist with post-fire restoration activities.

\section{Methods}

\section{Study Area}

Our study area is the Morley Nelson Snake River Birds of Prey National Conservation Area (BoP). It is located south, southeast of Boise, Idaho, and spans the Snake River. It covers 196,300 ha of shrub-steppe, and riparian ecosystems, with precipitation ranging from 20 to $30 \mathrm{~cm}$ annually contingent upon elevation (BLM, 2008; Danielson \& Gesch, 2011; Kochert \& Pellant, 1986). This is a protected area by US Public Law 103-64 for raptors, biological ecosystems, and cultural resources. The soil in this region is dominated by a parent material of loess and volcanic sediment, which has been used for agriculture and grazing practices (Soil Survey Staff, 2018; Spaete et al., 2016). Much of the region has been heavily grazed, and invasive species, including cheatgrass, have encroached into the native vegetation of Wyoming big sagebrush (Artemisia tridentata wyomingensis) (BLM, 2008; West \& Yorks, 2002). From 1957 to 2015 there were 425 fires that occurred in or bounding the BoP, with 229 occurring after 1990 (Welty et al., 2017). The BoP has documented fire boundaries, fire dates, and mapped vegetation over the entire region for analysis of fire effects on vegetation type and regrowth. 


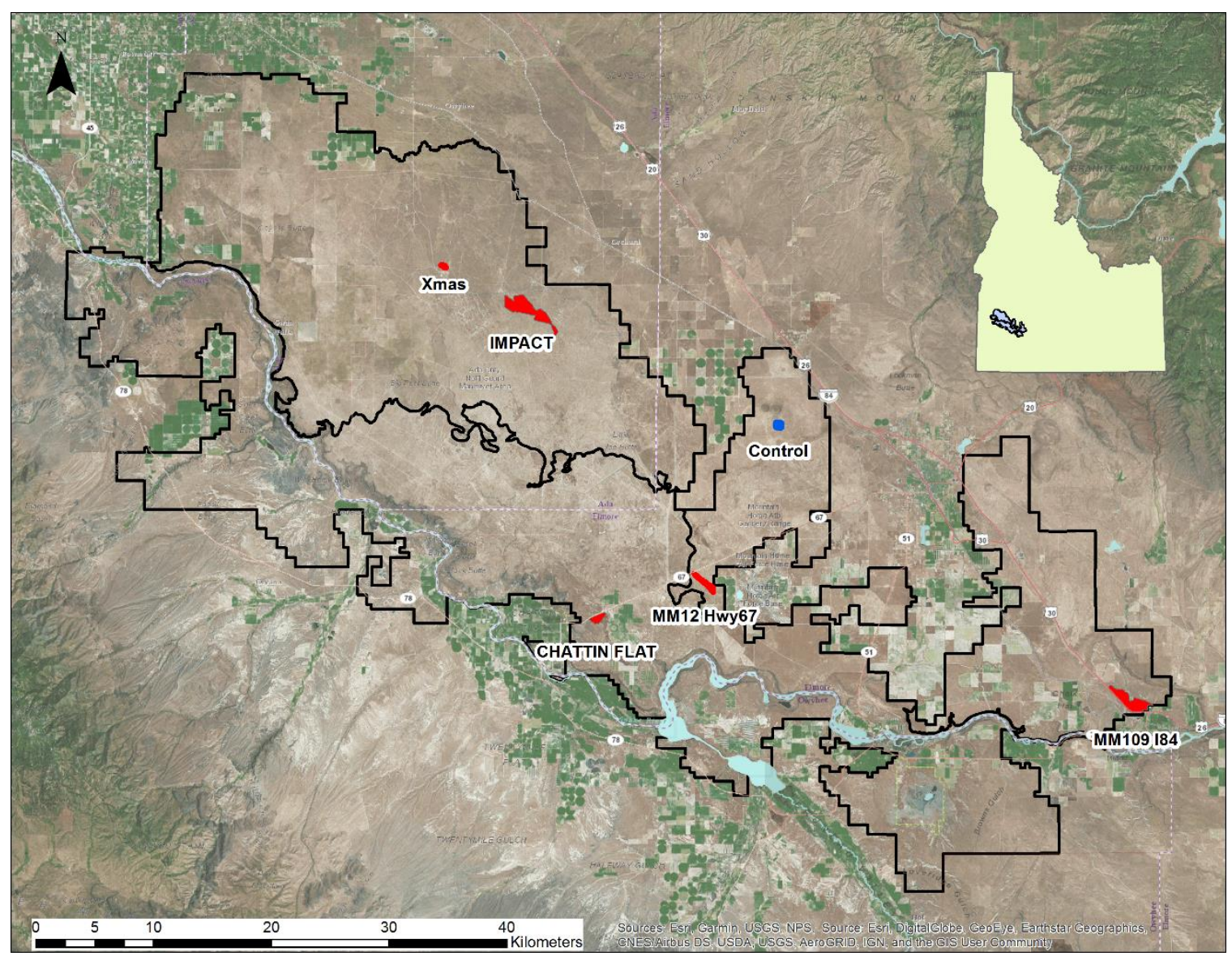

Figure 3.1: $\quad$ Morley Nelson Snake River Birds of Prey National Conservation Area with fires of interest in red, and the control area in blue.

$\underline{\text { Fires }}$

Five fires the occurred in 2012 are chosen based on dominant pre-fire vegetation and the seasonality of the fire. In 2012, over 23 fires occurred in the BoP (Figure ) (Wely et al., 2017). We chose this year because the data supported the opportunity to observe decadal-scale vegetation dynamics, including 5-years pre-fire and 5-years post-fire. The fires we chose had similar intensity burn effects with delta Normalized Burn Ratio ( $\triangle \mathrm{NBR}$ ) (see APPENDIX C) (Loboda et al., 2007; Lu et al., 2016). Four grass fires, Chattin Flatt, MM 109 I 84, Impact, and MM12 HWY 67 are chosen, as well as one shrub dominated fire, Xmas. We selected a control area, which is homogeneously cheatgrass and has not burned during our study period. No seeding treatments were 
applied to these areas, and all are located in areas managed by the BLM for grazing (BLM, 2017; BLM, 2018).

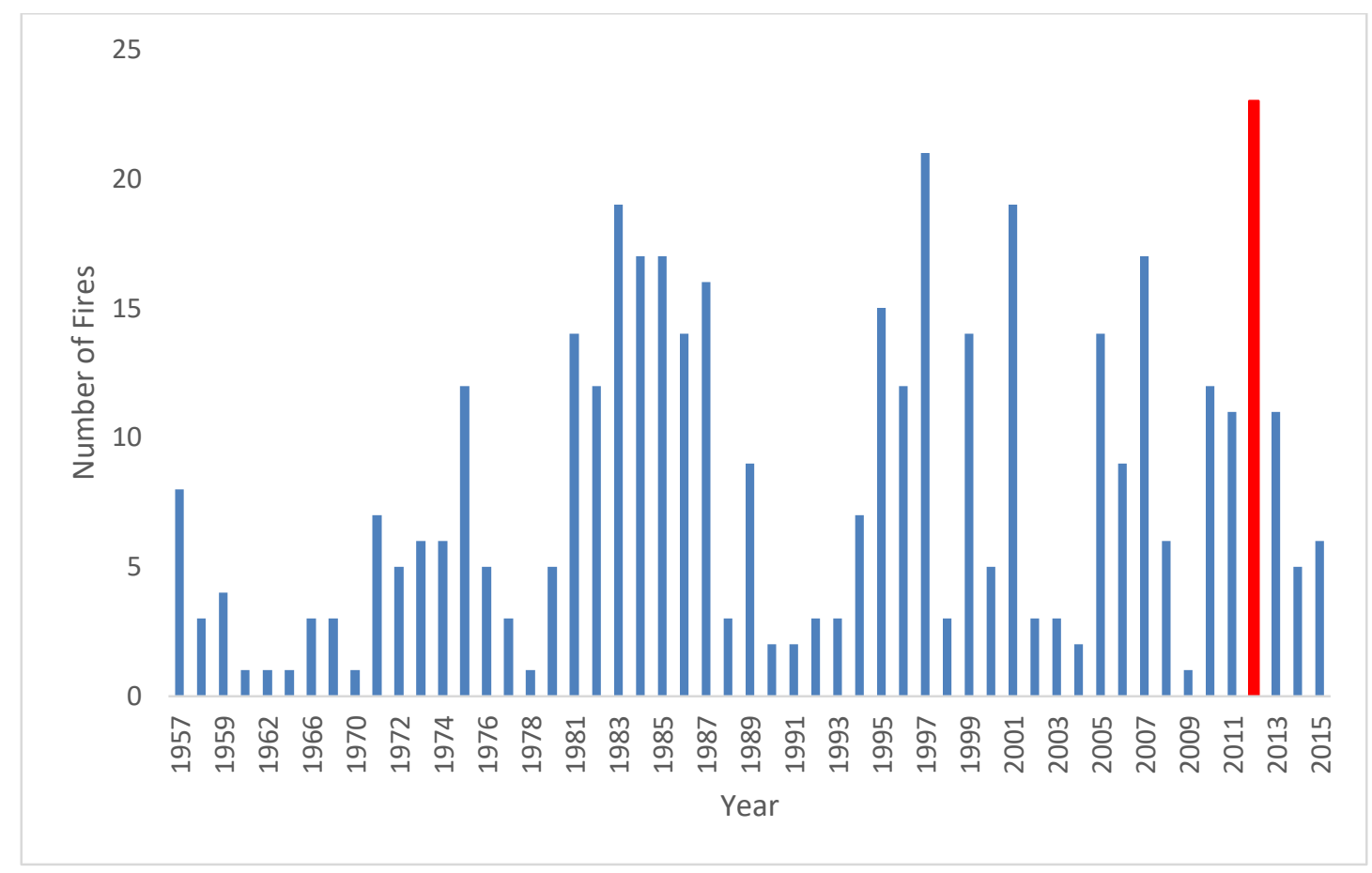

Figure 3.2: Number of fires per year in the BoP between 1957-2015. 2012 is the highest known fire year during this period.

The grass-dominated fire areas all had several previous fires. These fires occurred across different boundaries within and outside the 2012 fire areas, creating overlap between these historical and 2012 fires. The overlap areas range over space and time, making several areas that have burned once, twice, three, or even four times. For example, the Impact fire boundary has two separate areas that have burned once previously. One area was burned in the ZZ_Unnamed fire in 1994, while another burned in the OTA 85 fire in 2007. Both these areas are classified as the "One Burn" category. We used these previous fires, along with the 2012 fire to observe overall vegetation response as a function of the number of fires since 1957. 
Table 3.1: Fires in the BoP used in this study and their fire start and end dates, area, and dominant vegetation type.

\begin{tabular}{llllll}
\hline & Chattin Flatt & MM 109 I 84 & Impact & Xmas & MM 12 HWY 67 \\
\hline Start Date & $5 / 14 / 2012$ & $5 / 23 / 2012$ & $6 / 07 / 2012$ & $8 / 26 / 2012$ & $9 / 12 / 2012$ \\
End Date & $5 / 15 / 2012$ & $5 / 23 / 2012$ & $6 / 08 / 2012$ & $8 / 27 / 2012$ & $9 / 13 / 2012$ \\
Area & 73 ha & 330 ha & 450 ha & 7.6 ha & 72 ha \\
Type & Grass & Grass & Grass & Shrub & Grass \\
\hline
\end{tabular}

\section{Chattin Flatt}

The Chattin Flatt burn area is bounded in the northwest by Grand View Road / Idaho State Highway 167. There are agricultural fields to the east and west. A 2013 vegetation and landcover classification shows the area classified as bare ground surrounded by cheatgrass (Spaete et al., 2016). A 2016 classification shows this area to be a mix of exotic and native grasses, but predominantly cheatgrass (Enterkine, in prep.). This area has burned up to five times prior to 2012, with fires occurring in 1986, 1998, 2001, 2006, and a small fire in 2010 (Wetley et al., 2017). The fifth previously burned bounding area created from these fires is small and possibly caused by digitizing errors, so is not included as a separate previous burn. 


\section{109 I 84}

Bordered to the west and south by I 84, the MM 109 I 84 burn area covers an extensive expanse of land, with a riparian area running through the middle. The burn area is on the southern edge of the BoP. Though it is not covered in the 2013 vegetation classification, satellite imagery pre-fire indicates cheatgrass dominance, and the 2016 classification also indicates cheatgrass. This fire has an area of no previous burns, and has had up to four known historic fire areas. Fires have occurred in 1958, 1983, 1997, and 2001.

$\underline{\text { Impact }}$

The Impact fire is the largest fire used in this study. It is in an area of sandberg bluegrass (Poa Secunda), and cheatgrass (Spaete et al., 2016). In 1979 this area was annual grasses, and low amounts of Wyoming big sagebrush (BLM, unknown). The 2016 classification shows mixtures of sandberg bluegrass, as well as exotic annuals and cheatgrass (Enterkine, in prep). This area has up to four historic burned areas from fires in 1994, 1995, 1996, and 2007.

\section{12 HWY 67}

Cheatgrass dominates the area directly to the west of the Mountain Home Airforce Base (MHAFB) where the MM 12 HWY 67 fire occurred. There is a dirt road that runs through the burned area, and that road separates the area to the west that has had one historic fire in 1996, while the area to the east had an additional fire on 8/16/2011, the year before our fire of interest. In 1979 this area was moderately dominated by sagebrush, but the Canyon Creek fire in 1996 that covered over 25,000 ha demolished this population. 
$\underline{\text { Xmas }}$

The Xmas fire occurred as a late season fire on Xmas hill. It is one of two shrub dominated fires that occurred in 2012 (Welty et al., 2017). The 2013 vegetation classification and satellite imagery show this region to be sagebrush, with a small patch of cheatgrass to the south (Spaete et al., 2016). In 1979 this area was classified as both grass and shrub dominated, and in 2016 this region is sagebrush-dominated with sandberg bluegrass (BLM, unknown; Enterkine, in prep).

Control

A control area of cheatgrass is chosen to compare with areas that have burned to provide insight to the effects of seasonal temperature and precipitation on vegetation. The control is a 10 ha area that burned in the Craterring fire in 1983, and the Airbase fire in 1987; however, it has not burned since 1987. The control is homogeneously cheatgrass.

\section{Experimental Design}

A fusion method between Landsat and MODIS is used in this study to create fine spatial and temporal data for analysis. The original design of this code is created by Faye Peters, and it is updated in this study to work with daily MODIS data and Tier-1 Landsat in the previous chapter (Peters, 2016). Chattin Flatt, MM109, Impact, and MM12 have had multiple previous fires affect their vegetation. Areas within these fires have burned up to five times previously, as such fire is separated into sub boundaries that denote the number of times an area has burned since 1957.

\section{$\underline{\text { Satellite Imagery }}$}

We used 10 years of Landsat and MODIS imagery from March 18, 2007 to August 26, 2016 in this study. This includes Landsat 7 from March 18, 2007 to April 3, 
2013, and Landsat 8 from April 3, 2013 to August 26, 2016. Landsat 7 and 8 Surface

Reflectance Tier 1 are used for the fine spatial resolution imagery

(Landsat/LE07/C01/T1_SR Path 41 Row 30, Landsat/LC08/C01/T1_SR Path 41 Row 30,

$30 \mathrm{~m})$. The Tier 1 data have been geo-registered, orthorectified, and cloud masked

(USGS, 2018, Foga et al., 2017). MODIS Terra Surface Reflectance $250 \mathrm{~m}$ daily imagery is used (MOD09GQ.006 Terra Surface Reflectance Daily Global 250m). The imagery is corrected for atmospheric effects, and has a quality assurance band (Bit mask QC_250) which is used to mask out pixel values that have clouds or other errors. In 2003 Landsat 7 suffered from a scan-line-corrector (SLC) error, causing gaps to appear in the fringes of every image (Markham et al., 2004). The blank areas in the SLC-off Landsat 7 images are filled in with the large quantity of images that do have data in these regions over time.

\section{Data Processing}

We use Google Earth Engine (GEE) for data collection and pre-processing. GEE stores petabytes of remote sensing information in an easy to access browser based format, with all processes running in the cloud for ease of computation (Gorelick et al., 2017). All Landsat images are cloud masked using the CFmask band, clipped to the 5 study sites, and the NDVI is calculated (Fensholt et al., 2009; Weiss et al., 2004). MODIS imagery is also cloud masked using the Quality Assurance Band bit-mask, clipped to the 5 study sites, resampled to $30 \mathrm{~m}$ pixels, and NDVI is calculated (Foga, 2017). MODIS NDVI is scaled by 10,000 , so the Landsat NDVI is scaled to match. These images are exported from GEE as .tif files for the next stage in processing.

The Spatial and Temporal Adaptive Reflectance Fusion Model (STARFM) created by the USDA is a Linux shell based interpolation program for resolving MODIS pixel sizes 
down to a Landsat scale (Gao et al., 2006). It uses matching pairs of MODIS and Landsat images to build a model that includes spatial, temporal, and reflectance information (Zhu et al., 2010; Cammalleri et al., 2014; Jia et al., 2014). We use an R shell to apply STARFM to every MODIS image in the 10-year dataset. In Chapter Two we found STARFM to work well with moderate to long term (weekly to decadal) NDVI changes in semi-arid ecosystem vegetation, observing the phenology and NDVI amplitude differences. Thus, we hypothesize that analyzing vegetation response over a decade is an appropriate application for STARFM.

The data created from the interpolation of MODIS and Landsat are prone to noise caused by pixels suppressed during the cloud mask and SLC line error masking, as well as the inherent noisy response of the MODIS daily pixel values (Hmimina et al., 2013). We apply Gaussian smoothing to each pixel across time to fill in missing values and reduce the noise for improved signal response (Kandasamy et al., 2013). The standard deviation is set to 10 , and roughly two months of smoothing is applied. We then analyze the NDVI as a function of the number of burns, and investigate the effects of seasonality on NDVI.

\section{Results}

\section{Vegetation Response}

We analyzed 3,438 images for all five fires from the GEE/STARFM method. All fires have more than $75 \%$ of the pixels cloud free in all images. Gaussian smoothing was applied over a two-month period to reduce noise, but to retain the original signal (Figure 3.3) 


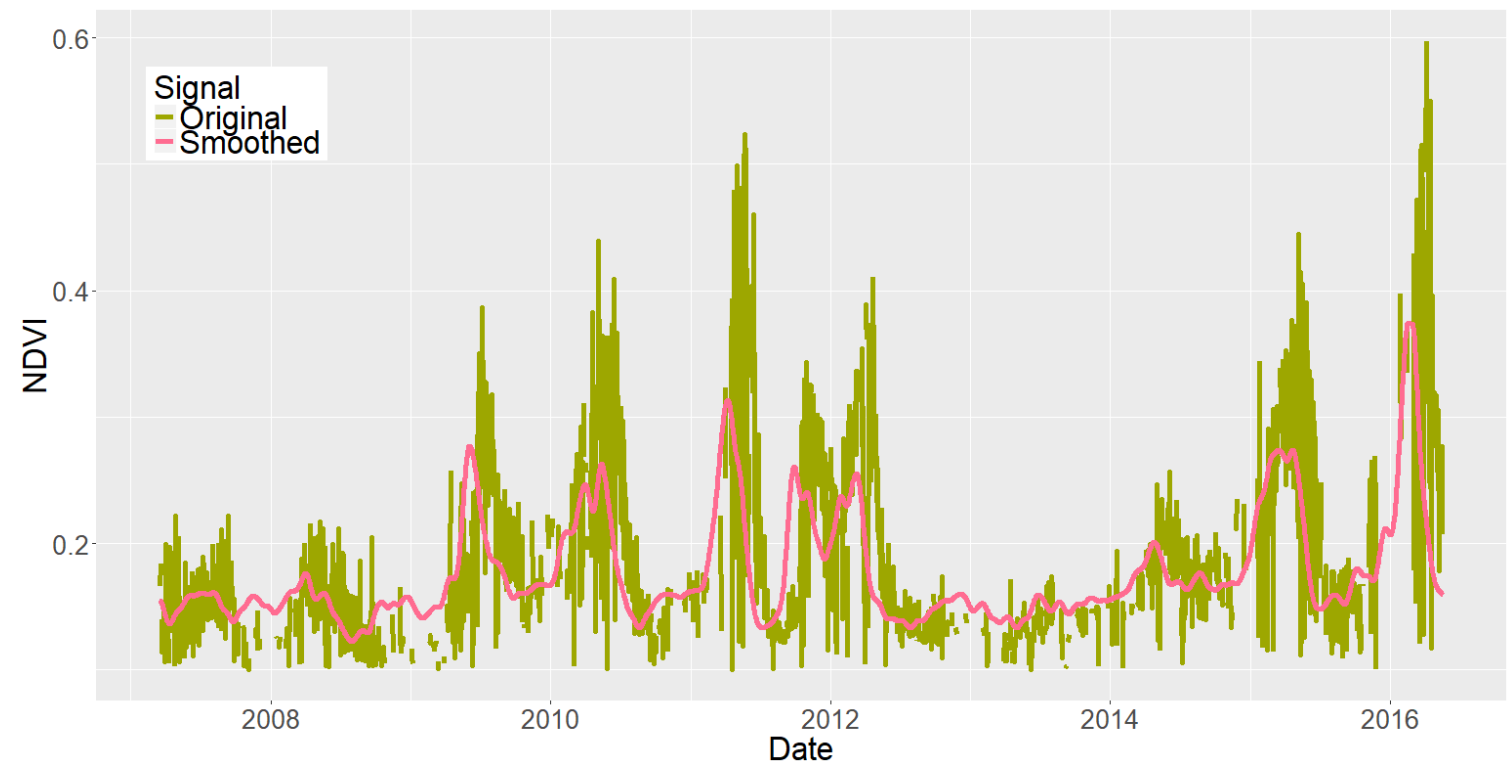

Figure 3.3: Daily NDVI pixel values from the Chattin Flatt burn area. Green are original values and red values are the Gaussian smoothing values. Subtle shifts in timing are seen in the smoothed data as compared to the original data.

Fire Response

\section{Chattin Flatt}

The Chattin Flatt burn response is fairly consistent pre-2012 but experiences a major decrease of NDVI after the 2012 fire (Figure 3.4). The NDVI increases from 2014 to 2016. Prior to 2016, the area that only burned once had the highest NDVI, but areas burned three or more times peaked in 2016 over the areas that has only burned once. 


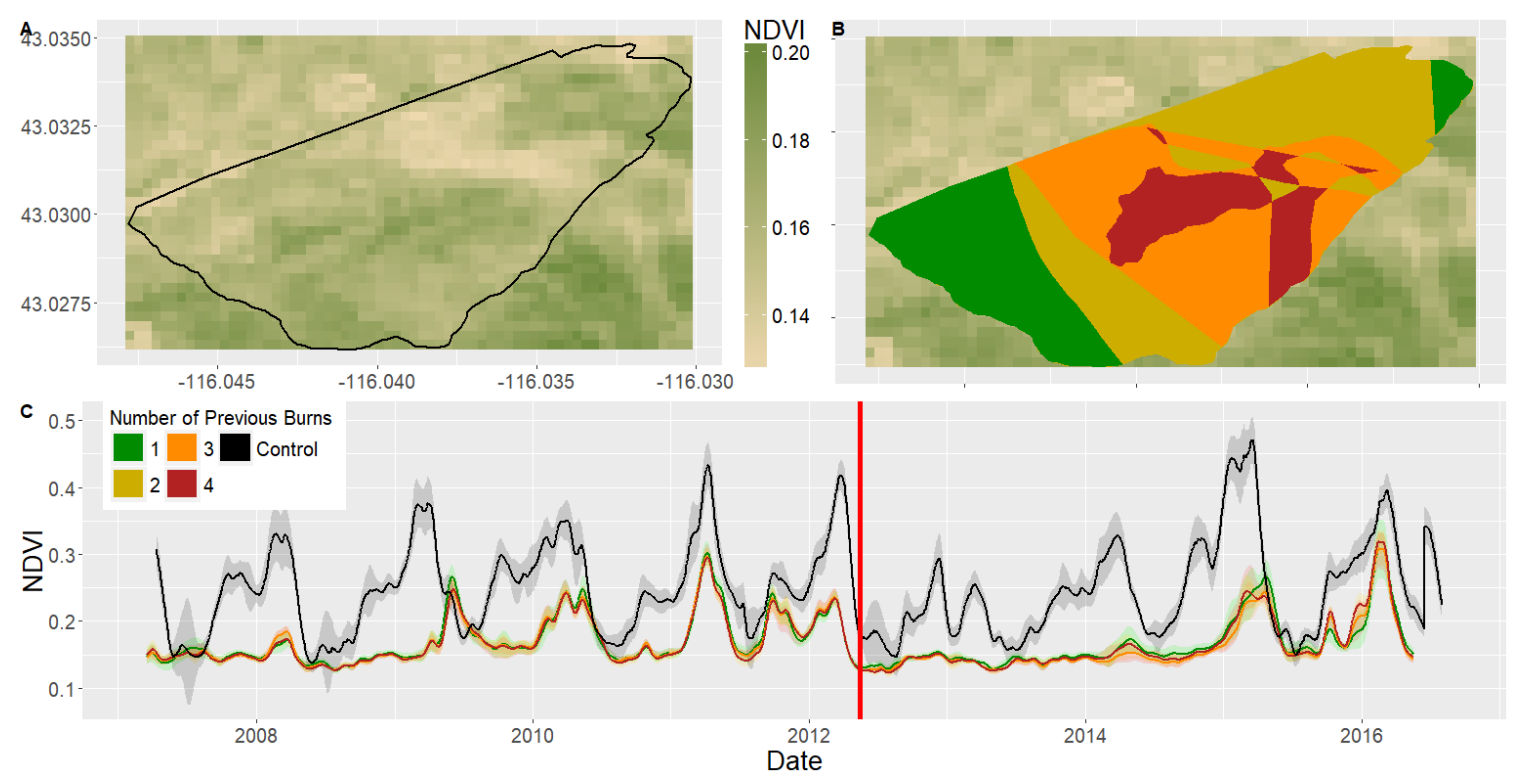

Figure 3.4: Chattin Flatt burned area NDVI in relation to number of historic fires. A) The Chattin Flatt region post-fire NDVI response on August 8, 2015. B) Historic burned areas by color (see legend in $(C)$ for number of times burned (between 20072016). C) Time series NDVI from 2007 to 2016. Standard deviation is shown with transparent ribbon around every line. The time of fire is shown with the red line, and the cheatgrass control in black.

\section{109 I 84}

MM 109 I 84 has an area with no previous burns near the agricultural fields and along a portion of the highway (Figure ). The area along the highway has not burned previously, and the variation of NDVI is the largest post-fire. Starting in 2014, the NDVI increases through 2016 at which time it is similar to the pre-fire (2012) NDVI. The area that has been burned once historically has a wide range of outliers likely caused by the riparian area inside this subset. There is a small area of shrub growth in the northeast corner, and a large mix of exotic annuals, cheatgrass, and sandberg bluegrass that dominates the regions that have only burned once (Enterkine, in prep.). 


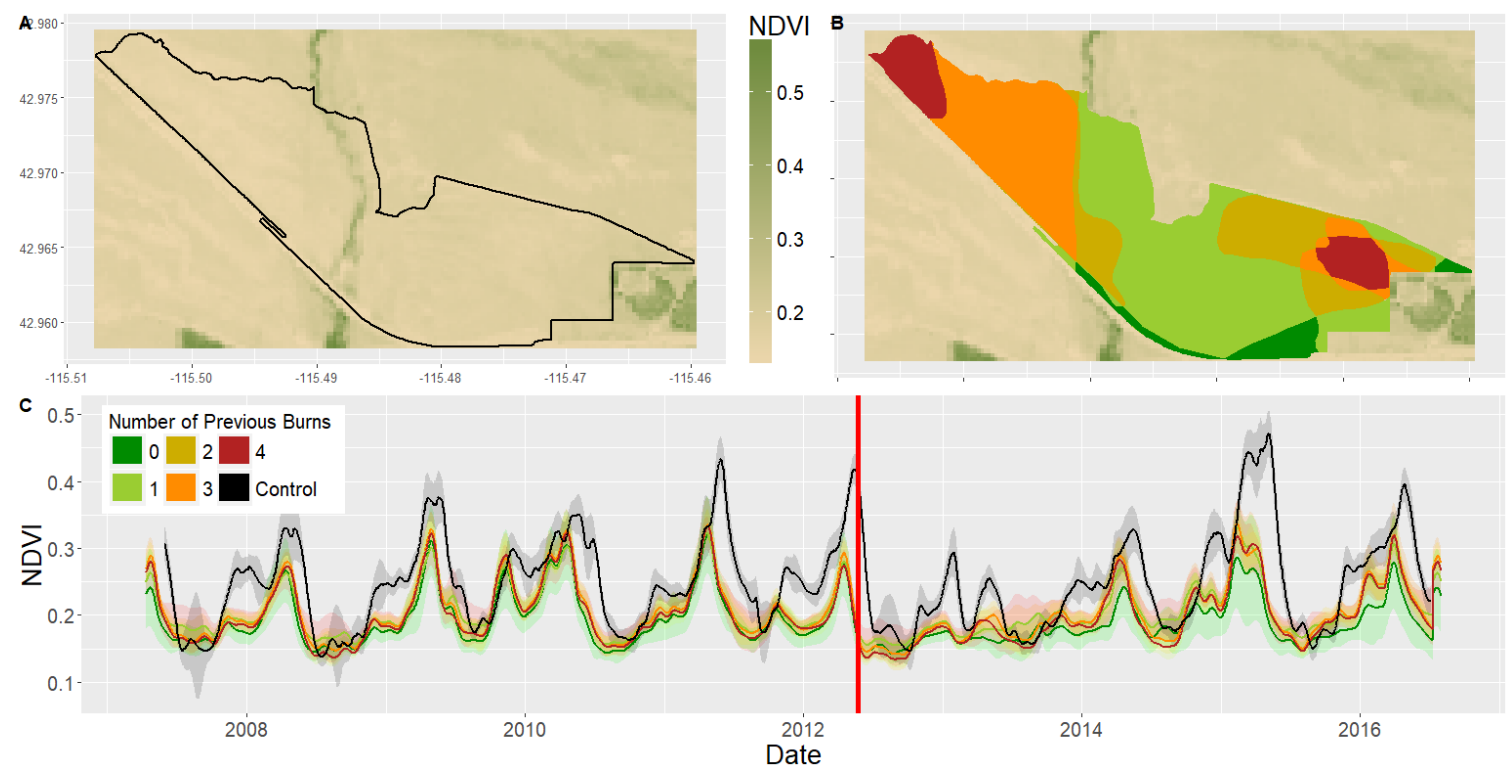

Figure 3.5: MM 109 I 84 burned area NDVI. A) The MM 109 I 84 post-fire NDVI response on August 8, 2015. B) Historic burned areas by color, see legend in (C) for number of times burned (between 2007-2016). C) Time series from 2007 to 2016, high variation is seen in the area with no previous burns. The time of fire is shown in red line, standard deviation is shown with transparent ribbons around lines.

\section{$\underline{\text { Impact }}$}

The Impact fire has little to no variation of NDVI dependent on the number of times burned (Figure ). NDVI variation decreases with the amount of burns over the region. Pre-and post-fire show sandberg bluegrass in many of the 2 or 3 times previously burned areas. The combined regions of 4 and 5 previously burned areas have the highest NDVI response 4 years post-fire. The large variation in the area that has burned 4 times previously may be the growth of new cheatgrass or other annual nonnative grasses, as sandberg bluegrass have been observed to have difficulty germinating after four successive fires (Raymondi, 2017). 


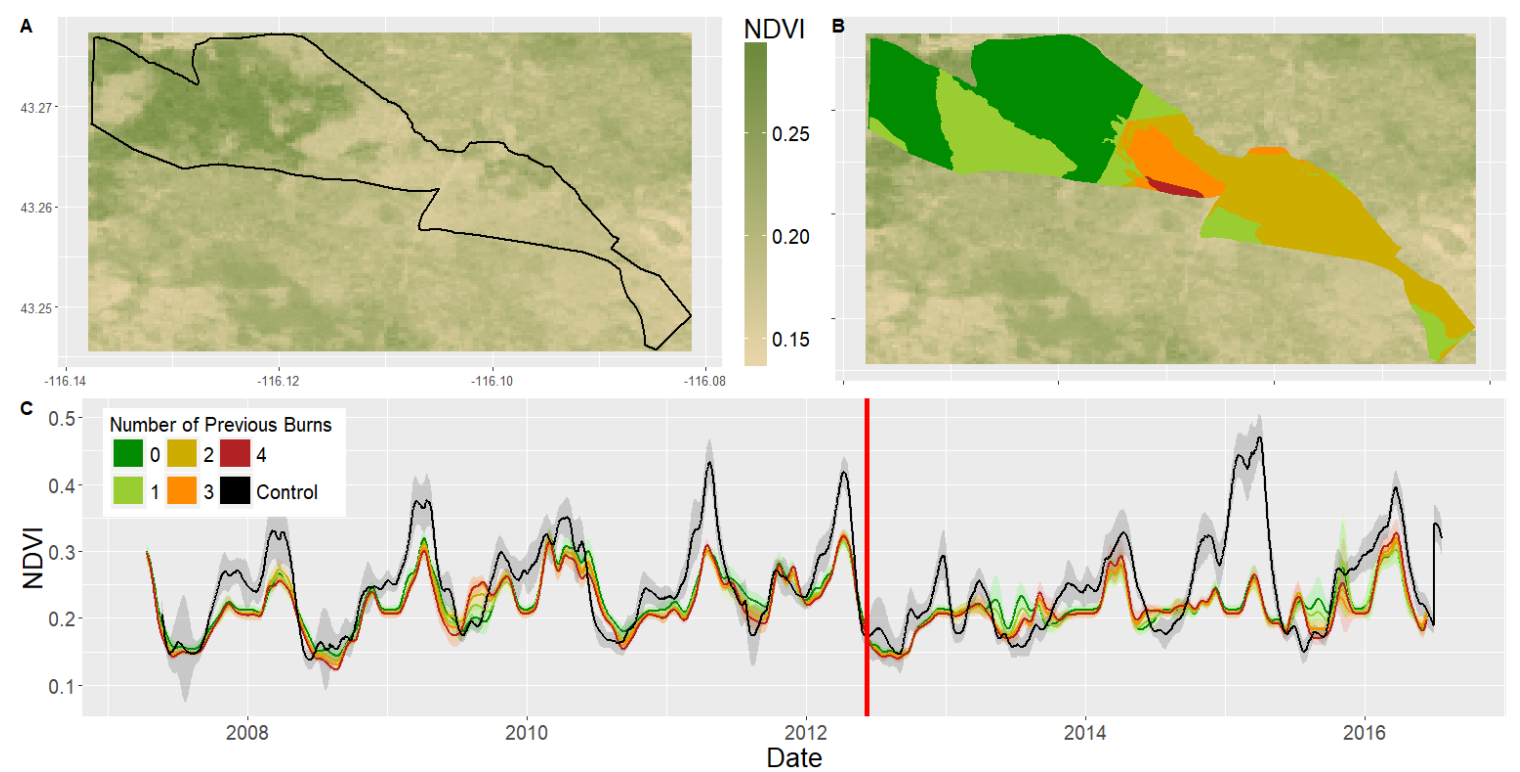

Figure 3.6: Impact fire burned area NDVI. A) The Impact post-fire NDVI response on August 8, 2015. B) Historic burned areas by color, see legend in (C) for number of times burned (between 2007-2016). C) Time series from 2007 to 2016, areas that have burned three to four times previously have the largest increase post-fire, areas that burned $<1$ before have the highest variation, with the standard deviation shown as the transparent ribbons for each area. Time of fire is shown with the red line.

\section{12 HWY 67}

On August 16, 2011, the South Sim fire occurred in the southeast region of the MM 12 HWY 67 fire, which causes a minor decrease in NDVI the year before our target fire. In late 2012 the two areas have matching NDVI values (Figure 3.7) A slow increase in greenness is observed in 2013 and 2014 where the area that burned once has higher NDVI, but in 2015 and 2016 the area that burned twice has a higher magnitude of NDVI. 


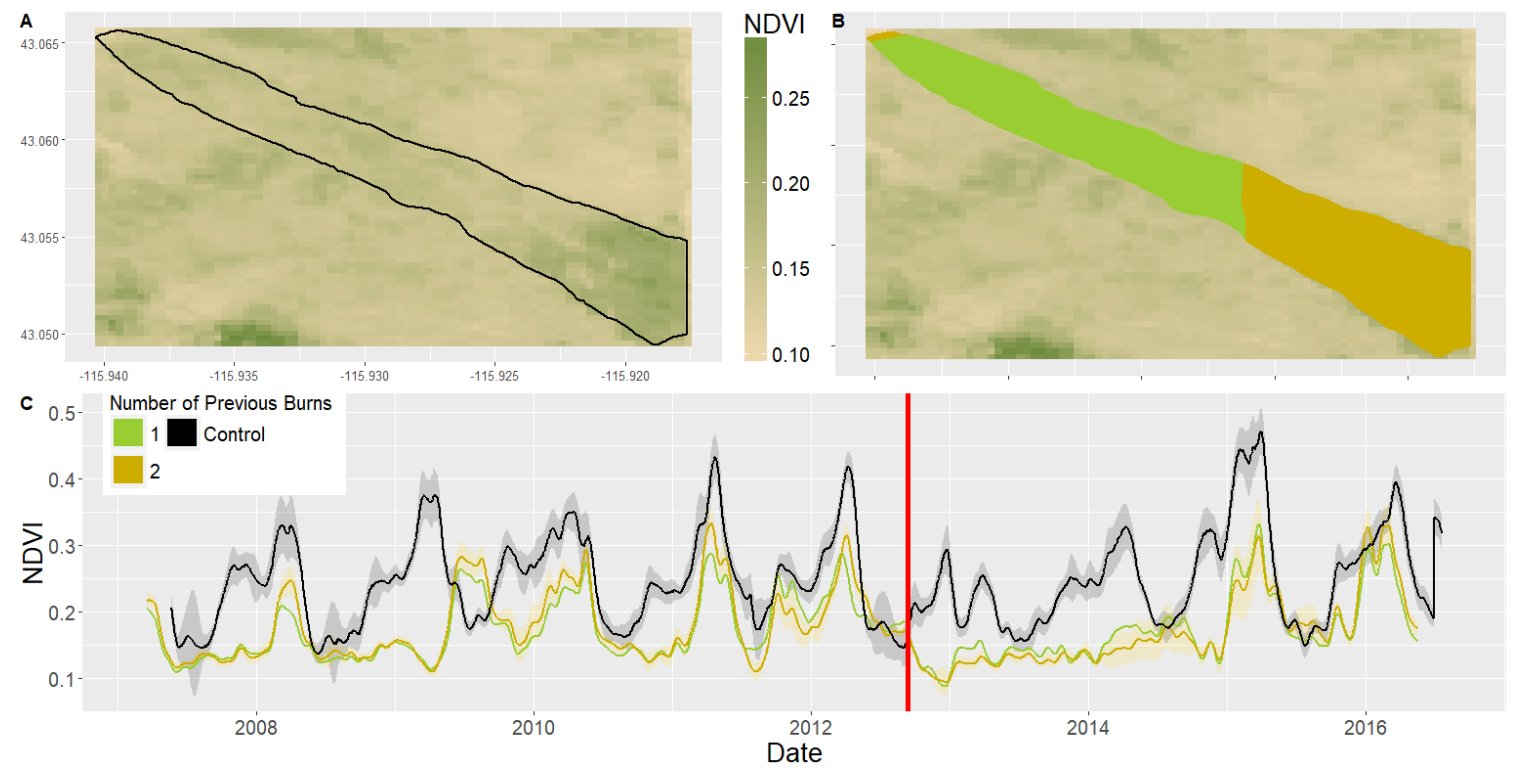

Figure 3.7: MM 12 HWY 67 burned area NDVI. A) The MM 12 HWY 67 post-fire NDVI response on August 8, 2015. B) Historic burned areas by color, see legend in (C) for number of times burned (between 2007-2016). C) Time series from 2007 to 2016, like the Chattin Flatt Fire low NDVI persists until 2015, when an abrupt increase in NDVI occurs. The area with two burns has a larger response once postfire NDVI increase begins. Time of fire shown with red line. Standard deviation is shown as the transparent ribbon on each line.

\section{$\underline{X m a s}$}

The Xmas fire has visible NDVI peaks the spring after the fire occurred, unlike the grass fires that have no visible response (Figure ). The greenness continues to rise every year, with a large increase in fall 2015. Both spring and fall NDVI responses are visible in the post-fire years, where the pre-fire years show large stable spring periods of low NDVI, as we have noted in Chapter 2 with the sagebrush response. 


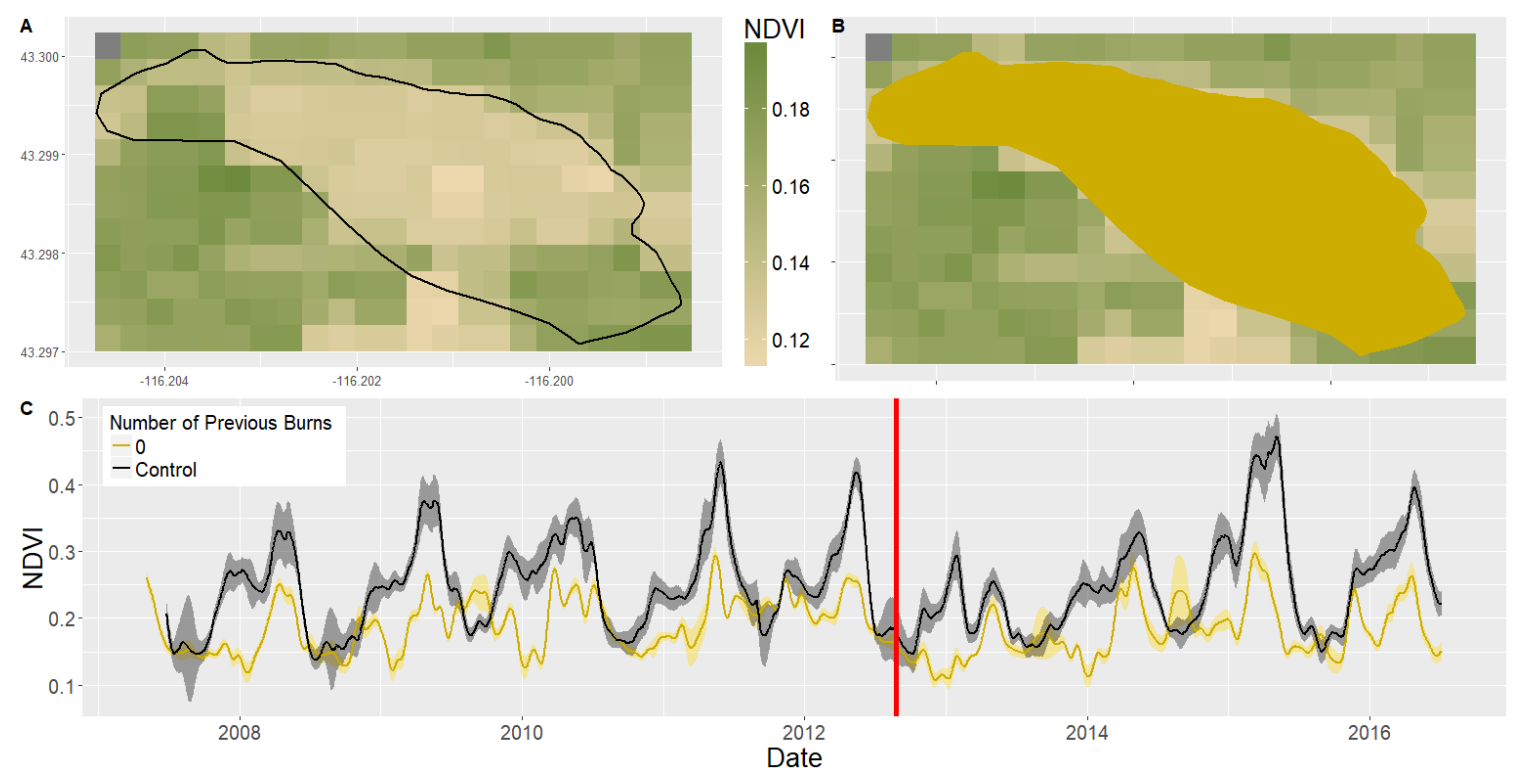

Figure 3.8: Xmas Fire (August 27, 2013) response. A) Region of Xmas fire. B) This shrub dominated region had never burned before the Xmas fire. C) Decadal response of the vegetation over the Xmas fire. NDVI is visible directly after the fire year, increases seen every year post-fire. Time of fire shown with red line, cheatgrass control in black.

$\underline{\text { Timing of Burns }}$

We compare the pre-fire 2011 mean to the post-fire yearly mean from 2013 to 2016 for the four grass dominated areas (Table ). The Chattin Flatt, MM 12 HWY 67, and Xmas fires have the greatest decrease in NDVI from pre-fire to four years post-fire. MM 109 I 84 and Impact have the least vegetation loss, while their pre-fire NDVI was among the highest. MM 109 I 84 has a rapid post-fire regrowth, eclipsing the pre-fire response by over $11 \%$. Chattin Flatt and Impact have slow and stable NDVI responses, and by the end of 2016 have not yet reached their pre-fire norm. MM 12 HWY 67 has the fastest NDVI recovery with an 11\% rate versus MM 109 I 84 with an $8 \%$ rate. Lastly, Xmas had a high overall response, but a sudden downturn of NDVI in 2016 is most likely related to the late fall greening we see in previous years, as this study did not continue through late fall 2016. 
Table 3.2: Change in NDVI for the burned areas. Though the late season MM 12 HWY 67 has the highest NDVI loss, it also has the largest total increase in NDVI, and the MM 109 I 84 fire has risen above its pre-fire mean by $11 \%$.

Post Fire from Pre-Fire NDVI

\begin{tabular}{lcclll}
\cline { 3 - 5 } Fire Name & 2011 NDVI Mean & $\mathbf{2 0 1 3}$ & $\mathbf{2 0 1 4}$ & $\mathbf{2 0 1 5}$ & $\mathbf{2 0 1 6}$ \\
\hline Chattin Flatt & 1978.61 & $-29.14 \%$ & $-21.90 \%$ & $-3.58 \%$ & $-3.58 \%$ \\
MM 109 I 84 & 2165.31 & $-14.79 \%$ & $0.03 \%$ & $0.05 \%$ & $11.81 \%$ \\
Impact & 2431.16 & $-15.84 \%$ & $-8.92 \%$ & $-10.51 \%$ & $-3.40 \%$ \\
MM 12 HWY 67 & 1908.55 & $-29.34 \%$ & $-16.56 \%$ & $3.40 \%$ & $4.31 \%$ \\
Xmas & 2173.00 & $-27.16 \%$ & $-7.15 \%$ & $-3.88 \%$ & $-8.72 \%$ \\
\hline
\end{tabular}

\section{Discussion}

We found that the fusion imagery produces NDVI at high temporal and spatial resolutions, allowing us to track the NDVI time series at a near-continuous scale. The fusion output images dampen the noise that occurs in the MODIS imagery through the model, and remaining noise is smoothed using the Gaussian filter. This filter causes dampening of the signal in both peaks and troughs, but each fusion image set is smoothed consistently to make them comparable. Even with smoothing, large seasonal and yearly changes are visible throughout the time series.

\section{Control Area}

The control area followed similar trends to the burned areas in the years immediately post-fire $(2013,2014)$. While the amplitude of these responses is greater than the burned areas, there is still a decrease in NDVI values compared to pre-2013 of the same area. These lower NDVI values may be the result of the temperature and weather in the immediate post-fire years. APPENDIX E contains precipitation and 
temperature data over the BoP, and the fall to winter season of 2012 shows little to no precipitation, and the coldest temperatures over this decadal study period. The dry and cold conditions may have influenced the NDVI response in 2013, and the low precipitation during 2013 to spring 2014 may have encouraged the relatively slow increase in NDVI. Though the control and the burned area responses follow a similar pattern, the areas burned in the early and late season fires (Chattin Flatt and MM 12 HWY 67) show little NDVI increase in 2014, whereas the control shows a relatively larger increase. The areas burned in the late spring and summer fires have similar NDVI responses post-fire to that of the control, though not to the same magnitude.

The control is homogenously cheatgrass and future studies should include control areas for other vegetation types, such as sandberg bluegrass and sagebrush. Native and non-native vegetation respond differently to precipitation and temperature, and control study areas may aid in understanding the vegetation dynamics. In addition, multiple control areas of diverse vegetation may help differentiate between native and nonnative plant species by using differences in phenological responses.

\section{Number of Historic Fires and Their Responses}

We found that in annual grass and cheatgrass-dominated regions the NDVI response post-fire was similar over every area of historic burns, unless it was the first time burnt. Areas that had not burned, or only burned once before the 2012 fire had lower and more variable responses. The MM 109 I 84 and the Impact fire had areas with no fires before 2012. The MM 109 I 84 fire has high variation in the areas of no pre-2012 fires, as it is bordering a road, but the Impact fire's large previously un-altered area shows great fluctuations between fall 2015, when it had the highest NDVI to spring 2016, 
when it had the lowest. This may be due to different vegetation types dominating the region. Sandberg bluegrass and cheatgrass are commonly found amongst post-fire vegetation growth, and large areas of bare ground may take time to seed (Raymondi, 2017; D’Antonio \& Vitousek, 1992).

Cheatgrass post-fire growth may have low to negative responses the first year after a fire occurs (Miller et al., 2013; Young et al.,1987). Two to four years post-fire cheatgrass may increase in cover up to $60 \%$ in warm wet regions (West \& Hassan, 1985), or below $10 \%$ in cool wet regions (Everret \& Ward, 1984, Pyle \& Crawford 1996). We found a similar response in the NDVI in all of our annual grass-dominated study areas including the control. These areas had low NDVI responses one - two years post-fire but rapid greening two- four years post-fire. This low to high period over four years is mirrored in the control, but with a much higher amplitude response, possibly revealing the effect of precipitation and temperature on the post-fire growth. Areas with more historic burns have a slightly higher NDVI four years post-fire, as these areas most likely had higher pre-fire cheatgrass cover, and use the feedback loop of fires to propagate quickly over newly disturbed land (Whisenant, 1990; Stewart \& Hull, 1949).

\section{Timing of Burns}

Previous studies found that management of cheatgrass invasion through grazing is best done in the spring, the time in which the grasses are starting to germinate, and when they are the most palatable to cattle (Klemmedson \& Smith, 1964, Diamond et al., 2010; Young et al., 1987). This early season disturbance cuts back on the possibility of seeds being produced, and leaves the area available for other plants to germinate (Baughman et al., 2016; Monaco et al., 2005). This pattern of early spring disturbance is also seen in the 
NDVI values of the early May fire of Chattin Flatt. This burned area has one of the largest decreases in post-fire NDVI, and continues to have low NDVI for two years postfire, while other cheatgrass fires have much larger rehabilitation during the second postfire year. The summer fires of MM 109 I 84 and Impact have both the lowest NDVI loss, and accelerated NDVI response. Cheatgrass fires are most common in the summer and fall months, and cheatgrass has already disseminated their seedbanks before this period (Zouhar, 2003). Grassland fire temperatures are not high enough to burn cheatgrass seed, coupled with the reduction in the above ground vegetation, it is a smooth transition for the cheatgrass to take root and spread (Balch et al., 2012; Billings, 1992). The MM 109 I 84 fire may have caused cheatgrass to increase their presence, and NDVI response, with rapid spreading over areas with a higher density of cheatgrass growth (Young \& Evans, 1978; West \& Hassan, 1986). The Impact fire shows a decrease in response three years post-fire, and this decrease is found relative to anthropogenic areas. No known seeding or treatment was done in this region, but it is possible that either anthropogenic activities or grazing caused the decline of the NDVI. The mid-September fire of MM 12 HWY 67 has a large NDVI loss in the year post-fire, and a high regrowth response in the years after. In 2013 there is almost no NDVI response in this region, with rapid NDVI increases in 2014-2016. This lack of any vegetation matches the yearly responses in 2007 and 2008 where low precipitation and high temperature kept the greenness relatively low (see APPENDIX E). We observe an increase in precipitation and warmer winters in 20092011, supporting large NDVI increases just before another drought period occurs (see Appendix E). Cheatgrass waits until the first fall rain of up to $5 \mathrm{~cm}$ to begin germination for the next season (Klemmedson \& Smith, 1964; Zouhar, 2003). There is a gap of time 
between the MM 12 HWY 67 late fall fire and the first large precipitation event in November. This gap may have kept many of the seeds dormant as they did not have the necessary growth conditions. The winter after this fire occurred is one of the coldest over our decadal study period, possibly impairing growth. Cheatgrass seeds can lay dormant until optimal conditions exist, and germinate when a proper environment develops (Mack, 1981; Hull \& Hansen, 1974). We note that many of the post-fire vegetation responses of cheatgrass remain reliant on the precipitation events that occur, and the interaction of those precipitation events with the timing of the fires (Bradley, 2009).

The Xmas shrub fire has a contrasting response in NDVI as compared to the grass fires. It has spring greening the first-year post-fire, which is not seen in any of the annual grass-dominated plots. The NDVI increases every year post-fire and in 2016 it is higher than the pre-fire greenness. The Xmas fire had the lowest dNBR intensity, but even low intensity fires can kill or greatly damage sagebrush (Britton \& Clark, 1985; Acker, 1992). This fire occurred in the early fall, so the sagebrush in that area may not have had time to disseminate their seed. However, the northern portion of this area is sagebrush dominated, and Wyoming big sagebrush can disperse seed to a range of $30 \mathrm{~m}$. Wyoming big sagebrush has a slow regrowth rate, taking years to recolonize. Thus, the NDVI responses we see in the shrub site are not those of the sagebrush itself, but the understory vegetation (Miller et al., 2013). We can track the pixels that have high NDVI values postfire to be on alert for possible invasion of cheatgrass, medusahead (Taeniatherum caputmedusae), and North African grass (Ventenata dubia). 


\section{Management Implications}

The NDVI in the Chattin Flatt and MM 12 Hwy 67 burned areas shows no increase for the longest period post-fire with three years of low NDVI. These fires occurred at either the beginning or end of the typical fire season (May $14^{\text {th }}$, and September $12^{\text {th }}$ respectively). There was little rain until November, and 2012 had one of the coldest winters in the BoP over our study time period (see Appendix E). The low precipitation and cold temperatures may have resulted in seeds being unable to germinate the following years, and effects of this weather pattern are visible in the control. In similar environments, this gap could potentially allow land managers to have time for seeding and other mitigation practices. Another application of this work for land management is the ability to track an area of possible shrub regrowth based on pattern and amplitude comparison with pre-fire response, and identify warning signs of invasive species encroachment, such as high NDVI, rapid greening and senescing, and the timing of green up. These indicators may be helpful when planning expensive seeding and herbicide treatments.

\section{Conclusion}

The GEE/STARFM fusion system allows us to view the NDVI temporal response of pre- and post-fire regions for long-term analysis in semi-arid ecosystems. In this proof of concept, our results indicate that the high spatial and temporal resolution imagery may help understand the role of fire seasonality on annual grass regrowth and the role of multiple historic burns in post-fire greenness. Future studies may use this method to track long-term burned area response, and thus serve as a tool to assist with land management. Further studies that incorporate precipitation and temperature patterns may reveal 
mechanisms for the dynamics in the phenological cycles of both native and annual vegetation in semi-arid ecosystems.

\section{References}

Acker, S. A. (1992). Wildfire and soil organic carbon in sagebrush-bunchgrass vegetation. The Great Basin Naturalist, 52(3), 284-287.

Arredondo, J. T., Jones, T. A., \& Johnson, D. A. (1998). Seedling growth of Intermountain perennial and weedy annual grasses. Journal of Range Management, 584-589.

Balch, J. K., Bradley, B. A., D'antonio, C. M., \& Gómez-Dans, J. (2013). Introduced annual grass increases regional fire activity across the arid western USA (1980 2009). Global change biology, 19(1), 173-183.

Baughman, O. W., Meyer, S. E., Aanderud, Z. T., \& Leger, E. A. (2016). Cheatgrass die offs as an opportunity for restoration in the Great Basin, USA: Will local or commercial native plants succeed where exotic invaders fail?. Journal of Arid Environments, 124, 193-204.

Billings, W. D. (1994). Ecological impacts of cheatgrass and resultant fire on ecosystems in the western Great Basin. SB Monsen and SG Kitchen, 22-30.

BLM. (2008). Final Environmental Impact Statement Volume I, Final Environmental Impact Statement,

BLM. (2017) BLM Idaho Grazing Pastures (POLYGON), vector digital data, U.S. Department of the Interior (DOI), Bureau of Land Management (BLM), Idaho State Office

BLM. (2018) Completed Vegetation Treatments (POLYGON), vector digital data, U.S. Department of the Interior (DOI), Bureau of Land Management (BLM), Idaho State Office

Bradley, B. A. (2009). Regional analysis of the impacts of climate change on cheatgrass invasion shows potential risk and opportunity. Global Change Biology, 15(1), 196-208. 
Britton, C. M., \& Clark, R. G. (1985). Effects of fire on sagebrush and bitterbrush. In Rangeland Fire Effects, A Symposium sponsored by the Bureau of Land Management and the University of Idaho. Published by Idaho State Office, USDI Bureau of Land Management, Boise, ldaho. Po (pp. 22-26).

Brooks, M. L., D'antonio, C. M., Richardson, D. M., Grace, J. B., Keeley, J. E., DiTomaso, J. M., ... \& Pyke, D. (2004). Effects of invasive alien plants on fire regimes. BioScience, 54(7), 677-688.

Cammalleri, C., Anderson, M. C., Gao, F., Hain, C. R., \& Kustas, W. P. (2014). Mapping daily evapotranspiration at field scales over rainfed and irrigated agricultural areas using remote sensing data fusion. Agricultural and forest meteorology, 186, 1-11.

Chander, G., Markham, B. L., \& Helder, D. L. (2009). Summary of current radiometric calibration coefficients for Landsat MSS, TM, ETM+, and EO-1 ALI sensors. Remote sensing of environment, 113(5), 893-903.

Danielson, J. J., \& Gesch, D. B. (2011). Global multi-resolution terrain elevation data 2010 (GMTED2010) (No. 2011-1073). US Geological Survey

D'Antonio, C. M., \& Vitousek, P. M. (1992). Biological invasions by exotic grasses, the grass/fire cycle, and global change. Annual review of ecology and systematics, 23(1), 63-87.

Diamond, J. M., Call, C. A., \& Devoe, N. (2010). Effects of targeted cattle grazing on fire behavior of cheatgrass-dominated rangeland in the northern Great Basin, USA. International Journal of Wildlands

Eiswerth, M. E., Krauter, K., Swanson, S. R., \& Zielinski, M. (2009). Post-fire seeding on Wyoming big sagebrush ecological sites: regression analyses of seeded nonnative and native species densities. Journal of Environmental Management, 90(2), 1320-1325.

Ellsworth, L. M., \& Kauffman, J. B. (2017). Plant community response to prescribed fire varies by pre-fire condition and season of burn in mountain big sagebrush ecosystems. Journal of Arid Environments, 144, 74-80. 
Enterkine J, in prep. Assessing impacts temporally based classification methods in asemiarid environment using Sentinel-2.

Everett, R.L. and K.O. Ward. (1984). Early plant succession in pinyon-juniper controlledburns. Northwest Sci.58:57-68.

Fensholt, R., Rasmussen, K., Nielsen, T. T., \& Mbow, C. (2009). Evaluation of earth observation based long term vegetation trends-Intercomparing NDVI time series trend analysis consistency of Sahel from AVHRR GIMMS, Terra MODIS and SPOT VGT data. Remote Sensing of Environment, 113(9), 1886-1898.

Foga, S., Scaramuzza, P. L., Guo, S., Zhu, Z., Dilley, R. D., Beckmann, T., ... \& Laue, B. (2017). Cloud detection algorithm comparison and validation for operational Landsat data products. Remote sensing of environment, 194, 379-390.]

Gao, F., Masek, J., Schwaller, M., \& Hall, F. (2006). On the blending of the landsat and MODIS surface reflectance: Predicting daily landsat surface reflectance. IEEE Transactions on Geoscience and Remote Sensing, 44(8), 2207-2218. http://doi.org/10.1109/TGRS.2006.872081

Geerken, R., \& Ilaiwi, M. (2004). Assessment of rangeland degradation and developmentof a strategy for rehabilitation. Remote Sensing of Environment, 90(4), 490-504.

Gorelick, N., Hancher, M., Dixon, M., Ilyushchenko, S., Thau, D., \& Moore, R. (2017). Google Earth Engine: Planetary-scale geospatial analysis for everyone. Remote Sensing of Environment.

Hmimina, G., Dufrêne, E., Pontailler, J. Y., Delpierre, N., Aubinet, M., Caquet, B., ... \& Gross, P. (2013). Evaluation of the potential of MODIS satellite data to predict vegetation phenology in different biomes: An investigation using ground-based NDVI measurements. Remote Sensing of Environment, 132, 145-158.

Huete, A. R. (1988). A soil-adjusted vegetation index (SAVI). Remote sensing of environment, 25(3), 295-309.

Hull Jr, A. C., \& Hansen Jr, W. T. (1974). Delayed germination of cheatgrass seed. Journal of Range Management, 366-368. 
Jessop, B. D., \& Anderson, V. J. (2007). Cheatgrass invasion in salt desert shrublands: benefits of postfire reclamation. Rangeland Ecology \& Management, 60(3), 235 243.

Justice, C. O., Townshend, J. R. G., Vermote, E. F., Masuoka, E., Wolfe, R. E., Saleous, N., ... \& Morisette, J. T. (2002). An overview of MODIS Land data processing and product status. Remote sensing of Environment, 83(1-2), 3-15.

Kandasamy, S., Baret, F., Verger, A., Neveux, P., \& Weiss, M. (2013). A comparison of methods for smoothing and gap filling time series of remote sensing observations-application to MODIS LAI products. Biogeosciences, 10(6), 4055 4071.

Klemmedson, J. O., \& Smith, J. G. (1964). Cheatgrass (Bromus tectorum L.). The Botanical Review, 30(2), 226-262.

Kochert, M. N., \& Pellant, M. (1986). Multiple use in the Snake River Birds of Prey Area. Rangelands Archives, 8(5), 217-220.

Loboda, T., O'neal, K. J., \& Csiszar, I. (2007). Regionally adaptable dNBR-based algorithm for burned area mapping from MODIS data. Remote Sensing of Environment, 109(4), 429-442.

Lu, B., He, Y., \& Tong, A. (2016). Evaluation of spectral indices for estimating burn severity in semiarid grasslands. International journal of wildland fire, 25(2), 147 157.

Lyon, J.G., Yuan, D., Lunetta, R.S., and C.D. Elvidge. (1998). A change detection experiment using vegetation indices. Photogrammetric Engineering and Remote Sensing 64(2):143-150.

Mack, R. N. (1981). Invasion of Bromus tectorum L. into western North America: anecological chronicle. Agro-ecosystems, 7(2), 145-165.

Mack, M. C., \& D'Antonio, C. M. (1998). Impacts of biological invasions on disturbance regimes. Trends in Ecology \& Evolution, 13(5), 195-198. 
Maestre, F. T., Salguero-Gómez, R., \& Quero, J. L. (2012). It is getting hotter in here: determining and projecting the impacts of global environmental change on drylands.

Markham, B. L., Storey, J. C., Williams, D. L., \& Irons, J. R. (2004). Landsat sensor performance: history and current status. IEEE Transactions on Geoscience and Remote Sensing, 42(12), 2691-2694.

Miller, R. F., Chambers, J. C., Pyke, D. A., Pierson, F. B., \& Williams, C. J. (2013). A review of fire effects on vegetation and soils in the Great Basin Region: response and ecological site characteristics (p. 126). Fort Collins, CO, USA: United States Department of Agriculture, Forest Service, Rocky Mountain Research Station.

Monaco, T. A., Monsen, S. B., Smith, B. N., \& Hansen, L. D. (2005). Temperature dependent physiology of Poa secunda, a cool season grass native to The Great Basin, United States. Russian Journal of Plant Physiology, 52(5), 653-658.

Obrist, D., DeLucia, E. H., \& Arnone, J. A. (2003). Consequences of wildfire on ecosystem $\mathrm{CO} 2$ and water vapour fluxes in the Great Basin. Global change biology, 9(4), 563-574.

O'Donnell, A. J., Boer, M. M., McCaw, W. L., \& Grierson, P. F. (2011). Climatic anomalies drive wildfire occurrence and extent in semi-arid shrub lands and woodlands of southwest Australia. Ecosphere, 2(11), 1-15.

Peters, F. (2016). "Analyzing the phenologic dynamics of kudzu (Pueraria montana) infestations using remote sensing and the normalized difference vegetation index." (2016). Electronic Theses and Dissertations. Paper 2437. https://doi.org/10.18297/etd/2437

Peterson, E. B. (2005). Estimating cover of an invasive grass (Bromus tectorum) using tobit regression and phenology derived from two dates of Landsat ETM+ data. International Journal of Remote Sensing, 26(12), 2491-2507.

Pettorelli, N., Vik, J. O., Mysterud, A., Gaillard, J. M., Tucker, C. J., \& Stenseth, N. C. (2005). Using the satellite-derived NDVI to assess ecological responses to environmental change. Trends in ecology \& evolution, 20(9), 503-510. 
Prichard, S. J., Stevens-Rumann, C. S., \& Hessburg, P. F. (2017). Tamm Review: shifting global fire regimes: Lessons from reburns and research needs. Forest Ecology and Management, 396, 217-233.

Puigdefábregas, J., \& Mendizabal, T. (1998). Perspectives on desertification: western Mediterranean. Journal of Arid Environments, 39(2), 209-224.

Pyle, W. H., \& Crawford, J. A. (1996). Availability of foods of sage grouse chicksfollowing prescribed fire in sagebrush-bitterbrush. Journal of RangeManagement, 320-324.

Raymondi, A. M. (2017). The Relative Importance of Fire History, Management Treatments, Biotic, and Abiotic Factors on the Abundance of Key Vegetative Components in an Endangered Sagebrush-Steppe Ecosystem.

Reed-Dustin, C. M., Mata-González, R., \& Rodhouse, T. J. (2016). Long-term fire effects on native and invasive grasses in protected area sagebrush steppe. Rangeland ecology \& management, 69(4), 257-264.

Richardson, A.J. and J.H. Everitt. (1992). Using spectral vegetation indices to estimaterangeland productivity. Geocarto International 7(1):63-69. - Compared several different vegetation indices (including SAVI) to see which ones performed best for predicting biomass in rangelands. SAVI performed about as well as other vegetation indices.

Sakamoto, T., Yokozawa, M., Toritani, H., Shibayama, M., Ishitsuka, N., \& Ohno, H. (2005). A crop phenology detection method using time-series MODIS data. Remote sensing of environment, 96(3-4), 366-374.

Schussman, H., Geiger, E., Mau-Crimmins, T., \& Ward, J. (2006). Spread and current potential distribution of an alien grass, Eragrostis lehmanniana Nees, in the southwestern USA: comparing historical data and ecological niche models. Diversity and Distributions, 12(5), 582-592.

Schmidt H., Karnieli A. (2000). Remote sensing of the seasonal variability of vegetation in a semi-arid environment, Journal of Arid Environments, Volume 45, Issue 1,I 2000, Pages 43-59, ISSN 0140-1963, http://dx.doi.org/10.1006/jare.1999.0607. 
Senseman, G.M., Bagley, C.F., and S.A. Tweddale. (1996). Correlation of rangeland cover measures to satellite-imagery-derived vegetation indices. Geocarto International 11(3):29-38

Shinneman, D. J., \& Baker, W. L. (2009). Environmental and climatic variables aspotential drivers of post-fire cover of cheatgrass (Bromus tectorum) in seeded and unseeded semiarid ecosystems. International Journal of Wildland Fire, 18(2),191-202.

Soil Survey Staff. (2018). Natural Resources Conservation Service, United States Department of Agriculture. Web Soil Survey. Available online at https://websoilsurvey.nrcs.usda.gov/. Accessed [May/19/2018].

Spaete, L., Glenn, N., and Baun, C. (2016). 2013 Morley Nelson Snake River Birds of Prey National Conservation Area RapidEye $7 m$ Landcover Classification [Data set]. Retrieved from http://dx.doi.org/10.18122/B21592

Stewart, G., \& Hull, A. C. (1949). Cheatgrass (Bromus Tectorum L.) --An Ecologic Intruder in Southern Idaho. Ecology, 30(1), 58-74.

Tucker, C. J., \& Sellers, P. J. (1986). Satellite remote sensing of primary production. International journal of remote sensing, 7(11), 1395-1416. USGS 2018, Landsat 8 Surface Reflectance Code (LaSRC) Product Version 4.3, Product Guide

Van Wagtendonk, J. W., Root, R. R., \& Key, C. H. (2004). Comparison of AVIRIS and Landsat ETM+ detection capabilities for burn severity. Remote Sensing of Environment, 92(3), 397-408.

Verbyla, D. L., Kasischke, E. S., \& Hoy, E. E. (2008). Seasonal and topographic effects on estimating fire severity from Landsat TM/ETM+ data. International Journal of Wildland Fire, 17(4), 527-534.

Welty, J.L., Pilliod, D.S., and Arkle, R.S. (2017). Combined wildfire dataset for the United States and certain territories, 1870-2015: U.S. Geological Survey data release, https://doi.org/10.5066/F75H7F5M

West, N. E., \& Hassan, M. A. (1985). Recovery of sagebrush-grass vegetation following wildfire. Journal of Range Management, 131-134. 
West, N. E., \& Yorks, T. P. (2002). Vegetation responses following wildfire on grazed and ungrazed sagebrush semi-desert. Journal of Range Management, 171-181.

Weiss, J. L., Gutzler, D. S., Coonrod, J. E. A., \& Dahm, C. N. (2004). Long-term vegetation monitoring with NDVI in a diverse semi-arid setting, central New Mexico, USA. Journal of Arid Environments, 58(2), 249-272.

Whisenant, S. G. (1990). Changing fire frequencies on Idaho's Snake River Plains: ecological and management implications. McArthur, E. Durant; Romney, Evan M.; Smith, Stanley D, 5-7.

Young, J. A., Evans, R. A., Eckert Jr, R. E., \& Kay, B. L. (1987). Cheatgrass. Rangelands, 266-270.

Zhang, X., Friedl, M. A., Schaaf, C. B., Strahler, A. H., Hodges, J. C., Gao, F., ... \& Huete, A. (2003). Monitoring vegetation phenology using MODIS. Remote sensing of environment, 84(3), 471-475.

Zhu, X., Chen, J., Gao, F., Chen, X., \& Masek, J. G. (2010). An enhanced spatial and temporal adaptive reflectance fusion model for complex heterogeneous regions. Remote Sensing of Environment, 114(11), 2610-2623.

Zouhar, Kris. (2003). Bromus tectorum. In: Fire Effects Information System, [Online]. U.S. Department of Agriculture, Forest Service, Rocky Mountain Research Station, Fire Sciences Laboratory (Producer). Available: https://www.fs.fed.us /database/feis/plants/graminoid/brotec/all.html [2018, May 17]. 


\section{CONCLUSION}

The objective of this thesis is to test the capability of using satellite fusion products to reveal the vegetation dynamics in a semi-arid ecosystem. Public, free satellite imagery is limited in both time and space. As new satellites, such as Sentinel-2 become available, we will be able to increase both the temporal and spatial resolutions of satellite data for vegetation studies. This finer resolution will improve accuracy in classifications and provide improved observations of invasive species. In addition, as we add new satellites to the temporal resolution, we will be able to provide long-term analyses of ecosystem dynamics.

The first study establishes a method for fusing two different satellite systems to model fine spatial and temporal resolution. Google Earth Engine is used in tandem with STARFM to create daily NDVI. This method is tested in the semi-arid sagebrush-steppe ecosystem of the Morley Nelson Snake River Birds of Prey National Conservation Area over the Mountain Home Air Force Base. 225 images are created over the 18,800 ha area from March 2, 2016 to October 13, 2016. Quality control tests are done using known ground observances of a large area of black asphalt, as well as testing fusion imagery against true satellite imagery. Lastly, plots and points of ground vegetation are tracked over a the 255-day period to examine their phenology.

The second study tracks NDVI response over a decade, focusing on five years pre-fire and five years post-fire (using 2012 as the median year). The fusion system created in the first study is used to interpolate daily $30 \mathrm{~m}$ measurements over this decade 
to increase our understanding of the patterns of NDVI responses. Five fires are chosen for this study, Chattin Flatt (5/14/2012, 73 ha), MM 109 I 84 (5/23/2012, 330 ha), Impact (6/07/2012, 450 ha), MM 12 HWY 67 (9/12/2012, 72 ha), and Xmas (8/26/2012, 7.6 ha). The first four fires are annual grass dominated areas, with a high amount of cheatgrass and sandberg bluegrass, while the Xmas fire is a shrub dominated fire. NDVI is observed in relation to the amount of historical fires over an area, and the seasonality of the fires. It is found that early spring and late fall fires have the largest effect on time before vegetation regrowth, and that any number of previous fires in annual grass dominated areas have similar regrowth patterns with little variation.

In the future, this fusion system can be used over areas of vegetation for temporal and spatial understanding of phenological trends. The system uses the standard NDVI for calculating vegetation responses from satellite imagery, but is straightforward to adapt to other vegetation indices. The monitoring may also be expanded to track specific pixels over the period, and obtain dates of percent regrowth for possible mitigation and treatment of areas that may have invasive species. The fusion system has a wide variety of possibilities related to long term change over large areas, and can be adapted to fill many missing data niches.

While the fusion method may be applied to other ecosystems, it is of great benefit for understanding the heterogeneous vegetation in semi-arid ecosystems. We hope that the use of this system will help expand the knowledge and awareness of these crucial, yet threatened global environments. 
APPENDIX A 


\section{Google Earth Engine STARFM Code link}

https://github.com/MacGallagher/GEE_STARFM_FUSION 
APPENDIX B 
Correlation between the Fusion Product and MODIS Asphalt Pixel Response

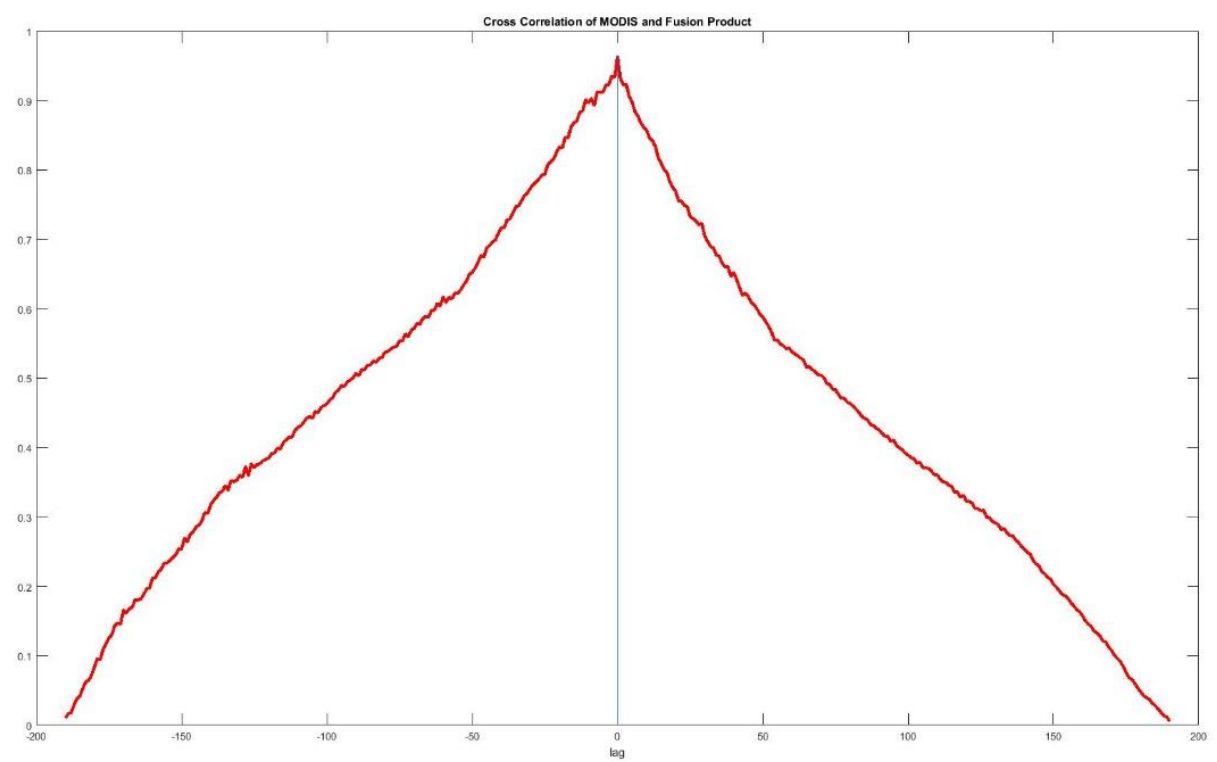


APPENDIX C 


\section{Delta Normalized Burn Ratio, Equation and Fire Information}

Normalized burn ratio uses the near-infrared band, NIR, and the short-wave infrared band, SWIR, to calculate the change in an area from an image before and after a fire.

$$
\begin{gathered}
N B R=\frac{(N I R-S W I R)}{(N I R+S W I R)} \\
\Delta N B R=N B R_{\text {prefire }}-N B R_{\text {postfire }}
\end{gathered}
$$

This measurement allows the use of a standardized table to track burn severity (below). This table was tested mainly in forested environments, and there are known differences in applying NBR to dryland ecosystems (Norton et al., 2009). Regardless, we used the below information for a relative measure of NBR between our study regions. The following pages includes histograms of dNBR over every fire included in this study. (Miller et al., 2007 ; Key \& Benson, 2006)

\begin{tabular}{l|l}
\multicolumn{1}{c|}{$\Delta \boldsymbol{N B R}$} & Burn Severity \\
\hline$<-0.25$ & High post-fire regrowth \\
\hline-0.25 to -0.1 & Low post-fire regrowth \\
\hline-0.1 to 0.1 & Unburned \\
\hline 0.1 to 0.27 & Low-severity burn \\
\hline 0.27 to 0.44 & Moderate-low severity burn \\
\hline 0.44 to 0.66 & Moderate-high severity burn \\
\hline$>0.66$ & High-severity burn
\end{tabular}



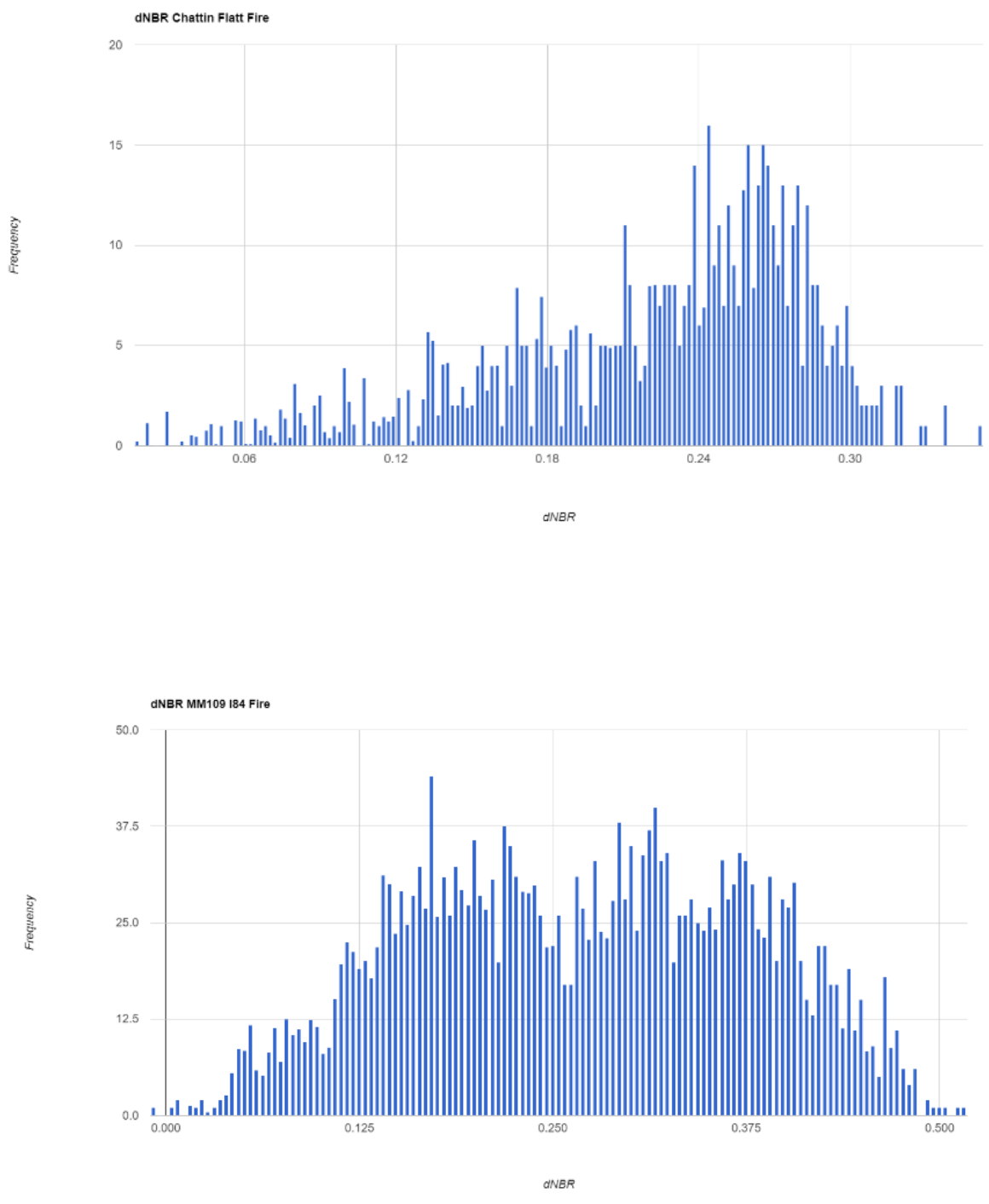

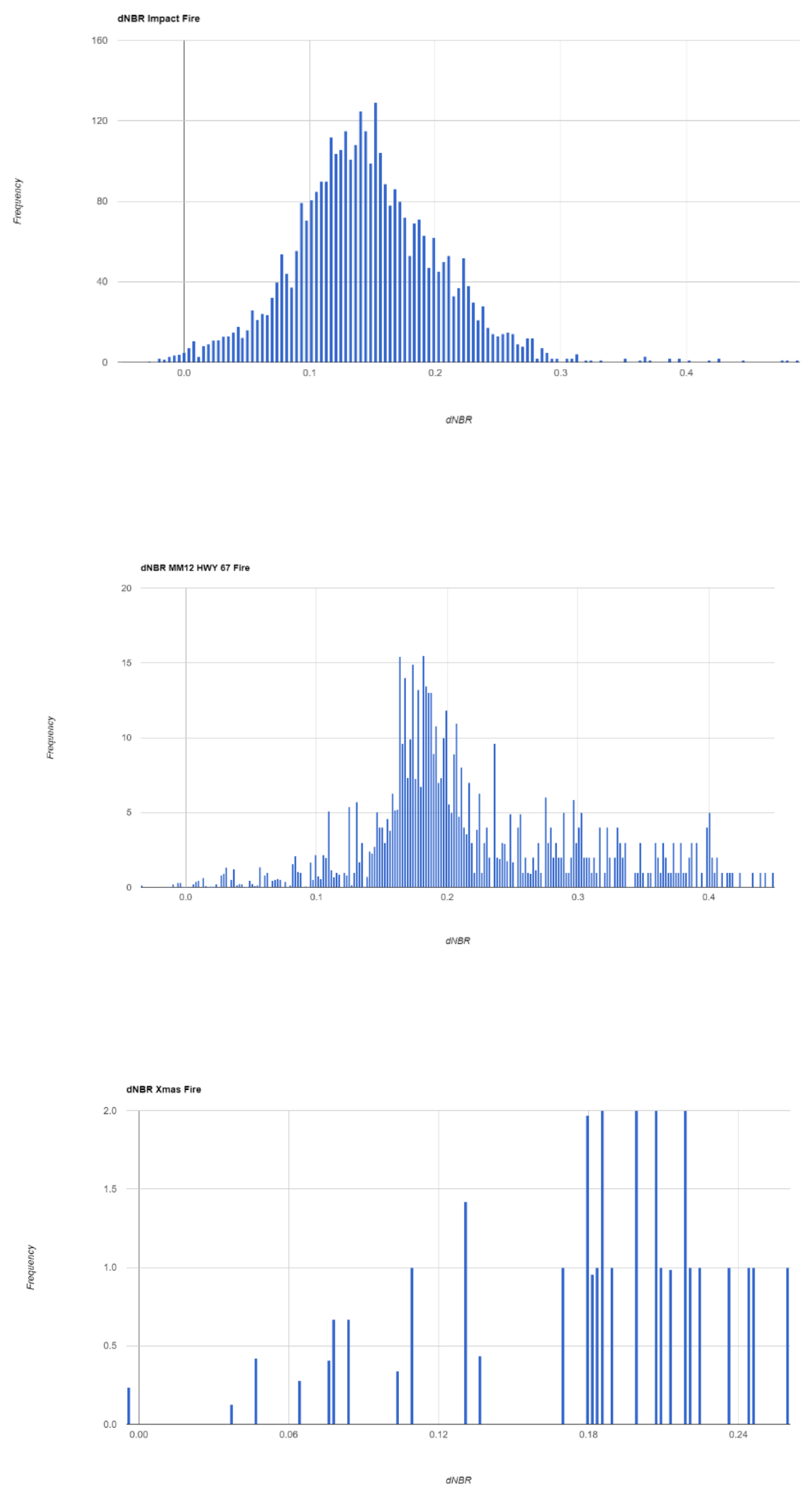


\section{References}

Key, C. H., \& Benson, N. C. (2006). Landscape assessment (LA). FIREMON: Fire effects monitoring and inventory system. Gen. Tech. Rep. RMRS-GTR-164-CD, Fort Collins, CO: US Department of Agriculture, Forest Service, Rocky Mountain Research Station.

Miller, J. D., \& Thode, A. E. (2007). Quantifying burn severity in a heterogeneous landscape witha relative version of the delta Normalized Burn Ratio (dNBR). Remote Sensing of Environment, 109(1), 66-80.

Norton, J., Glenn, N., Germino, M., Weber, K., \& Seefeldt, S. (2009). Relative suitability of indices derived from Landsat ETM+ and SPOT 5 for detecting fire severity in sagebrush steppe. International Journal of Applied Earth Observation and Geoinformation, 11(5), 360-367. 
APPENDIX D 
MODIS, Landsat, Fusion Product Comparison

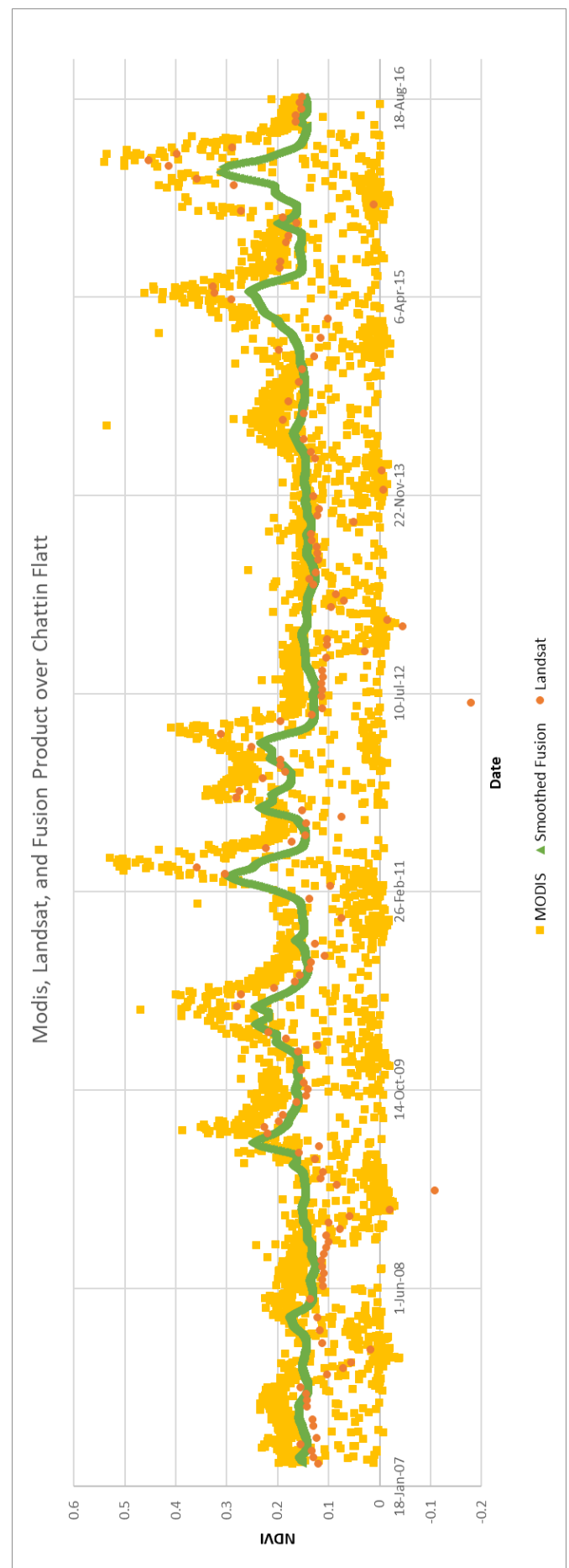

Example of MODIS, Landsat (less than $50 \%$ cloud cover), and smoothed fusion product data mean over the Chattin Flatt fire Boundary from 2007 to 2016 
APPENDIX E 


\section{Precipitation and Temperature over the BoP}

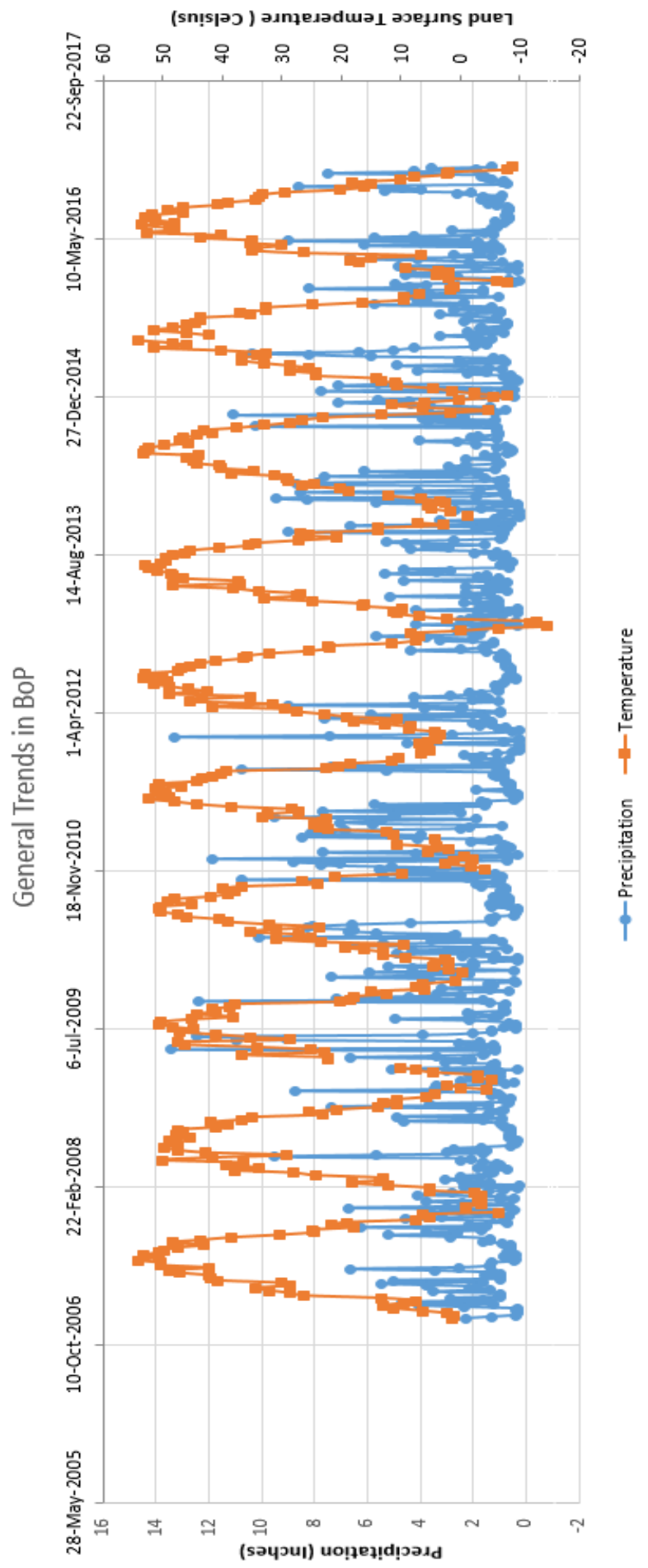

